\title{
Bending behavior of concrete T-beams reinforced with glass fiber- reinforced polymer (GFRP) bars
}

\author{
Rajesh Kumar Kalluri \\ West Virginia University
}

Follow this and additional works at: https://researchrepository.wvu.edu/etd

\section{Recommended Citation}

Kalluri, Rajesh Kumar, "Bending behavior of concrete T-beams reinforced with glass fiber-reinforced polymer (GFRP) bars" (1999). Graduate Theses, Dissertations, and Problem Reports. 1178.

https://researchrepository.wvu.edu/etd/1178

This Thesis is protected by copyright and/or related rights. It has been brought to you by the The Research Repository @ WVU with permission from the rights-holder(s). You are free to use this Thesis in any way that is permitted by the copyright and related rights legislation that applies to your use. For other uses you must obtain permission from the rights-holder(s) directly, unless additional rights are indicated by a Creative Commons license in the record and/ or on the work itself. This Thesis has been accepted for inclusion in WVU Graduate Theses, Dissertations, and Problem Reports collection by an authorized administrator of The Research Repository @ WVU. For more information, please contact researchrepository@mail.wvu.edu. 


\title{
BENDING BEHAVIOR OF CONCRETE T-BEAMS REINFORCED WITH GLASS FIBER REINFORCED POLYMER (GFRP) BARS
}

\author{
Rajesh K. Kalluri
}

\author{
Thesis \\ Submitted to the College of Engineering \\ at West Virginia University
}

In Partial Fulfillment of the requirements for the degree of

Master of Science in Civil Engineering

\author{
Hota V.S.GangaRao, Ph.D., Chair \\ Rakesh Gupta, Ph.D. \\ Vijay P.V, Ph.D.
}

Morgantown West Virginia

1999

Key Words: Compression failure, Tension failure, effective flange width, Shear lag, and balanced failure. 


\section{ABSTRACT \\ BENDING BEHAVIOR OF CONCRETE T-BEAMS REINFORCED WITH GLASS FIBER REINFORCED POLYMER (GFRP) BARS}

Rajesh K. Kalluri

Concrete slabs are integrally cast with girders or stringers (stiffening system) resulting in floor slabs, bridge decks, footers, retaining structures and others. A portion of slab between a stiffening system acts as flange and bends in unison with the stiffening system, i.e., classic T-beam action. The emphasis of this study is to determine the effective flange width, failure modes, deformability factors, pre- and post-cracking deflections and crack widths at first crack and at ultimate failure of T-beams.

Eight concrete $\mathrm{T}$ - beams with two different flange widths and two reinforcement configurations were tested under four point bending to study the factors cited above. Shear lag effect was established based on the strains measured along the width of compressive flange at mid-span. Based on the test results and theoretical evaluations, design equations to predict bending behavior, deflection, effective flange width and crack-widths are developed. 


\section{NOMENCLATURE}

A Effective tension area of concrete surrounding the flexural tension reinforcement and having the same centroid as that reinforcement, divided by the number of bars, in ${ }^{2}$

$\mathrm{A}_{\mathrm{f}} \quad$ Area of cross-section of tensile FRP reinforcement in ${ }^{2}$

a Depth of rectangular concrete stress block, in

b Flange width, in

$b_{\mathrm{w}} \quad$ Web width, in

$b_{m} \quad$ Effective flange width on either side of the overhang, in

$b_{o} \quad$ Web Width, in

C Compressive force

c distance from extreme compressive fiber to cracked neutral axis, in

d Effective depth, in

$d_{c} \quad$ Thickness of concrete cover measured from extreme tension fiber to the center of longitudinal bar, in

$\mathrm{t}_{\mathrm{f}} \quad$ Thickness of the flange, in

$\mathrm{E}_{\mathrm{c}} \quad$ Modulus of elasticity of concrete, Ksi

$\mathrm{E}_{\mathrm{f}} \quad$ Modulus of elasticity of FRP tensile reinforcement, Ksi

$\mathrm{E}_{\mathrm{x}} \quad$ longitudinal modulus of elasticity

$\mathrm{G}_{\mathrm{xy}} \quad$ In-plane shear modulus

$\mathrm{f}_{\mathrm{c}}{ }^{\prime} \quad$ Compressive strength of concrete, Ksi

$\mathrm{f}_{\mathrm{f}} \quad$ Tensile strength of GFRP rebar, Ksi

$\mathrm{h}_{1} \quad$ Distance from centroid of tension reinforcement to neutral axis, in

$\mathrm{h}_{2} \quad$ Distance from extreme tension fiber to neutral axis, in

$\mathrm{I}_{\mathrm{cr}} \quad$ Cracked moment of inertia of the beam section, in $^{4}$

$\mathrm{I}_{\mathrm{e}} \quad$ Effective moment of inertia of the beam section, in ${ }^{4}$

$I_{m} \quad$ Modified moment of inertia of the beam section, $i^{4}$

$\mathrm{I}_{\mathrm{g}}$ Gross moment of inertia of the beam section, in ${ }^{4}$

1 Beam Span, $\mathrm{ft}$

$\mathrm{M}_{\mathrm{a}} \quad$ Applied moment, $\mathrm{K}-\mathrm{ft}$ 


$\begin{array}{ll}M_{n} & \text { Nominal moment capacity, K-ft } \\ M_{c r} & \text { Cracked moment, K-ft } \\ y_{t} & \text { Distance from the centroid to extreme tension layer of the section, in } \\ \rho_{\text {bal }} & \text { Balanced reinfrocement ratio } \\ \rho_{\text {bal-r }} & \text { Balanced reinforcement ratio of a rectangular section } \\ \rho_{\text {bal-t }} & \text { Balanced reinforcement ratio of a T-section } \\ \rho & \text { Reinfrocement ratio } \\ \omega_{\text {max }} & \text { Maximum crack width, in } \\ v_{x y} & \text { Poisson's ratio }\end{array}$




\section{LIST OF TABLES}

Table $3.1 \quad$ C-BAR Composition 13

Table 3.2 Various C-BAR Designation and Configuration 14

Table 3.3 Rebar Strength and Stiffness Values 14

Table 3.4 Concrete Cylinder Compressive Strengths 15

$\begin{array}{lll}\text { Table } 3.5 & \text { Details of Test Specimens } & 18\end{array}$

$\begin{array}{lll}\text { Table } 3.6 & \text { Reinforcement Details } & 19\end{array}$

$\begin{array}{lll}\text { Table } 4.1 \quad \text { Failure Modes } & 25\end{array}$

Table 4.2 Ultimate Moment Capacities 26

Table 4.3 Limiting Deflections (Compression Failures) 28

Table 4.4 Limiting Deflections (Tension Failures) 29

Table 4.5 Limiting Crack-Width Comparison 33

Table 4.6 Load Crack-Width (in) Beam B3C2 34

Table 4.7 Load Crack-Width (in) Beam B4T1 35

Table 4.8 Maximum Concrete Strain Comparison 38

Table 5.1 Balanced Reinforcement Ratios 46

Table 5.2 Code Requirement of Various Nations for Effective Width 49

Table 5.3 Comparison of Experimental and Theoretical Deflections for Fatigue Tested Slabs $\quad 51$

Table 5.4 Effective Width Evaluation of McKinleyville Bridge 52

Table 5.5 Evaluation of Effective Width in Beams Failing in Compression Mode $\quad 55$

Table 5.6 Evaluation of Effective Width in Beams Failing in Tension Mode 56

Table 5.7 Comparison of Experimental and Theoretical Moment Capacities in $\begin{array}{ll}\text { Tension Failure Mode } & 61\end{array}$

Table 5.8 Comparison of Experimental and Theoretical Moment Capacities in Compression Failure Mode $\quad 62$

Table 5.9 Correlation of Crack-Width Equation Beam B1T1 64

Table 5.10 Correlation of Crack-Width Equation Beam B2T1 65

Table 5.11 Correlation of Crack-Width Equation Beam B3C1 65 
Table 5.12 Correlation of Crack-Width Equation Beam B3C2

Table 5.13 Comparison of Experimental and Theoretical Deflections during PreCracking Stage

Table 5.14 Comparison of Experimental and Theoretical Deflections for PostCracking Stage for Beam B1T1

Table 5.15 Comparison of Experimental and Theoretical Deflections for Post-

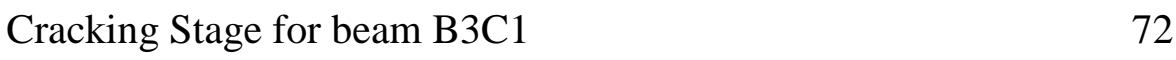

Table 5.16 Curvature Calculation at Deflection Serviceability Limit States 74

Table 5.17 Curvature Calculation at Crack Width Serviceability Limit States 74

Table 5.18 Curvature Calculation at Deflection Serviceability Limit States 75

Table 5.19 Curvature Calculation at Deflection Serviceability Limit States 75

Table 5.20 Deformability Factors for Beams with Varying Failure Mode 76

Table 5.21 Deformability Factors for Beams with Varying Failure Mode 76 


\section{LIST OF FIGURES}

Fig 3.1 a Surface characteristics of GFRP bar International Grating Inc. 12

Fig 3.1 b Surface characteristics of GFRP bar Marshall Inc. 12

Fig 3.2 Typical stress vs. strain diagram for \#4 GFRP bar 13

Fig 3.3 Typical stress vs. strain curve for concrete 16

$\begin{array}{lll}\text { Fig 3.4 Formwork and reinforcement details } & 17\end{array}$

$\begin{array}{lll}\text { Fig 3.5 Specimen details } & 19\end{array}$

$\begin{array}{lll}\text { Fig 3.6 Experimental setup } 20 & 23.6\end{array}$

Fig 4.1 Tension failure beam B1T1 23

Fig 4.2 Tension failure beam B1T2 23

Fig 4.3 Compression failure beam B4C1 24

Fig 4.4 Compression failure beam B3C2 NA extending into the web 25

Fig 4.5 Load-Deflection diagram beam B1T2 30

Fig 4.6 Load-Deflection diagram beam B3C1 30

Fig 4.7 Load-Deflection diagram beam B2T1 31

Fig 4.8 Crack-Patterns for beam B2T1 AT 80\% Ultimate load 36

Fig 4.9 Crack-Patterns for beam B3C1 AT 80\% Ultimate load 36

Fig 4.10 Concrete strain monitoring across the flange at midspan 37

Fig 4.11 Shear lag in beam B4T1 39

Fig 4.12 Shear lag in beam B3C1 39

Fig 4.13 Load GFRP strain in beam B2C1 40

Fig 4.14 Load GFRP strain in beam B4T1 41

Fig 5.1 a Classification of T-beam Systems. (Rectangular) 42

Fig 5.1 b Classification of T-beam Systems. (T-beam) 43

Fig 5.2 Fatigue tested concrete slabs reinforced with GFRP bars $\quad 50$

Fig 5.3 Effective flange width based on concrete strains beam B4C1 54

Fig 5.4 Concrete stress distribution (Parabolic) 57

Fig 5.5 Force equilibrium in concrete T-beams 58

Fig 5.6 Crackwidth evaluation 63

$\begin{array}{lll}\text { Fig A.1 Neutral axis in the flange } & 82\end{array}$ 
Fig A.2 Neutral axis in the web

84

Fig C.1 Strain compatibility diagram 


\section{Table of Contents}

ABSTRACT

ii

NOMENCLATURE

iii

LIST OF TABLES

$\mathbf{v}$

LIST OF FIGURES

vii

CHAPTER 1

INTRODUCTION

1.1 INTRODUCTION 1

1.2 ADVANTAGES AND APPLICATIONS OF

COMPOSITE BARS 1

1.3 OVERVIEW 2

1.4 OBJECTIVE 3

1.5 SCOPE 4

$\begin{array}{lll}\text { CHAPTER } 2 & 5\end{array}$

LITERATURE REVIEW

2.1 INTRODUCTION

2.2 GFRP BARS 6

2.3 CONCRETE ELEMENTS REINFORCED

WITH GFRP BARS

2.3.1 Static and Fatigue Response of Bridge Decks 7

2.3.2 Bending Behavior of Rectangular Beams 7

2.3.3 Bond 9

$\begin{array}{lr}\text { CHAPTER } 3 & 11\end{array}$

MATERIALS EQUIPMENT AND TEST PROCEDGURES

3.1 SPECIMEN FABRICATION 11

3.1.1 Material Properties $\quad 11$

3.1.1.1 GFRP bars 11

3.1.1.2 Concrete 14 
3.1.2 Form Work 16

3.1.3 Reinforcement Cage 16

3.1.4 Concrete Placement 17

3.1.5 Test Specimens 18

3.2 TEST SETUP FOR FOUR POINT BENDING TESTS 20

CHAPTER4

22

RESULTS AND DISCUSSIONS

4.1 INTRODUCTION 22

4.2 FAILURE MODES 22

4.2.1 Tension Failure 22

4.2.2 Compression Failure $\quad 24$

4.3 ULTIMATE MOMENT CAPACITIES 26

4.4 PRE- AND POST-CRACKING DEFLECTIONS 27

4.5 MOMENT-CURVATURE RELATIONSHIP 31

4.6 CRACKING BEHAVIOR 32

4.6.1 Crack-Width 32

4.6.2 Crack-Patterns 35

4.7 CONCRETE STRAIN DISTRIBUTION 37

4.8 LOAD vs. STRAIN DISTRIBUTION IN GFRP BARS 40

CHAPTER 5

THEORETICAL CORRELATION OF EXPERIMENTAL RESULTS 42

5.1 CLASSIFICATION OF T-BEAM SYSTEMS 42

5.2 PREDICTION OF BALANCED REINFORCEMENT RATIO 43

5.2.1 Rectangular section $\quad 43$

5.2.2 T-section 44

5.3 EFFECTIVE WIDTH EVALUATION 47

5.3.1 Concrete Stress Distribution across the Flange $\quad 47$

5.3.2 Existing Codal Specs on Effective Flange Width 47

5.3.3 Effective Width of Orthrotropic Plate-beam Systems 50 
5.3.4 Effective Width of Slabs Reinforced with GFRP Bars 50

5.3.4 Evaluation of Effective Width in McKinleyville Bridge51

5.3.5 Theoretical Correlation of Effective Flange Width 54

5.4 ANALYTICAL MODELLING OF FLEXURAL

BEHAVIOR OF T-BEAMS 57

5.4.1 Stress Distribution in Compression Zone 57

5.4.2 Force Equilibrium $\quad 58$

5.4.3 Analysis of Under-Reinforced Beams 59

5.4.4 Analysis of Over-Reinforced Beams 59

5.4.4.1 Rectangular $\quad 60$

5.4.4.2 T-beam 60

5.5 FLEXURAL CRACKING 62

5.5.1 Cracking-Overview 62

5.5.2 Crack-width Modeling 63

5.6 DEFLECTION PREDICTIONS 66

5.6.1 Deflection Prediction of Uncracked Concrete Section 67

5.6.2 Deflection Prediction of Cracked Concrete Section $\quad 70$

5.7 DUCTILITY/DEFORMABILITY 73

5.7.1 Unified Serviceability Criterion for Deformability 73

5.7.2 Deformability Factors $\quad 76$

CHAPTER 6

SUMMARY CONCLUSIONS AND RECOMMENDATIONS

6.1 SUMMARY 78

6.2 CONCLUSIONS 79

6.3 RECOMMENDATIONS 81

APPENDIX A ANALYSIS OF GFRP-REINFORCED T-BEAMS 82

$\begin{array}{lll}\text { APPENDIX B DESIGN PROCEDURE } & 86\end{array}$

$\begin{array}{lll}\text { APPENDIX C DESIGN EXAMPLE } & 89\end{array}$

$\begin{array}{lll}\text { APPENDIX D DESIGN CHARTS } & 93\end{array}$

REFERENCES 96

$\begin{array}{ll}\text { VITA } & 100\end{array}$ 


\section{CHAPTER 1 INTRODUCTION}

\subsection{Introduction}

Aging infrastructure needs to be rehabilitated to minimize user inconveniences and maximize original returns through extended service life. In addition, the emerging economy also demands new infrastructure systems, which can perform more efficiently than the existing ones (Composites for Infrastructure, 1998). Fiber reinforced polymer (FRP) composite systems are promising better performance in terms of rehabilitation as well as new construction.

Fiber reinforced polymer composites are outperforming metals, wood, concrete, and un-reinforced plastics in a wide variety of applications (Composites for Infrastructure, 1998). Various composites suit specific market applications based on their properties. The fields involving the use of advanced composites are:

- Transportation

- Electrical/Electronics

- Building Construction

- Infrastructure

- Aerospace

- Medical products

- Defense

- Automobile industry

\subsection{Advantages and applications of GFRP rebar application}

\section{Advantages}

Composite materials offer benefits like (GangaRao, 1996)

- Design flexibility

- Better cost-benefit ratio in relation to steel

- High strength to weight ratio

- Dimensional stability 
- Fewer corrosion problems and related maintenance and repair costs

- Easier transportation, handling on site and installation compared to steel rebars

- Low electric conductivity or electromagnetic neutrality

\section{Applications}

Applications that are most likely to benefit by usage of GFRP rebars are

- Parking structures

- Bridge decks

- Parapets

- Curbs

- Retaining walls

- Foundations

- Roads and pavements, especially in northern climates

- Slabs on grade

- Marine structures

-Retaining walls

-Caissons

-Piles

-Bulk heads

-Swimming pools

-Offshore plat-forms

- Wastewater treatment plants

- Petrochemical plants

- Gasoline plants

- Concrete pipelines

- Nuclear power plants

\subsection{Overview}

Concrete slabs are cast integrally with girders/stringers (stiffening system) as floor slabs, bridge decks, footings, retaining structures and others. In any one of these structural systems a portion of the slab bends in unison with the stiffening girders/stringers, thus resulting in a T- beam action. Therefore, it is necessary to study the 
pre- and post-cracking behavior of FRP reinforced concrete T-beams, develop design equations for bending capacity, effective flange width, and deflection, and compare them with the existing ACI 318-95 equations. Cracking of concrete may be mainly due to shrinkage, creep, thermal variations, or inadequate design for external loads (Nawy, 1990). Cracking can lead to early deterioration of concrete structures. Deterioration of highway bridges, parking garages and other reinforced concrete structures particularly in coastal areas is leading to traffic tie-ups and productivity losses. Consequently, rehabilitation is taking a heavy toll on the national budget (Bedard et al, 1992).

Non-corrosive fiber reinforced polymer (FRP) materials can be considered as an alternative material to alleviate corrosion related problems in steel reinforced concrete members. Most of the bridges, multi-story parking garages and buildings reinforced with steel consist of T-beams as their primary structural elements. Therefore, a thorough understanding of design approach of concrete T-beams with FRP composite bars based on fundamental engineering principles is essential. Research has been conducted on the physical properties of GFRP bars including their aging effects under varying environmental conditions (Vijay and GangaRao, 1999). In addition, design procedures and specifications have been developed for rectangular cross-sections reinforced with GFRP bars (ACI 440-H).

\subsection{Objective}

- Study the bending behavior of concrete T-beams reinforced with FRP rebars with emphasis on flexural tension and compression failure modes.

- Evaluate the stiffness of T-beams before and after cracking and develop mathematical models for deflection response, crack width, and ultimate moment.

- Evaluate energy based ductility/deformability factors using serviceability based curvature criteria for deflection and crack width.

- Study the shear-lag phenomenon along the flange width before and after cracking for establishing effective flange width.

- Develop design equations, procedures, and design specifications for T-beams with FRP bars. 


\subsection{Scope}

The scope of this study consists of testing eight concrete T-beams reinforced with GFRP bars. Concrete T-beams, designed to fail in tension or compression modes, were cast in the laboratory. Two types of GFRP bars, one with sand-coated surface and the other having a ribbed surface, were used. The ratio of flange width to web width was varied, and the effect of shear lag across flange width was studied for varying loads.

The beams were tested to failure and parameters recorded were strains, deflections, and crack-widths. Theoretical correlation of parameters like bending capacity, crack-widths, deflections are carried out and design equations similar to ACI 318-95 and ACI 440-H have been developed. The test results will be used towards implementing GFRP bars for highway applications such as bridges and developing AASHTO specifications. 


\section{CHAPTER 2}

\section{LITERATURE REVIEW}

\subsection{INTRODUCTION}

Corrosion - related deterioration of the Nation's constructed facilities, such as bridge decks, has resulted in costly repairs and led to user inconveniences (America's Highway, 1997). To improve the longevity of these facilities, non-corrosive FRP bars offer an alternative to steel rebars as reinforcement in concrete structures. The use of Glass Fiber Reinforced Polymer (GFRP) composite bars instead of steel bars has increased in the recent years (Benmokrane, 1998). The advantages of using FRP reinforcement are (1) design flexibility (2) cost performance (3) high strength (4) corrosion resistance and (5) weight reduction. Bridges, buildings, off-shore structures, mining operations, chemical plants, highway pavements, geotechnical applications, structural or nonstructural elements are being reinforced, rehabilitated or stabilized with glass FRP in the form of bars, fabrics and grids (Rostasy, 1996, Seible and Karbhari, 1996).

Agencies performing the maintenance of U.S. highways, bridges and piers cannot keep pace with required repairs of steel-reinforced concrete structures. Increasing construction activity increases the maintenance burden. This explains the necessity of longer lasting structures and repair of the existing structures. An extensive amount of research is being conducted (Benmokrane 96, GangaRao, 1996, Nanni, 96, and Brown, 1996) to develop advanced composite system for infrastructure applications. The results

of this research are being incorporated into successful infrastructure projects. Depending on the type of fiber used for reinforcing the composite, various types of FRP bars (carbon, glass and aramid) are now available for field applications. At present, GFRP bars are the most researched item. However, long term safety, serviceability and durability of structures reinforced with FRP need to be established and guaranteed. One such accelerated aging study on reinforced concrete beams and GFRP bars was conducted by Vijay and GangaRao (1999). Durability of FRP depends upon the chemical, mechanical and thermal properties of their constituents, i.e., resins and fibers also 
accelerated aging chamber conditioning for 30 months corresponds to 63.75 years of natural weathering with 20\% sustained stress (Vijay and GangaRao, 1999).

\subsection{GFRP BARS}

Fibers in the FRP bars may be made of glass, aramid, carbon, or a combination thereof. Surface of the rebars may be smooth, sand-coated, deformed, helically wrapped, ribbed and/or sand coated (has a ribbed surface texture similar to that of a steel bar). Alkaline solutions and sustained stress are found to reduce the strength and stiffness of GFRP bars (Vijay and GangaRao 1999). The properties and behavior of FRP bars can vary significantly based upon the type of fibers and resins, fiber volume fraction, fiber orientation, and quality control during manufacturing.

The on-going GFRP bar research in improving manufacturing techniques, resin selection, and fiber orientation has enhanced the rebar strength, stiffness and bond characteristics. Researchers at the Constructed Facilities Center (WVU, Morgantown) evaluated the mechanical and thermal behavior of FRP rebars and the behavior of concrete beams and decks reinforced with FRP rebars under the project "Fiber Reinforced Plastics for Bridge Decks" (Sanjeev and GangaRao, 1996).

Strength and stiffness properties of GFRP bars are characterized by $\mathrm{Wu}(\mathrm{Wu}$, 1991). The type of GFRP bar influenced failure modes. For example, bars without any surface deformation showed fiber breakage, whereas wrapped or ribbed bars exhibited matrix cracking before the fiber breakage. The failure was initiated by the failure of outer fibers and peeling off before total failure. The ultimate strength and stiffness of bars depends upon the bar diameter, type of fibers, fiber volume fraction, quality control in manufacturing, and matrix system. The strength and stiffness of GFPR bars in compression were lower than those in tension (Wu, 1991).

GFRP bars exhibit shear lag phenomenon, which is due to the difference in stress carried by outer fibers as compared to the core fibers. Ultimate failure stress is inversely proportional to the bar diameter. This can be attributed to a more uniform stress distribution between the outer and inner fibers in lower diameter bars than in larger diameter bars (GangaRao, 1995). 


\subsection{CONCRETE ELEMENTS REINFORCED WITH GFRP BARS}

Concrete slabs and beams reinforced with FRP bars have been studied by many researchers. The combined study of beams and slabs as a single unit such T-beam are limited. The work done by various researchers on concrete elements like beams and slabs reinforced with GFRP rebars are summarized in the section below.

\subsubsection{Static and Fatigue Response of Bridge Decks}

The Research project entitled "Fatigue Response and Design of Concrete Bridge Decks Reinforced with Fiber Reinforced Plastic (FRP) Rebars" (Sanjeev, 1995) addressed the fatigue behavior of four concrete deck-stringer systems reinforced with FRP bars. The fatigue tests revealed that:

1) Fatigue crack patterns were similar to a concrete deck reinforced with steel rebars.

2) Major cracks were in the direction parallel to steel wide flange stringers.

3) No loss of bond was found between FRP bars and concrete in test specimens.

This study also concludes that the experimental deflections measured at the center of the deck are within $1 \%$ of the theoretical deflections, suggesting that the whole of the width is effective, This can also be attributed to the support conditions of the specimen and smaller size of the specimen.

\subsubsection{Bending Behavior of Rectangular Beams}

Nawy and Neuwerth $(1972,1977)$ made one of the earliest efforts to study concrete elements with FRP rebars. They studied both slabs and beams for flexure, cracking and deflections, and load capacities to failure. At $20 \%$ of ultimate load, the FRP bar reinforced slabs were observed to be within existing code limits for deflections and cracking. Experimental data on the flexural behavior of concrete beams reinforced with FRP bars can be found in technical conference proceedings like CDCC-1998, FRPRCS3-1998, ICCI-1996, and ACMBS-II-1996. The existing mathematical models for crackwidth and deflection need refinement in order to predict the beam behavior more precisely. Many researchers have been suggesting a shift in design philosophy from tension to compression failure mode. The linear behavior of FRP bar upto failure, without a yield plateau, concerns design engineers with reference to achieving adequate ductility 
in the post-cracking zones. However, researchers (Vijay, 1999) have shown that the serviceability criterion of deflection and crack-width can be achieved through compression failure of concrete only. The deformability factor is defined as the ratio of energy absorbed at failure load to that at serviceability level (which may be taken as a curvature limit state of 0.006/d, d-eff. Depth). The bending behavior of concrete beams reinforced with GFRP bars including sudden rupture of FRP bars in tension has been studied by Vijay and GangaRao (1999), Benmokrane et al. (1996), Saadatmanesh and Malik (1998), Hosny et al (1996), Abdallah et al., (1996), Matthys and Taerwe (1996), Nanni (1993), Razaqpur and Ali, (1996), Faza and GangaRao (1992), and Nawy et al. (1977). Moment capacity, $\mathrm{M}_{\mathrm{n}}$ of a concrete beam failing in tension is evaluated from:

$$
M_{n}=A_{f} f_{f}(d-a / 2)
$$

$\mathrm{M}_{\mathrm{n}}$ - Moment capacity

$\mathrm{A}_{\mathrm{f}}-$ Area of tension reinforcement

$\mathrm{f}_{\mathrm{f}}$ - Ultimate stress in rebar

$\mathrm{d}$ - Effective depth of the beam

a - Depth of the neutral axis

Tension failure capacity of concrete beams with GFRP bars are predicted reasonably well (within 5\%-10\%), and compression failure predictions are not conservative and vary by $30 \%$ or more (Sonobe, et al., 1997).

ACI equations for deflection and crackwidth for steel reinforced concrete beams need to be accounted for lower stiffness and higher cracking of GFRP reinforced beams (Almusallam et al., 1996, Abdalla et al., 1996, Arockisamy et al, 1996).

$$
I_{e f f}=I_{c r}+\left(I_{r}-I_{c r}\right)\left(\frac{M_{c r}}{M_{a}}\right)^{3}
$$

$I_{\text {eff }}$-Effective moment of inertia

$I_{g}$-Gross moment of inertia

$I_{c r}$-Cracked moment of inertia

Benmokrane et al, (1996), use a modification factor in the calculation of $I_{\text {eff }}$, so that lower effective moment of inertia of the concrete section can be obtained. Brown et al. (1996), suggested power coefficient to be 5 instead of 3 as suggested in the ACI equation for $\mathrm{I}_{\text {eff }}$ estimation. Faza and GangaRao (1992) have proposed a modified 
moment of inertia $\left(\mathrm{I}_{\mathrm{m}}\right)$, where, the central region was considered as highly cracked compared to the region close to the supports. Expressions for various loading conditions are derived for the modified moment of inertia. For a beam with uniformly distributed load $\mathrm{I}_{\mathrm{m}}$ is given by:

$$
I_{m}=\frac{240 I_{c r} I_{e f f}}{39 I_{c r}+24 I_{\text {eff }}}
$$

$I_{\text {eff }} \quad$ Effective moment of inertia

$I_{m^{-}} \quad$ Modified moment of inertia

$I_{c r} \quad$ Cracked moment of inertia

Crack width predictions similar to the ACI guidelines are given by many researchers, by accounting the increase in crack widths (Masmoudi et al., 1996, Benmokrane et al., 1996). One such formula by GangaRao (1995) is given below where crack-width values were increased by a factor of $\left(E_{s} / E_{f}\right)$, which is the ratio of modulus of elasticity of steel to FRP.

$$
w_{\text {max }}=0.076 \beta \frac{E_{s}}{E_{f}} f_{f} \sqrt[3]{d_{c} A} 10^{-3}
$$

\subsubsection{Bond}

Bond development lengths for GFRP bars are given by modifying the ACI formula by many researchers (Tepfers, 1998, Freimanis et al., 1998, Tighiourt et al., 1998, Dulaijan et al., 1996, Lundy and Kachlakev, 1996, Saadatmanesh and Tao, 1996, Mustafa and Barakaypt, 1996). One such formula is given below (GangaRao, 1995), which predicts the bond length to be 50\% higher than those given for steel reinforced concrete beams.

$$
1_{\mathrm{db}}=0.06 \frac{A_{b}\left(f_{f}\right)}{\sqrt{f_{c}^{\prime}}}
$$


Limited literature is available on T-beams reinforced with GFRP rebars. In a Tbeam the flexural stress in the flange is not uniform over its width. The flexural stress varies from a maximum over the web to a lower value away from the web (Benmokrane 1997). T-beams in field are often designed such that the distance of neutral axis to the top compression fiber at ultimate is less than the thickness of the flange i.e., the compression zone is rectangular (Gurfinkel, 1993). The bending behavior of concrete T-beams reinforced with GFRP bars is being studied by researchers like Brown, (1996), Benmokrane (1997), Jaeger, (1997) etc.

An experimental program in this project was planned by carefully understanding the behavior of rectangular beams reinforced with FRP bars. In the chapters to follow detailed discussion of the specimens, test procedures, results, and analytical modeling of the beam behavior are presented. 


\section{CHAPTER 3}

\section{MATERIALS, EQUIPMENT AND TEST PROCEDGURES}

\subsection{SPECIMEN FABRICATION}

T-beam specimens were designed by varying several geometric parameters and reinforcement ratios to understand beam response, failure modes and other issues. Careful consideration was given to identify design issues for T-beams under flexure. Some of these issues are:

- Span/depth ratios for ultimate moment capacity

- Flange width and thickness in T beams

- Percentage of main FRP reinforcement for tension and compression failure modes

- Percentage and spacing of flange reinforcement

- Design compressive strength of concrete

\subsubsection{Material Properties}

Two grades of concrete concrete, two different types of GFRP bars and steel stirrups were used for casting the T-beams. Relevant material properties are provided in this section.

\subsubsection{GFRP bars}

GFRP bars are anisotropic in nature. A good understanding of their mechanical properties and long term behavior is essential for providing safe and economic concrete beam design with GFRP bars. GFRP bars have the following constituents.

- Fibers -Principal load carrying constituents of composites

- Resins - To hold fibers in place and avoid fiber abrasion

- Fillers and Additives - To reduce cost and increase modulus of a composite.

- Sizing - To avoid fiber abrasion.

Manufacturers use different manufacturing methods, i.e., pultrusion, compression molding and others. Two types of FRP rebars (Figure 3.1), C-bars supplied by Marshall Industries Composites, Inc., and sand coated bars supplied by International Grating, Inc., were used as reinforcement in the flange and web. The former type had E-glass fibers and core combined with compression-molded (SMC) shell. The shell consists of chopped and 
continuous E-glass fiber as reinforcement, with low viscosity urethane modified vinyl ester. In sand coated rebars, the pultruded bar with urethane modified vinyl ester was wrapped with two additional fiber chords in a helical pattern and then coated with another layer of epoxy resin and finally rolled in sand. The wrapped chords and sand coating provide better mechanical bond with the surrounding concrete. Both types of FRP bars were used in our experimental work.

GFRP bars were subjected to static, uniaxial tensile tests. The following rebar properties were considered for designing the beams in flexure.

- Failure stress and strain

- Modulus of elasticity

The surface characteristics improving the mechanical bond of rebars to concrete are shown in the figure $3.1 \mathrm{a}$ and $3.1 \mathrm{~b}$.

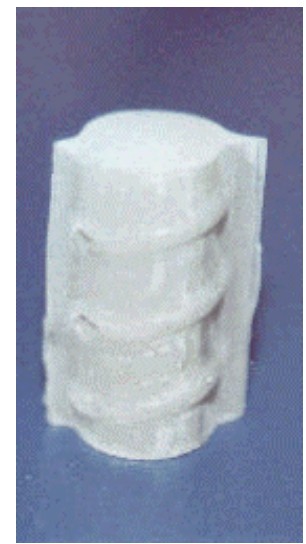

C-Bar

(a)

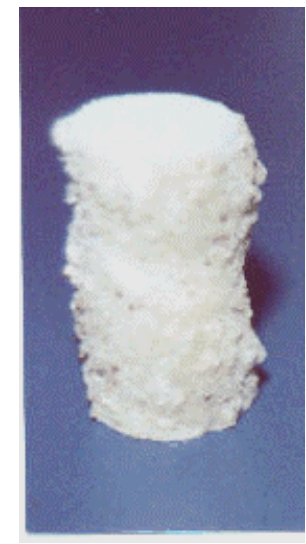

International Grating

(b)

\section{Fig 3.1 Surface characteristics of GFRP rebar}

Table 3.1 shows the composition of C-BAR and describes various components constituting the inner core and outer mold. Table 3.2 shows the designation and configuration of various $\mathrm{C}$-Bars as provided by the manufacturer. 
Table 3.1 C-BAR Composition (\% weight) (Manufacturers Data)

\begin{tabular}{|c|c|}
\hline Rebar Type & C-Bar \\
\hline \% of E-glass Fiber & $70 \%$ \\
\hline Urethane Modified Vinyl Ester & $15 \%$ \\
\hline Recycled P.E.T & $10 \%$ \\
\hline Ceramic Reinforcement & $3.5 \%$ \\
\hline Corrosion Inhibitor & $1.5 \%$ \\
\hline
\end{tabular}

The stress vs. strain curve for GFRP rebar was linear up to failure. At failure, the bar breaks by matrix cracking and fiber rupturing. Fig 3.2 shows a typical stress vs. strain curve for \#4 C-Bar.

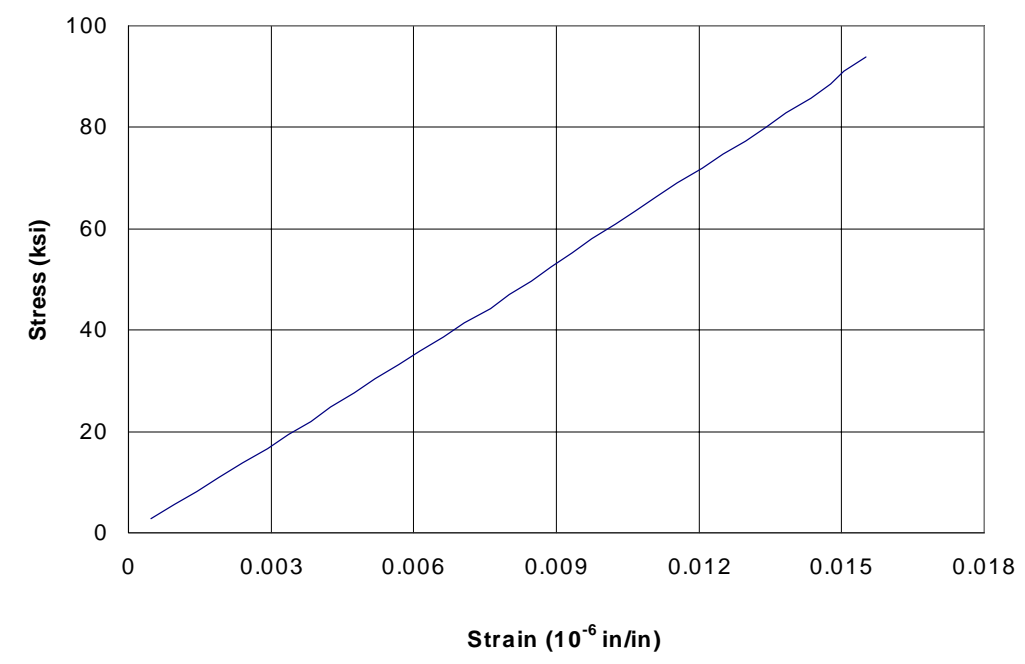

Fig 3.2 Typical stress vs. strain diagram for \#4 GFRP rebar 


\section{Table 3.2 Various C-BAR Designation and Configuration (SI units) (Manufacturer's Data)}

\begin{tabular}{|c|c|c|c|c|c|c|}
\hline \multicolumn{2}{|c|}{$\begin{array}{c}\text { Bar } \\
\text { Designation }\end{array}$} & \multirow{2}{*}{$\begin{array}{c}\text { Nominal } \\
\text { Weight, } \\
\mathrm{Kg} / \mathrm{m}\end{array}$} & \multirow{2}{*}{$\begin{array}{c}\text { Cross } \\
\text { Sectional } \\
\text { Area, } \\
\mathrm{mm}^{2}\end{array}$} & \multirow{2}{*}{$\begin{array}{c}\text { Perimeter, } \\
\mathrm{mm}\end{array}$} & \multirow{2}{*}{$\begin{array}{c}\text { Maximum } \\
\text { Average } \\
\text { Spacing, } \\
\text { mm }\end{array}$} & \multirow{2}{*}{$\begin{array}{c}\text { Minimum } \\
\text { Average } \\
\text { Height, } \\
\text { mm }\end{array}$} \\
\hline No. & $\begin{array}{l}\text { Dia } \\
\text { mm }\end{array}$ & & & & & \\
\hline \# 3 & 9.73 & .1750 & 74.36 & 30.56 & 5.72 & 0.74 \\
\hline$\# 4$ & 12.29 & .3564 & 118.63 & 38.61 & 7.47 & 0.99 \\
\hline \# 5 & 14.86 & .4344 & 173.43 & 46.66 & 9.40 & 1.22 \\
\hline \# 6 & 17.86 & .5552 & 245.5 & 55.5 & 11.43 & 1.47 \\
\hline
\end{tabular}

Table 3.3 lists the strength and stiffness values of rebars subjected to uniaxial tensile test. Minimum of three samples were tested per each bar diameter and manufacture type.

Table 3.3 Rebar Strength and Stiffness Values

\begin{tabular}{|c|c|c|c|c|}
\hline \multirow{2}{*}{ Type } & \multicolumn{3}{|c|}{$\mathrm{f}_{\mathrm{f}}(\mathrm{ksi})$} & $\mathrm{E}_{\mathrm{f}}$ \\
\cline { 2 - 4 } & $\# 4$ & $\# 5$ & $\# 8$ & $10^{6} \mathrm{psi}$ \\
\hline Marshall & $90-100$ & 92 & - & $5.5-6$ \\
\hline International grating & $85-95$ & 85 & 70 & $6-7$ \\
\hline
\end{tabular}

\subsubsection{Concrete}

Class $\mathrm{K}$ concrete conforming to the WVDOH specification was purchased from a ready-mix plant, and the mix was designed with a suitable water/cement ratio to achieve the required concrete strength and workability conditions. Concrete cylinders were 
simultaneously cast with the beam casting to obtain the concrete compressive strength. Two cylinders per specimen were cast. Twenty-four hours after casting, curing was carried out through wet burlaps. On the $28^{\text {th }}$ day, concrete cylinders were tested for compressive strength as per ASTM C-39. Typical stress vs. strain curve for concrete is given in Fig 3.4. Table 3.4 gives the average cylinder compressive strength for four batches of concrete castings.

The compressive strength of concrete plays an important role in the design of GFRP reinforced beams. Higher amounts of GFRP reinforcement are required to counteract the compressive force provided by high strength concrete. In addition, the neutral axis of a concrete beam shifts down with the increase in the amount of tensile reinforcement. Keeping in mind the above mentioned factors lower concrete strengths are used in batches 3 and 4 to achieve true T-beam behavior (NA in the web) using optimum amounts of FRP tensile reinforcement.

\section{Table 3.4 Concrete Cylinder Compressive Strengths}

\begin{tabular}{|c|c|c|}
\hline Beam & $\begin{array}{c}\mathrm{f}_{\mathrm{c}}^{\prime} \\
\mathrm{ksi}\end{array}$ & Batch \\
\hline B1T1 & 5.6 & 1 \\
\hline B2T1 & 5.1 & 2 \\
\hline B3C1 & 3.1 & 3 \\
\hline B4T1 & 2.7 & 4 \\
\hline B1T2 & 5.6 & 1 \\
\hline B2C1 & 5.1 & 2 \\
\hline B3C2 & 3.1 & 3 \\
\hline B4C1 & 2.7 & 4 \\
\hline
\end{tabular}

Stress vs. strain curve for concrete is linear unto a strain of about0.001 (in/in), and attains maximum strength of $f_{c}$ ' at a strain of about 0.002 (in/in). The strength of concrete 
remains more or less the same after reaching strain of about 0.002 (in/in). Concrete ruptures at a strain of about 0.0025-0.004 (in/in) depending on the strength of concrete.

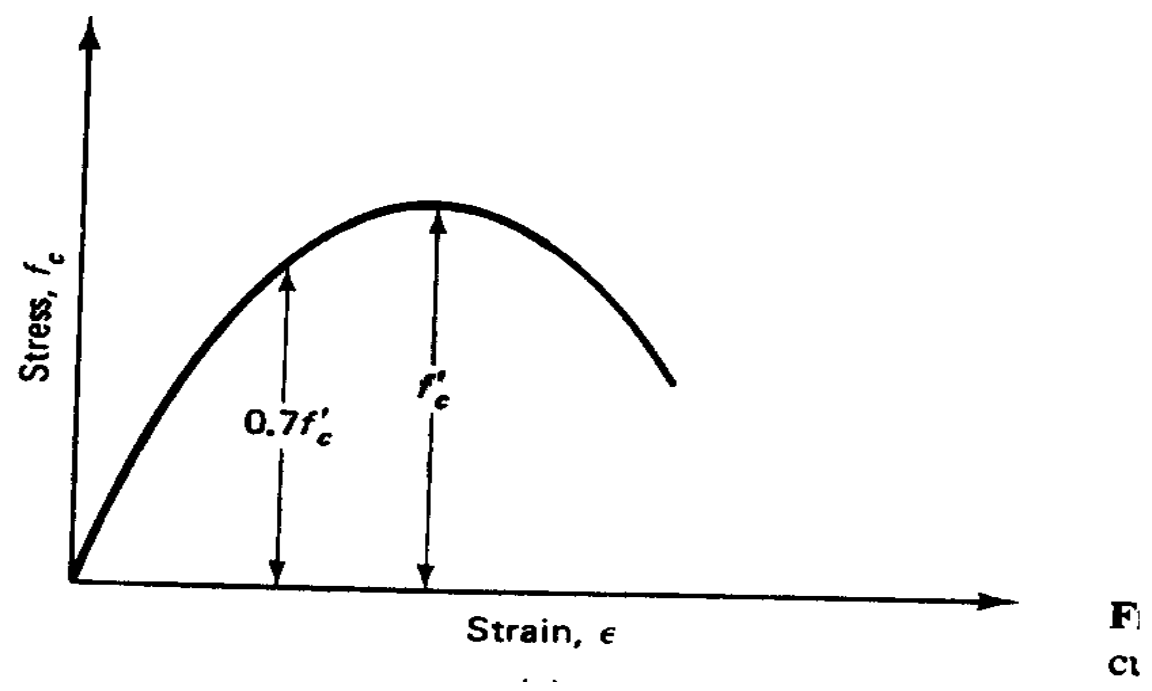

Fig3.3 Typical stress strain curve for concrete

\subsubsection{Form Work}

Formworks consisting of adjustable and slidable units were built for casting in order to achieve different beam dimensions such as flange width, flange thickness and web depth for different beam castings. Fig 3.5 shows the top view of the formwork with reinforcement cages in-place for specimen casting. The formwork was properly oiled before casting. Two formworks were used to cast two beams at a time. The forms were properly cleaned after the beams were removed and reassembled to the required dimensions. Wooden form offered flexibility in terms of adjusting the flange width due to its lightweight.

\subsubsection{Reinforcement Cage}

The reinforcement for the web and flange were suitably combined before casting the concrete beams. The reinforcement consisted mainly of GFRP bars in both web and flange. Conventional stirrups were used in all eight beams to counteract shear forces. The reinforcement cage was properly instrumented before concrete pour to measure strains in 
the compression and tension reinforcements; strain gages were also attached to the main reinforcement of flange. Lead wires were attached to the strain gages and protective coatings like nitrile rubber from Vishay Measurements Group were applied. The wires were secured in place and tags were attached to identify the source of each wire. Chairs were used to provide the required concrete cover similar to construction work with steel reinforced concrete. The reinforcement in the flange consisted of \#4 GFRP rebars in the transverse and longitudinal directions and the details of the reinforcement are shown in table 3.6.

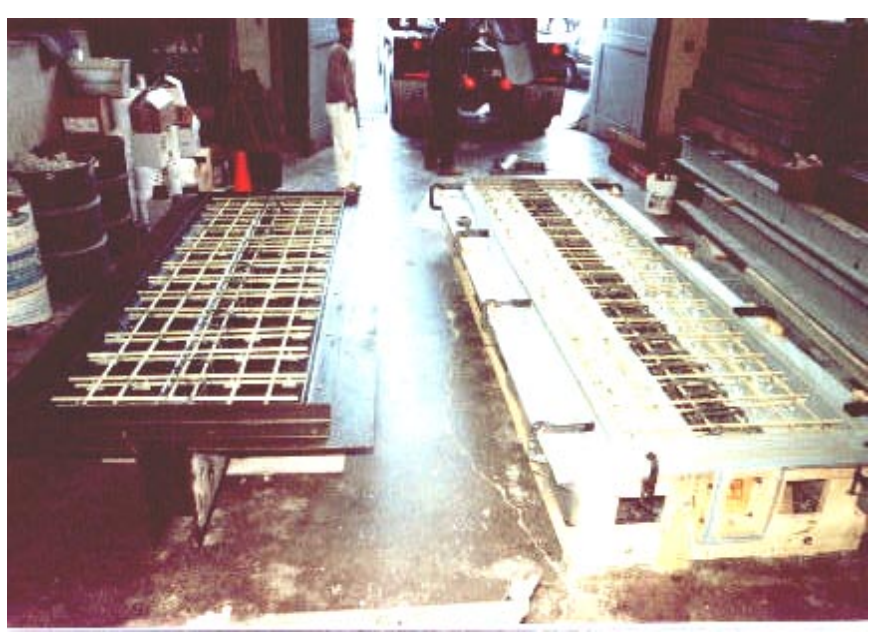

Fig 3.4 Form work and Reinforcement details

\subsubsection{Concrete Placement}

A total of four castings were carried out with two beam castings at a time. Class $\mathrm{K}$ concrete conforming to the WVDOT-DOH specification was purchased from a ready-mix plant and the mix was designed with a suitable water/cement ratio to achieve the required concrete strength and workability conditions. The beams were properly vibrated to minimize honeycombing.

Concrete cylinders were simultaneously cast to obtain the concrete compressive strength. Twenty-four hours after casting the beams and cylinders, curing was carried out through wet burlaps. Formwork is stripped after seven days and beams were covered with 
wet burlap for 21 days. On $28^{\text {th }}$ day, concrete cylinders were tested for compressive strength as per ASTM C-39.

\subsubsection{Test Specimens}

Eight concrete T-beams were cast with different reinforcement ratios and dimensional configurations. Details of beam dimensions are provided in Table 3.5 and reinforcement details are given in Table 3.6. Reinforcement ratios were varied to achieve both compression and tension failure and to study the variation in moment capacity with increase in reinforcement ratio. Various flange width to depth ratios (b/t) were adopted in the beams to establish effective width of the beam.

Table 3.5 Details of Test Specimens

\begin{tabular}{|l|c|c|c|c|c|}
\hline Beam & $\mathrm{b}$ & $\mathrm{b}_{\mathrm{w}}$ & \multicolumn{1}{c|}{$\mathrm{h}_{\mathrm{f}}$} & $\mathrm{h}$ & $\begin{array}{c}\text { Test } \\
\text { Span }\end{array}$ \\
\cline { 2 - 6 } & in & in & in & in & $\mathrm{ft}$ \\
\hline B1T1 & 36 & 6 & 3 & 18 & 8 \\
\hline B2T1 & 30 & 6 & 3 & 18 & 8 \\
\hline B3C1 & 18 & 6 & 2.5 & 17.5 & 8 \\
\hline B4T1 & 42 & 6 & 2.5 & 17.5 & 8 \\
\hline B2C1 & 36 & 9 & 3 & 15 & 11 \\
\hline B3C2 & 24 & 9 & 2.5 & 14.5 & 11 \\
\hline B4C1 & 42 & 9 & 2.5 & 14.5 & 11 \\
\hline
\end{tabular}


b

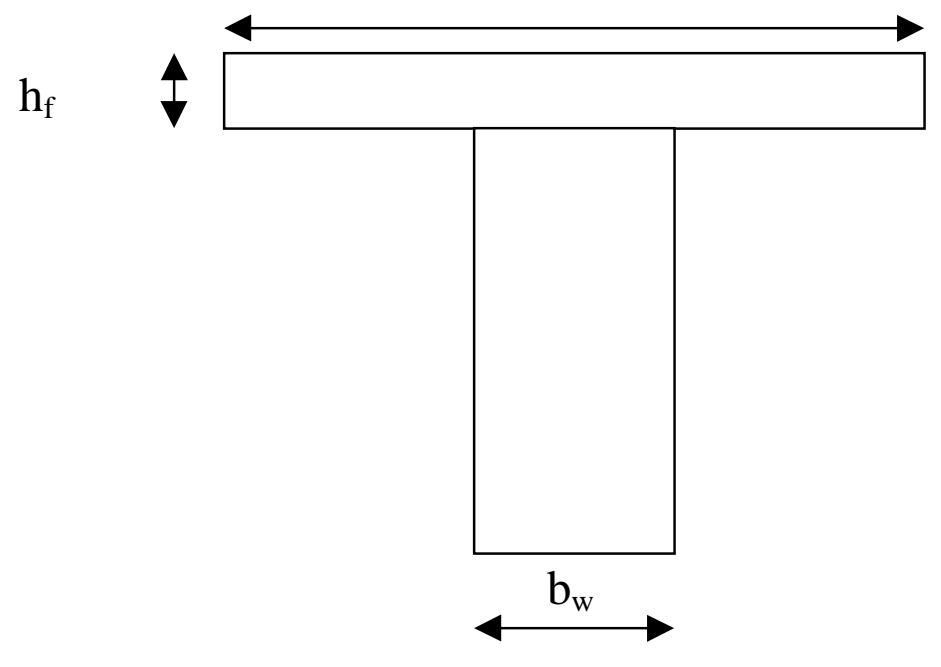

$\mathrm{h}$

Fig 3.5 Specimen Details

Table 3.6 Reinforcement Details

\begin{tabular}{|c|c|c|c|c|c|}
\hline \multirow[t]{2}{*}{ Beam } & \multicolumn{2}{|c|}{ Web } & \multirow{2}{*}{$\begin{array}{c}\text { Shear } \\
\text { Stirrups }\end{array}$} & \multicolumn{2}{|c|}{ Flange Reinforcement } \\
\hline & $\begin{array}{c}\text { Tension } \\
\left(\mathrm{in}^{2}\right)\end{array}$ & $\begin{array}{l}\text { Compres- } \\
\text { sion }\left(\text { in }^{2}\right)\end{array}$ & & Main & Transverse \\
\hline B1T1 & 0.61 & 0.4 & \#3@6 in c/c & \#4 @6 in c/c & $\# 4 @ 12$ in c/c \\
\hline B2T1 & .61 & 0.4 & \#3 @6 in c/c & \#4 @6 in c/c & \#4 @ 12 in c/c \\
\hline B3C1 & 4.32 & 0.4 & \#4@4 in c/c & \#4 @6 in c/c & $\# 4 @ 6$ in c/c \\
\hline B4T1 & 0.98 & 0.4 & $\# 3 @ 6$ in c/c & $\# 4 @ 6$ in c/c & \#4 @ 12 in c/c \\
\hline B1T2 & 2.45 & 0.4 & $\# 3 @ 6$ in c/c & \#4@6 in c/c & $\# 4 @ 12$ in c/c \\
\hline $\mathrm{B} 2 \mathrm{C} 1$ & 3.59 & 0.4 & \#4@3.5 in & \#4@6 in c/c & \#4 @ 10 in c/c \\
\hline B3C2 & 4.77 & 0.4 & \#4 @3.5in & \#4@6 in c/c & \#4@6 in c/c \\
\hline B4C1 & 5.55 & 0.4 & \#4 @3.5in & \#4 @6 in c/c & \#4 @ 10 in c/c \\
\hline
\end{tabular}




\subsection{TEST SETUP FOR FOUR POINT BENDING TESTS}

Four point-bending tests were conducted until specimen failure, i.e., rebar rupture in tension failure and concrete crushing in compression failure. Test setup is shown in Fig. 3.6. Each test consisted of several cycles of loading and unloading to evaluate the ductility behavior and energy absorption of each beam. The parameters measured include:

1. Concrete and GFRP bar strains using strain gages.

2. Mid-span deflection using LVDT.

3. Crack-width and spacing using micrometer and ruler.

Beams were tested to failure in several loading and unloading cycles. Residual strains and deflections were measured in each load cycle. Load cell, strain gage, and LVDT data were automatically recorded using the UPC 607 data acquisition system during loading and unloading. Crack widths were measured by using a micrometer, and crack patterns in all the eight beams were traced onto a tracing sheet. Some of them are represented in Chapter 4. To study shear lag, compressive strains were recorded at a minimum of three locations along half the flange width at mid-span.

Torsional effects were minimized on the beam by providing wooden blocks and neoprene pads at the supports. A hydraulic loading jack was used for loading the beam. Irregularities in the concrete flange surface where load was applied were smoothened by using a grinder to attain higher uniformity in applied loading along the beam width. A neoprene pad was positioned below the spreader beam to nullify uneven load distribution due to any flaws on the concrete surface.

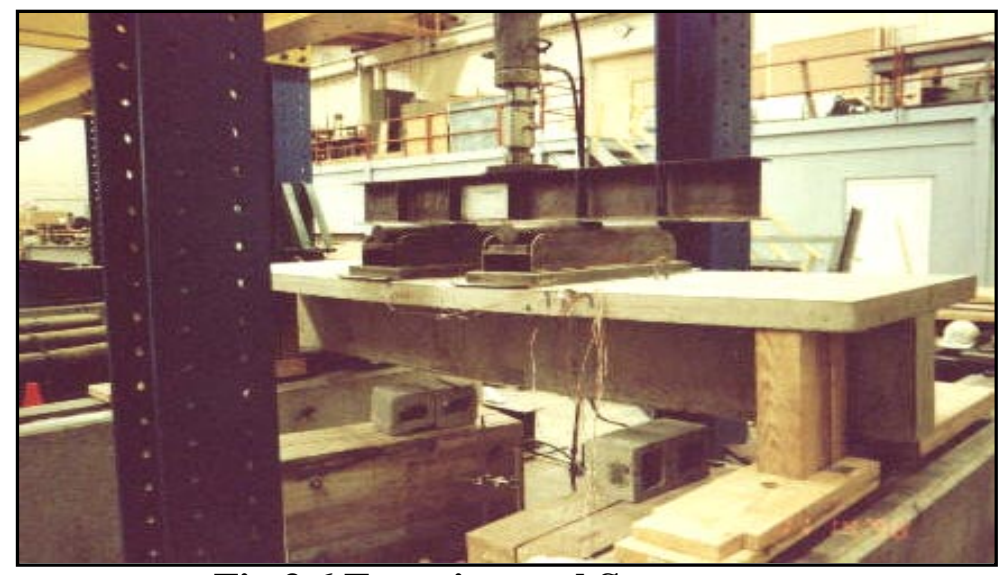

Fig 3.6 Experimental Setup 
Loading frames were strengthened with heavy steel angles to resist higher loads, i.e., up to 150 kips. To ensure proper distribution of load along the width of the flange, distribution beams with adequate stiffness are selected. The spreader beam used in testing was also stiffened according to the anticipated moment capacities of the T-beams.

Data obtained from the experiments was carefully analyzed and appropriate discussions are provided in Chapter 4. 


\section{CHAPTER 4}

\section{EXPERIMENTAL RESULTS AND DISCUSSION}

\subsection{INTRODUCTION}

Experimental results of eight concrete T-beams with GFRP bars are discussed in this chapter. The parameters of interest are ultimate moment capacities, failure modes, crack widths, strains in concrete along the flange (shear-lag) and rebar and pre-and postcracking deflections. These data will be used in the following chapters to develop design equations for concrete T-beams reinforced with GFRP bars.

\subsection{FAILURE MODES}

The reinforcement ratios, beam dimensions and concrete strengths were varied to achieve different failure modes. All the beams failed as per the anticipated failure modes. Details of failure modes and FRP tension reinforcement are shown in Table 4.1. Higher reinforcement areas shown in Table 4.1 were used to force bending failures in to the web location of the T-beams.

\subsubsection{Tension Failure}

Tension failure consisted of bar rupture at mid-span, followed by spalling of the concrete in the shape of a small vertical wedge surrounding the bars on tension side. In beams having multiple rows of reinforcement, the bars in the bottom-most row reached

ultimate failure strains first and failed, whereas the bars in the second row from bottom had comparatively less damage. Beams B1T1, B2T1, B1T2, and B4T1 failed in tension mode as shown in Table 4.1. Beams B1T1 and B2T1 had one row of reinforcement and the rebar rupture took place with spalling of concrete. Beams B1T2 and B4T1 had two rows of reinforcement and the bottom-most row of reinforcement had rebar rupture while the second row reinforcement suffered less damage.

The current design procedure for steel reinforced concrete beams is based on tension failure. However, in the case of GFRP reinforced concrete beams, the failure of concrete is more gradual as compared to rebar rupture; hence compression failure philosophy is suggested (Vijay \& GangaRao, 1996). Figs 4.1 and 4.2 show tension failure 
of beams B1T1 and B1T2 respectively. Cracking along the longitudinal bar at high strains indicated possible localized bond failures at high GFRP strains of 12000 to 14000 $\left(\mathrm{x} 10^{-6} \mathrm{in} / \mathrm{in}\right)$ in the flexural tension zone.

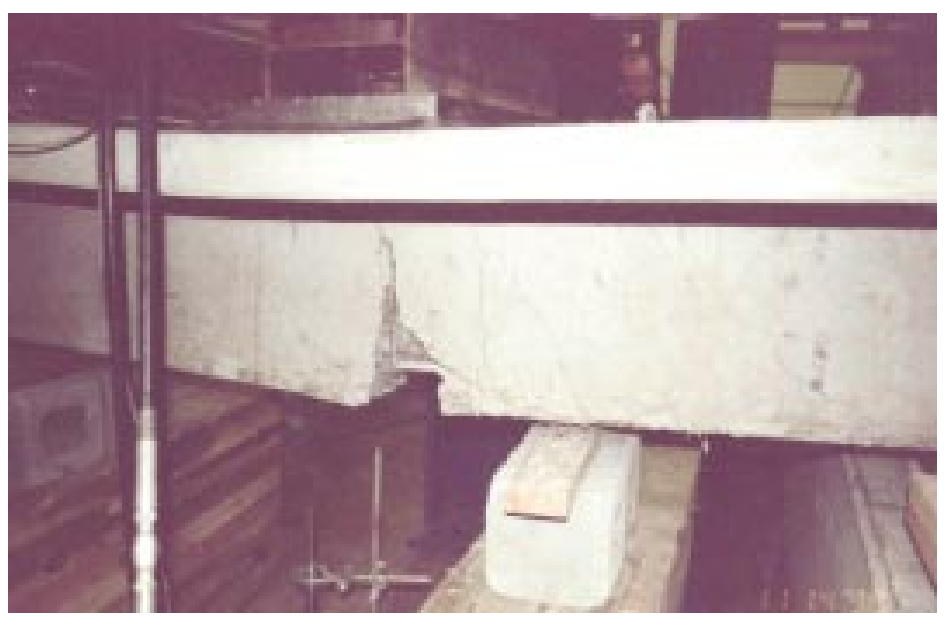

Fig 4.1 Tension failure of Beam B1T1

Beam B1T1 spanning $8 \mathrm{ft}$ (Table 3.5) was reinforced with 0.61 sq.-inches ribbed C-Bars from Marshall Industries, Inc. Failure mode was observed to be tension with rupture of rebar.

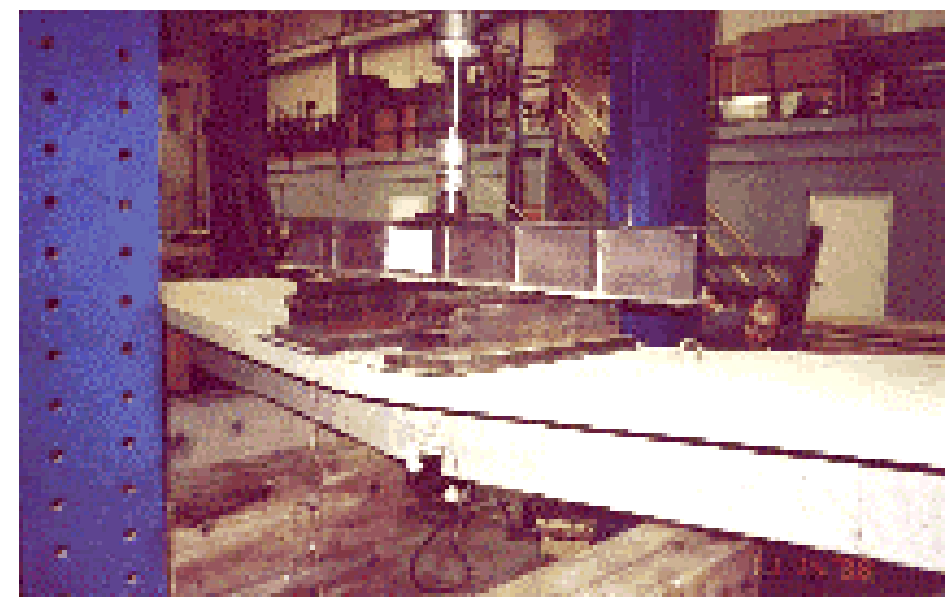

Fig 4.2 Tension failure of Beam B1T2 
Beam B1T2 spanning 11ft reinforced with 2.45 in $^{2}$ of sand coated rebars failed in tension. Large deflections were seen just before failure. After failure residual deflections were found to be about an inch.

\subsubsection{Compression Failure}

Compression failures consisted of crack formations at mid-section parallel to the flange-width followed by gradual concrete crushing (Fig 4.3). Beams failing in compression were designed such that neutral axis was either in the flange or in the web. When the neutral axis fell within the flange, concrete crushing was usually observed within the middle third of the flange. This behavior is similar to the failure of rectangular beams and was observed in $\mathrm{B} 2 \mathrm{C} 1$ and $\mathrm{B} 4 \mathrm{C} 1$ with concrete hinge formation. Beams $\mathrm{B} 3 \mathrm{C} 1$ and $\mathrm{B} 3 \mathrm{C} 2$ failed in compression with the neutral axis extending into the web because these beams had higher reinforcement ratios than B2C1 and B4C1. Figs 4.3 and 4.4 show compression failure of beams $\mathrm{B} 2 \mathrm{C} 1$ and $\mathrm{B} 3 \mathrm{C} 2$, respectively.

The serviceability characteristics of beams failed in tension and compression are compared in the following sections.

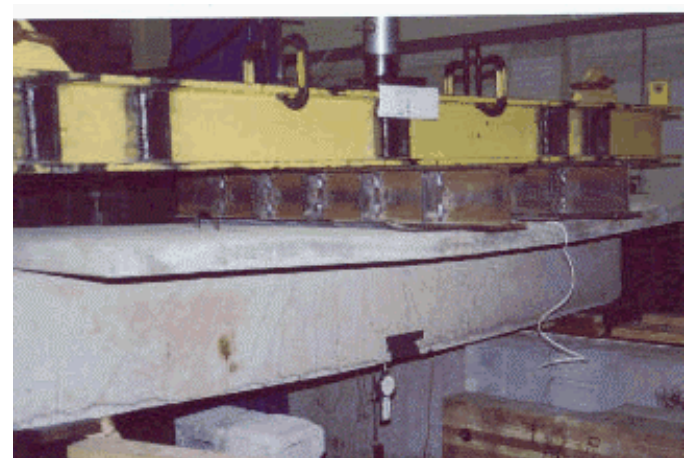

Fig 4.3 Compression failure of Beam B4C1

Beam B4C1 (Fig 4.3) spanning $11 \mathrm{ft}$ designed for compression failure showed uniform cracking rather than a single large crack as seen in tension failures. 


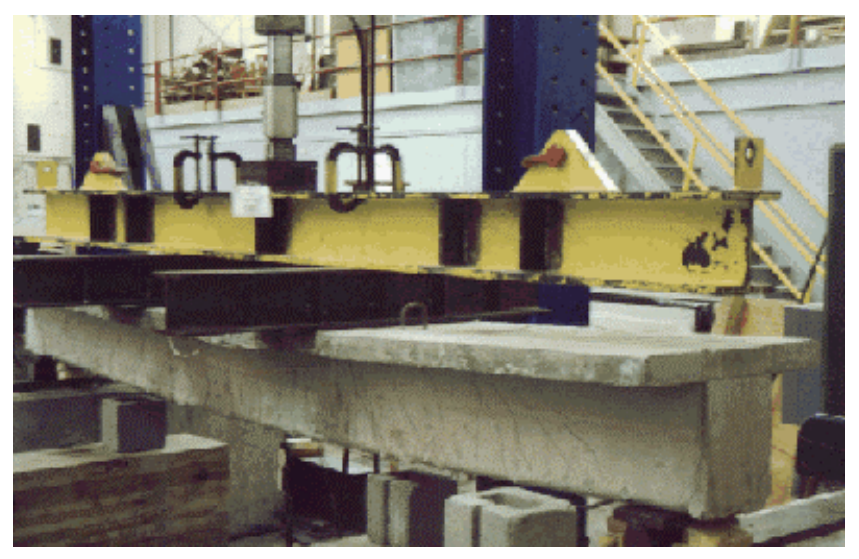

Fig 4.4 Compression failure of Beam B3C2 (N/A extending into web)

Fig 4.4 shows beam B3C2 spanning 11ft with closely-knit crack pattern. Compression failure took place in this beam by concrete crushing in the middle third region.

TABLE 4.1 FAILURE MODES

\begin{tabular}{|c|c|c|}
\hline Beam & Failure mode & $\begin{array}{c}\mathrm{A}_{\mathrm{f}}\left(\mathrm{in}^{2}\right) \\
\text { Area of tension } \\
\text { reinforcement }\end{array}$ \\
\hline B1T1 & Tension & 0.61 \\
\hline B2T1 & Tension & 0.61 \\
\hline B3C1 & Compression & 4.32 \\
\hline B4T1 & Tension & 0.98 \\
\hline B1T2 & Tension & 2.45 \\
\hline B2C1 & Compression & 3.59 \\
\hline B3C2 & Compression & 4.77 \\
\hline B4C1 & Compression & 5.55 \\
\hline
\end{tabular}




\subsection{ULTIMATE LOAD AND MOMENT CAPACITIES}

Failure load and moment capacities are shown in Table 4.2. The increase in load carrying capacity is studied by varying the reinforcement ratios and flange widths in the T-beams. There was an increase of $40 \%$ in moment carrying capacity when $60 \%$ more FRP bar area was provided in beam B4T1 as compared to beam B1T1. The moment capacity of beam B4T1 was more by $45 \%$ when compared to beam B2T1 where the reinforcement ratio was increased by $60 \%$ in beam B4T1 (Refer to Table 4.2, concrete strength variations). There was an increase of $6 \%$ in moment carrying capacity of B1T1 over B2T1 with the same reinforcement ratio even with flange width reduction from 36" to 30 " (Table 4.2, Refer to concrete strength variations).

\section{TABLE 4.2 ULTIMATE MOMENT CAPACITIES}

\begin{tabular}{|c|c|c|c|}
\hline Beam & $\begin{array}{c}\mathrm{f}_{\mathrm{c}}{ }^{\prime} \\
\mathrm{ksi}\end{array}$ & $\begin{array}{c}\text { Ultimate } \\
\text { Moment } \\
\text { Kip-ft }\end{array}$ & $\mathrm{M} /\left(\mathrm{f}_{\mathrm{c}}{ }^{\prime} \mathrm{bd}^{2}\right)$ \\
\hline B1T1 & 5.6 & 82.5 & 0.0197 \\
\hline B2T1 & 5.1 & 79.5 & 0.0251 \\
\hline B3C1 & 3.1 & 150 & 0.1909 \\
\hline B4T1 & 2.7 & 115.5 & 0.0581 \\
\hline B1T2 & 5.6 & 157.5 & 0.0708 \\
\hline B2C1 & 5.1 & 180 & 0.1166 \\
\hline B3C2 & 3.1 & 165 & 0.1927 \\
\hline B4C1 & 2.7 & 180 & 0.1727 \\
\hline
\end{tabular}

In beam B3C1 having a flange width of 18”, the failure was accompanied by crushing the entire flange width under the load points. Maximum compressive concrete strain at mid-span exceeding 4000 (x $10^{-6} \mathrm{in} / \mathrm{in}$ ) was recorded just before crushing. Among the beams with same dimensions and concrete strengths, the beams that failed in compression failure had higher moment capacities at failure compared to the beams that 
failed in tension. Even though reinforcement ratio of beam $\mathrm{B} 3 \mathrm{C} 2$ is higher than the reinforcement ratio in beam $\mathrm{B} 2 \mathrm{C} 1$ by $32.86 \%$, their moment capacity varied by only $8 \%$ due to $45 \%$ reduction in the concrete strength of beam $\mathrm{B} 3 \mathrm{C} 2$. Beams $\mathrm{B} 3 \mathrm{C} 1$ and $\mathrm{B} 3 \mathrm{C} 2$ both had concrete crushing failure with cracks initiating at the top and propagating into the flange. These beams were designed for failure with neutral axis extending into the web to study true T-beam behavior.

\subsection{PRE- AND POST- CRACKING DEFLECTIONS}

All the T-beams were tested to failure (rupture of tension reinforcement in tension and crushing of concrete in compression) after loading and unloading them several times. Deflections during loading and unloading were recorded. Residual deflections after each cycle were recorded to establish their recovery after unloading.

The load vs. deflection diagrams of all beams show two distinct regions. An initial linear stiff zone representing the un-cracked behavior of the beam. After concrete stress reached its rupture strength, the deflection curve showed reduction in beam stiffness. Figs 4.3 and 4.4 show the cracked concrete sections for beams $\mathrm{B} 4 \mathrm{C} 1$ and $\mathrm{B} 3 \mathrm{C} 2$ respectively. 
TABLE 4.3 LIMITING DEFLECTIONS (COMPRESSION FAILURES)

\begin{tabular}{|l|c|c|c|c|c|c|c|}
\hline Beam & $\begin{array}{c}\text { L/180 } \\
\text { (in) }\end{array}$ & $\begin{array}{c}\text { L/360 } \\
\text { (in) }\end{array}$ & $\begin{array}{c}\text { LOAD } \\
\text { at } / 180 \\
\text { limit } \\
\text { kips }\end{array}$ & $\begin{array}{c}\text { LOAD } \\
\text { at L/360 } \\
\text { limit } \\
\text { kips }\end{array}$ & $\begin{array}{c}\text { ULT- } \\
\text { LOAD } \\
\text { kips }\end{array}$ & $\begin{array}{c}\text { LOAD } \\
\text { at L/180 } \\
\text { LIMIT } \\
\text { as OF } \\
\text { ULT }\end{array}$ & $\begin{array}{c}\text { LOAD at } \\
\text { L/360 } \\
\text { LIMIT as } \\
\% \text { OF } \\
\text { ULT }\end{array}$ \\
\hline B3C2 & 0.73 & 0.37 & 32.51 & 18.51 & 90 & 36.11 & 20.56 \\
\hline B3C1 & 0.53 & 0.27 & 59.12 & 34.11 & 100 & 59.12 & 34.11 \\
\hline B2C1 & 0.73 & 0.37 & 29.17 & 17.75 & 80 & 36.46 & 21.25 \\
\hline B4C1 & 0.73 & 0.37 & 31.12 & 20.87 & 80 & 38.91 & 26.08 \\
\hline
\end{tabular}

Table 4.3 gives the load level at which different beams designed for compression failure satisfied L/360 and L/180 deflection limit. Deflections of the beam varied as a function of the stiffness of the cracked section and the amount of reinforcement provided. The beams reached a deflection limit of span/180 between 36 and 59\% of their ultimate load capacity. Span/360 deflection limit is satisfied at load limits in the range of 20 to $35 \%$. Beam $\mathrm{B} 3 \mathrm{C} 1$ has a $20 \%$ higher depth compared to other beams designed for compression failure in the web. Hence the beam has attained the deflection limits at higher load levels. 
TABLE 4.4 LIMITING DEFLECTIONS (TENSION FAILURES)

\begin{tabular}{|c|c|c|c|c|c|c|c|}
\hline Beam & $\begin{array}{c}\mathrm{L} / 180 \\
\text { (in) }\end{array}$ & $\begin{array}{c}\mathrm{L} / 360 \\
\text { (in) }\end{array}$ & $\begin{array}{c}\text { LOAD } \\
\text { at } \mathrm{L} / 180 \\
\text { limit } \\
\text { kips }\end{array}$ & $\begin{array}{c}\text { LOAD } \\
\text { at L/360 } \\
\text { limit } \\
\text { kips }\end{array}$ & $\begin{array}{c}\text { ULT- } \\
\text { LOAD } \\
\text { kips }\end{array}$ & $\begin{array}{c}\text { LOAD at } \\
\text { L/180 } \\
\text { LIMIT as } \\
\% \text { OF }\end{array}$ & $\begin{array}{l}\text { LOAD } \\
\text { at L/360 } \\
\text { LIMIT } \\
\text { as \% OF }\end{array}$ \\
\hline B1T1 & 0.53 & 0.27 & 19.87 & 9.56 & 55 & 36.13 & 17.38 \\
\hline B1T2 & 0.73 & 0.37 & 24.12 & 14.11 & 70 & 34.45 & 20.15 \\
\hline B2T1 & 0.53 & 0.27 & 19.77 & 14.32 & 53 & 37.30 & 27.02 \\
\hline B4T1 & 0.53 & 0.27 & 19.99 & 13.76 & 77 & 25.96 & 17.87 \\
\hline
\end{tabular}

Table 4.4 gives the load level at which the beams designed for tension satisfy the span/180 and span/360 deflection limit specified in ACI 318R-95.

Load deflection curves for beams B1T2, B3C1 and B2T1 are shown in Figs 4.5, 4.6 and 4.7 respectively. The beams B1T1 and B2T1 (Fig 4.7) recorded maximum deflections of 1.85 and 1.7 inches, respectively, and were tested to failure in four cycles. The residual deflection in beam B1T1 was 1.6 inch and the residual deflection in beam B2T1 was 1.1 inch. The deflection values at failure in beams B1T2 and B4T1 are 1.8 and 1.82 inch, respectively. The lower strength of concrete in B4T1 and lower effective width in B2T1 nullified the effect of increased reinforcement ratio in B4T1. 


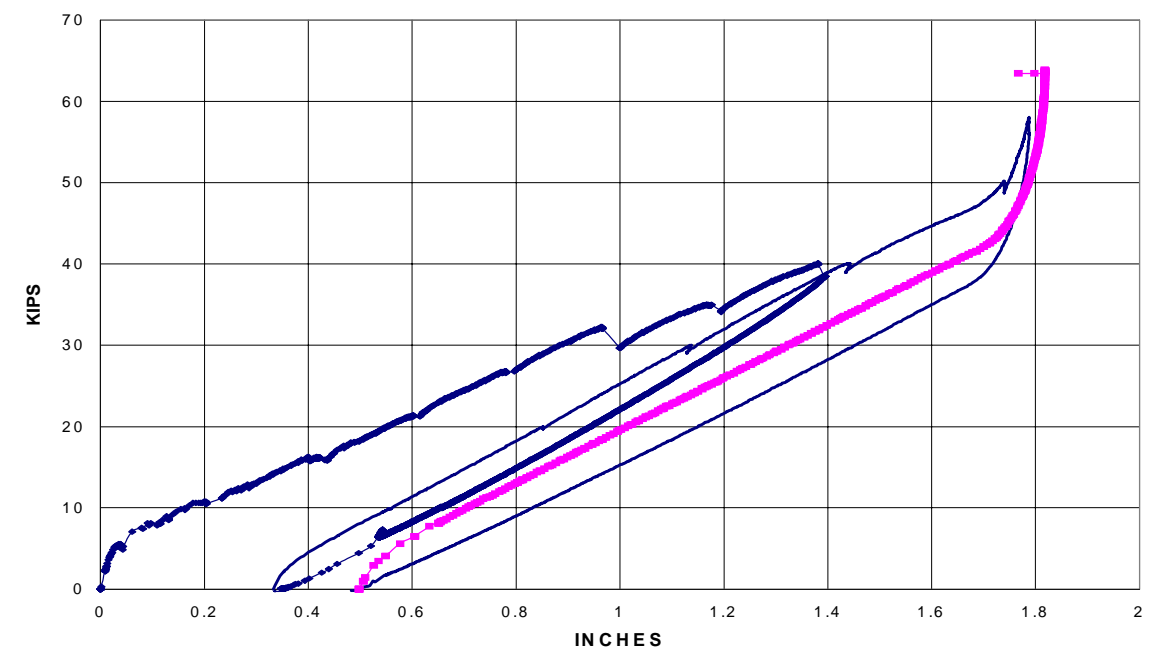

Fig 4.5 Load-deflection diagram of beam B1T2

Beam B3C1 (Fig 4.6) failed in compression and recorded the lowest deflection of 1.3 inch due to higher stiffness of the beam and low cracking and high reinforcement ratio.

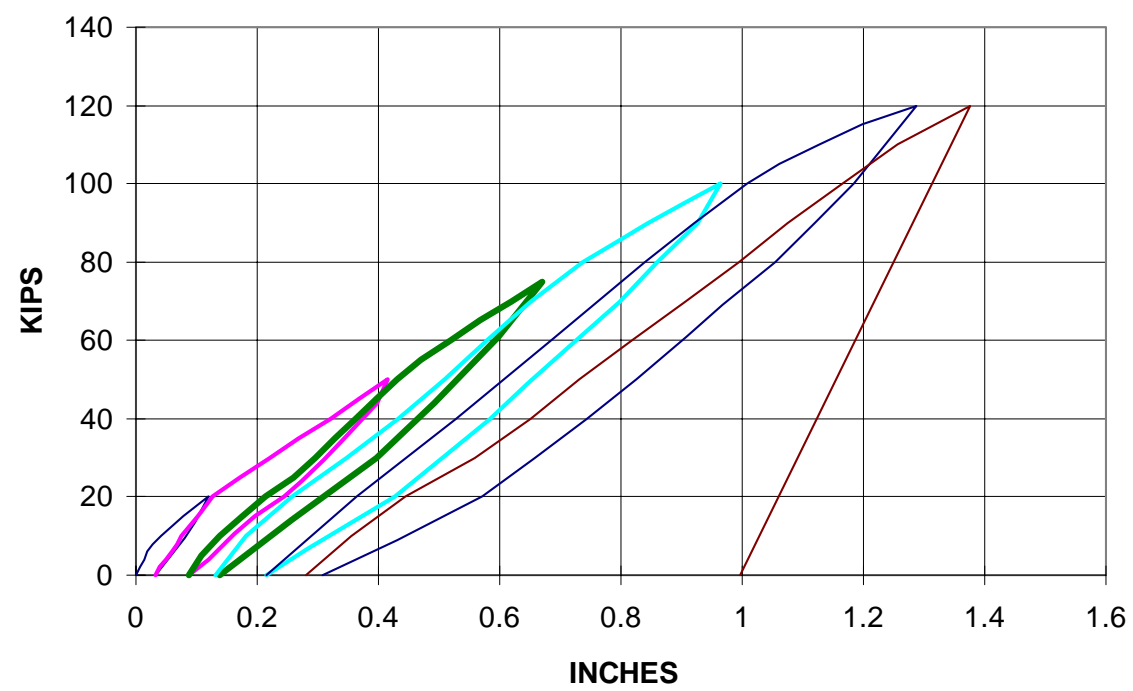

Fig 4.6 Load-deflection diagram of beam B3C1 
Due to lower stiffness values of GFRP reinforcement, the deflections are higher than in steel reinforced concrete beams. The residual deflections in beams failing in compression are less compared to the ones failing in tension.

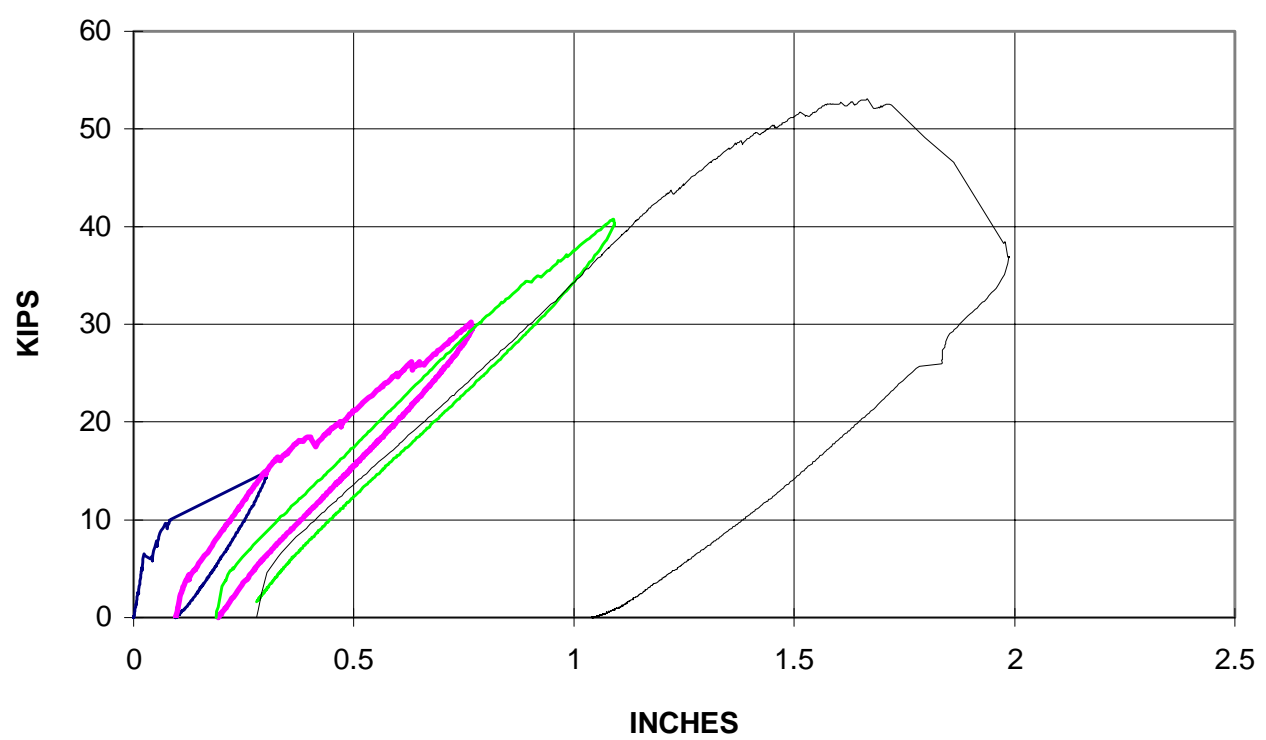

Fig 4.7 Load-deflection diagram of beam B2T1

\subsection{MOMENT - CURVATURE RELATIONSHIPS}

Moment vs. curvature diagrams are drawn for all the beams based on the load vs. deflection diagrams. Deformablity factors are calculated from moment vs. curvature diagrams to evaluate the ductility of the beam. It is possible to identify a certain curvature limit state (like $0.005 / \mathrm{d}$ or $0.006 / \mathrm{d}$ ) at which the beam satisfies the serviceability conditions of deflection and crack-width. This issue is discussed in section 5.7. 


\subsection{CRACKING BEHAVIOR}

\subsubsection{Crack-Width}

Crack widths are measured at tension reinforcement level on the side of each beam using a micrometer. Table 4.5 shows the loading level at which various beams reached their limiting value of 0.016 inch as specified in ACI 318-95. Table 4.5 clearly shows that the beams designed for tension failure have difficulty in satisfying the serviceability limit state of crackwidth. The following conclusions can be drawn based on Table 4.5.

- Beams designed for tension failure reached the limiting value of crack width (0.016") between 23 and $28 \%$ of their ultimate load carrying capacity (Table 4.5 ), which is a function of the amount of reinforcement and concrete strength.

- Beams designed for compression failure reached the limiting value of crack width (0.016") between 44and 55\% of their ultimate load carrying capacity (Table 4.5), which is a function of the amount of reinforcement and concrete strength.

- Steel reinforced T-beams reach their limiting crack width (0.016") between 60 and $80 \%$ of their ultimate load carrying capacity.

Table 4.6 shows crack widths in beam $\mathrm{B} 3 \mathrm{C} 2$ failed in compression failure. Table 4.7 shows crack widths in beam B4T1 failed in tension mode. In all beams, two parallel longitudinal cracks symmetrically spaced at a distance approximately equal to the web width along flange-web junction were observed beyond $50 \%$ or higher of the ultimate load. Formation of two or more symmetrical transverse cracks was observed over the entire flange width along the load points around $60 \%$ of ultimate load or higher. 
TABLE 4.5 LIMITING CRACK-WIDTH COMPARISON

\begin{tabular}{|c|c|c|c|c|c|l|}
\hline Beam & $\begin{array}{c}\text { Crack- } \\
\text { width } \\
\text { (inch) }\end{array}$ & Cycle & $\begin{array}{c}\text { Load at 0.016 in } \\
\text { crackwidth } \\
\text { (kips) }\end{array}$ & $\begin{array}{c}\text { Ult- } \\
\text { Load } \\
\text { (kips) }\end{array}$ & $\begin{array}{c}\text { Load at } \\
0.016 \text { in } \\
\text { crackwidth } \\
\text { as } \% \text { of }\end{array}$ & $\begin{array}{c}\text { Failure } \\
\text { Mode }\end{array}$ \\
\hline B1T1 & 0.016 & 1 & 15 & 55 & 27.27 & Tension \\
\hline B2T1 & 0.016 & 1 & 15 & 53 & 28.3 & Tension \\
\hline B3C1 & 0.016 & 3 & 55 & 100 & 55.11 & Compression \\
\hline B4T1 & 0.016 & 1 & 18 & 77 & 23.37 & Tension \\
\hline B1T2 & 0.016 & 1 & 30 & 70 & 42.85 & Tension \\
\hline B2C1 & 0.016 & 1 & 35 & 80 & 43.75 & Compression \\
\hline B3C2 & 0.016 & 2 & 40 & 90 & 44.44 & Compression \\
\hline B4C1 & 0.016 & 1 & 40 & 80 & 50.00 & Compression \\
\hline
\end{tabular}

Beam $\mathrm{B} 3 \mathrm{C} 1$ reached its limiting crack-width value at $55.11 \%$ of its ultimate loading capacity. This beam also experienced minor crack-closure phenomenon of the order of 0.001-0.003 inches, due to the downward shift of neutral axis. Crack closure phenomenon was not significantly observed in other beams. 
Table 4.6 Load- Crack-Width (inch) for Beam B3C2

\begin{tabular}{|c|c|c|c|c|c|}
\hline $\begin{array}{c}\text { Load } \\
\text { (kips) }\end{array}$ & $\begin{array}{c}\text { cycle1 } \\
\text { (in) }\end{array}$ & $\begin{array}{c}\text { Load } \\
\text { (kips) }\end{array}$ & $\begin{array}{c}\text { cycle2 } \\
\text { (in) }\end{array}$ & $\begin{array}{c}\text { Load } \\
\text { (kips) }\end{array}$ & $\begin{array}{c}\text { cycle3 } \\
\text { (in) }\end{array}$ \\
\hline 0 & 0 & 0 & 0.001 & 0 & 0.002 \\
\hline 8 & 0.003 & 8 & 0.006 & 10 & 0.009 \\
\hline 10 & 0.006 & 10 & 0.007 & 20 & 0.012 \\
\hline 16 & 0.007 & 15 & 0.009 & 30 & 0.018 \\
\hline 20 & 0.008 & 20 & 0.012 & 40 & 0.021 \\
\hline 30 & 0.01 & 30 & 0.015 & 50 & 0.02 \\
\hline 20 & 0.008 & 40 & 0.016 & 55 & 0.022 \\
\hline 0 & 0.001 & 50 & 0.018 & 60 & 0.026 \\
\hline & & 55 & 0.022 & 70 & 0.028 \\
\hline & & 60 & 0.026 & 0 & 0.004 \\
\hline & & 50 & 0.019 & & \\
\hline & & 0 & 0.003 & & \\
\hline
\end{tabular}

Table 4.6 shows crack width data and residual crackwidths obtained during different loading and unloading cycles for Beam $\mathrm{B} 3 \mathrm{C} 2$. The residual crack widths are of the order of 0.001-0.004 in., thus showing the superior recovery characteristics of GFRP reinforced beams. Table 4.7 shows crack width data for beam B4T1 during loading and unloading cycles. 
Table 4.7 Load- Crack-Width (inch) for Beam B4T1

\begin{tabular}{|c|c|c|c|}
\hline $\begin{array}{c}\text { LOAD } \\
\text { (kips) }\end{array}$ & $\begin{array}{c}\text { CYCLE1 } \\
\text { (in) }\end{array}$ & $\begin{array}{c}\text { LOAD } \\
\text { (kips) }\end{array}$ & $\begin{array}{c}\text { CYCLE2 } \\
\text { (in) }\end{array}$ \\
\hline 0 & 0 & 0 & 0.005 \\
\hline 6 & 0.003 & 10 & 0.008 \\
\hline 10 & 0.011 & 20 & 0.023 \\
\hline 20 & 0.018 & 30 & 0.027 \\
\hline 30 & 0.026 & 40 & 0.033 \\
\hline 20 & 0.018 & 50 & 0.049 \\
\hline 9.5 & 0.01 & 40 & 0.033 \\
\hline 0 & 0.005 & 30 & 0.027 \\
\hline & & 20 & 0.021 \\
\hline & & 10 & 0.009 \\
\hline & & 0 & 0.006 \\
\hline
\end{tabular}

\subsubsection{Crack-Patterns}

Typical crack patterns of beams failing in tension and compression are shown in Figs 4.8 and 4.9, respectively. Fig 4.8 represents the crack patterns in beam B2T1 failed in tension failure showing a wide crack at $80 \%$ of the ultimate load. The lower depth of neutral axis leads to the quick propagation of cracks into the flange from beam soffit, in case of beams designed for tension failures. Fig 4.9 shows crack patterns in beam B3C1 failing in compression at $80 \%$ of the ultimate load. In beams designed for compression failure, cracking was more uniform and less intense. In beam $\mathrm{B} 3 \mathrm{C} 1$, crack-closure is observed due to downward neutral axis shift. The crack spacing was more or less equal to the stirrup spacing in all the beams. Residual widths were around 0.006 to 0.011 inch for tension failure after releasing $80 \%$ of the ultimate load. For compression failures residual crack-widths were around 0.003 to 0.005 inch after releasing $80 \%$ of the ultimate load. 
Thus beams designed for compression failure have lower crack widths and better recovery in terms of crack-widths compared to beams designed for tension failure.

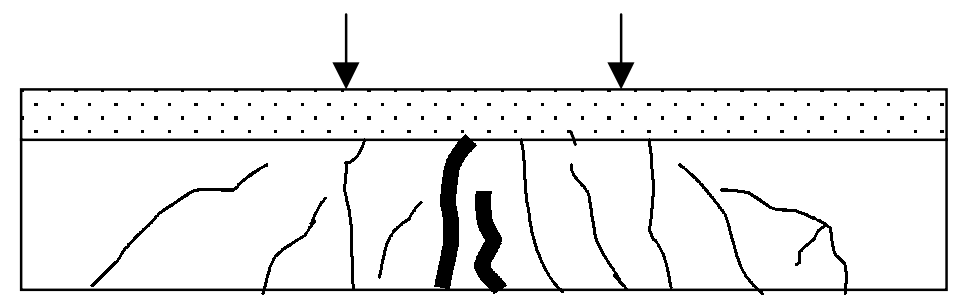

Fig 4.8 Crack-Pattern of beam B2T1 at $80 \%$ of Ultimate load

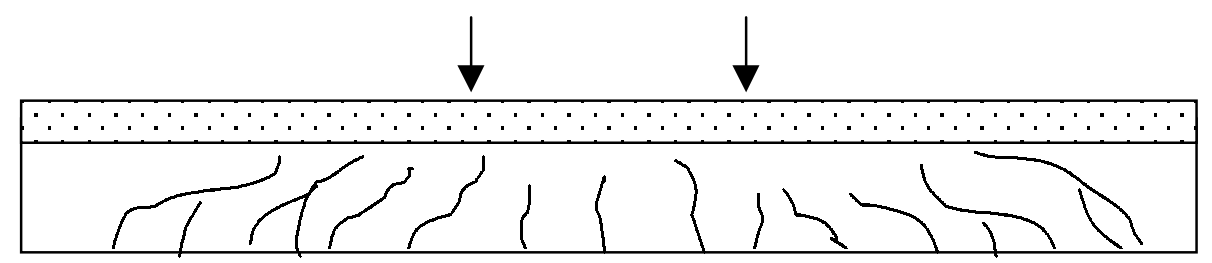

Fig 4.9 Crack-Pattern of beam B3C1 at $80 \%$ of Ultimate load 


\subsection{CONCRETE STRAIN DISTRIBUTION}

Locations of strain gages to measure concrete strain distribution at mid-span across the flange are shown in Fig 4.10. Table 4.8 shows the maximum concrete strains at failure in the beams. Concrete strain in beams designed for compression failures were in the range of 3300-4400 ( $\times 10^{-6}$ in/in). Beams designed with lower concrete strengths attained concrete strains above 4000 ( $\left.\times 10^{-6} \mathrm{in} / \mathrm{in}\right)$. In beams designed for tension failures concrete strains were of the order of 1200-2500 ( $\left.\times 10^{-6} \mathrm{in} / \mathrm{in}\right)$, i.e., concrete's resistance to additional compression has not been fully utilized.

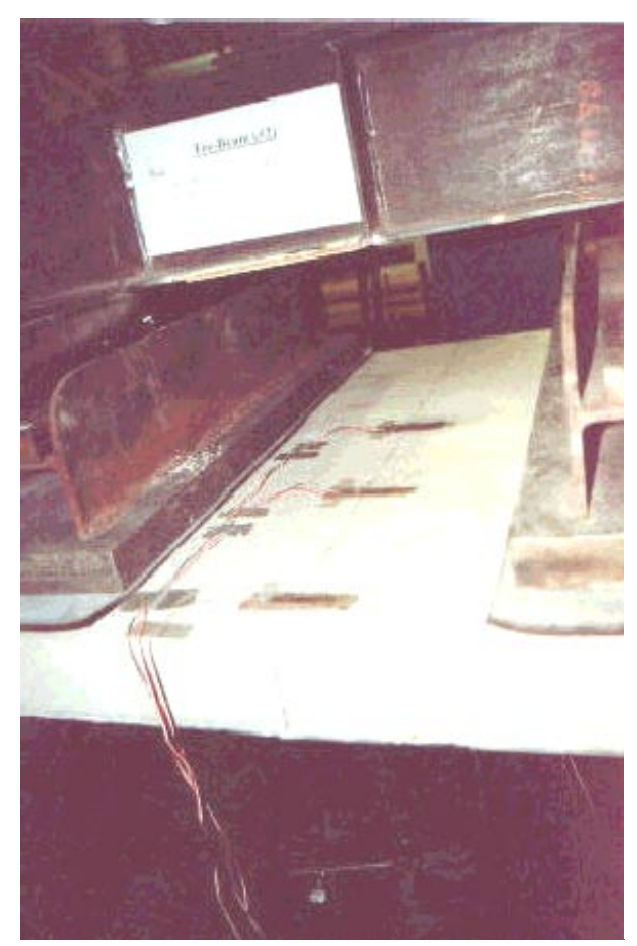

Fig 4.10 Concrete strain monitoring across the flange at mid-span

Concrete strains across the flange were found to gradually decrease away from the center. Reduction of concrete strains away from the center is called shear lag. Concrete strains may also be affected by non-uniform load distribution due to irregularities in the concrete surface. Maximum concrete strains attained in various beams are compared in Table 4.8. 
Table 4.8 Maximum Concrete Strain Comparison at Ultimate Moment

\begin{tabular}{|c|c|c|}
\hline BEAM & $\begin{array}{c}\text { MAXIMUM } \\
\text { CONCRETE } \\
\text { STRAIN(10 }\end{array}$ & $\begin{array}{c}\text { CONCRETE } \\
\text { STRENGTH }\end{array}$ \\
\hline B1T1 & 2100 & psi \\
\hline B2T1 & 1267 & 5600 \\
\hline B3C1 & 4200 & 5100 \\
\hline B4T1 & 2574 & 3100 \\
\hline B1T2 & 1713 & 2700 \\
\hline B2C1 & 3128 & 5100 \\
\hline B3C2 & 4400 & 3100 \\
\hline B4C1 & 3330 & 2700 \\
\hline
\end{tabular}


Shear lag phenomenon was evident in all test beams. Beams with tension failure that utilized only part of the flange for generating the compressive forces exhibited highest shear lag. Beams failing in compression exhibited relatively less shear lag because most of the flange width was utilized in generating the compressive force particularly when the neutral axis was within the web. Strains at 12" and 20" away from the mid-section (refer to Fig. 4.10) were $29 \%$ and 58\% less compared to mid-span strains in beam B4T1. Beam B4T1 was designed for tension failure. Strains at 12" and 20" away from the mid-section were identical and about $20 \%$ less compared to the mid-span strains in the beam B4C1 designed for compression failure. Fig 4.12 shows the variation of concrete strains in beam B3C1

Fig 4.11 Shear lag in Beam B4T1

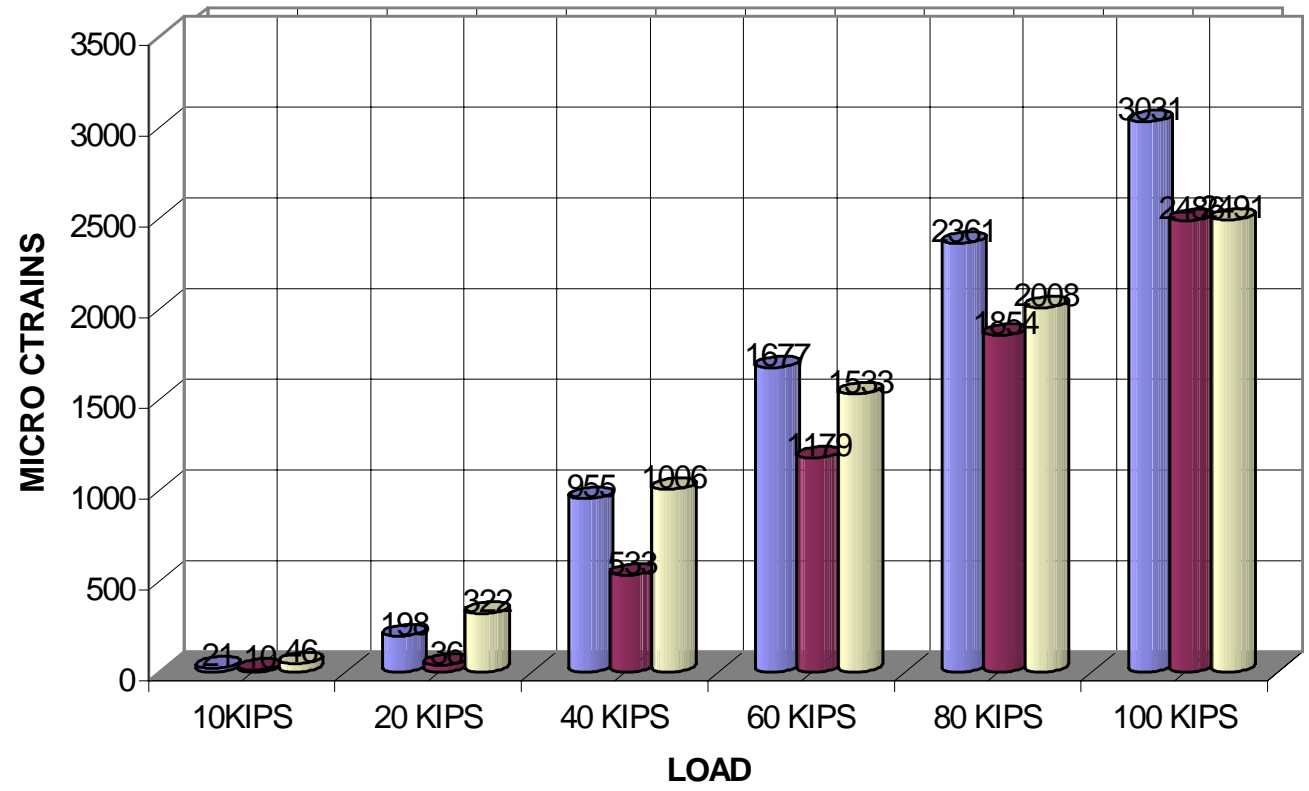

Fig 4.12 Shear lag in Beam B3C1 


\subsection{LOAD VS STRAIN VARIATION IN GFRP BARS}

The strains in GFRP bars are measured through electrical resistance strain gages. The load vs. strain diagram is linear for a GFRP bar. The strain data are utilized in calculating the stresses in the rebar at various load levels and the depth of neutral axis is calculated by using the strain compatibility conditions. Strains exceeded 0.02 in beams failing in tension and reinforced with Marshall Industries Inc. C-bars. The failure strains of beam B2T1 reinforced with sand-coated bar from International-Grating Inc. are 0.014. The failure strains in beams designed for compression failure varied with reinforcement ratio and stiffness of the rebars used. The strains in GFRP bars located farthest from neutral axis are greater than those bars at a higher level. The GFRP bar strains were calculated at the centroid of tension reinforcement for analysis purposes. GFRP bar Strains reached $50 \%$ of their ultimate in beams B3C2 designed for compression failure. In beam $\mathrm{B} 4 \mathrm{C} 1$ designed for compression failure the tensile GFRP bar strains reached $60 \%$ of the ultimate. Fig 4.13 shows the load versus strain diagram of tensile GFRP bar in beam $\mathrm{B} 2 \mathrm{C} 1$. The graphs show strain data as obtained in the experiments.

Higher strains in GFRP bar in tension failures compared to compression failures leads to higher crackwidths and there by higher deflections. This is one of the reasons why compression failures mode was suggested in concrete beams designed with GFRP bars.

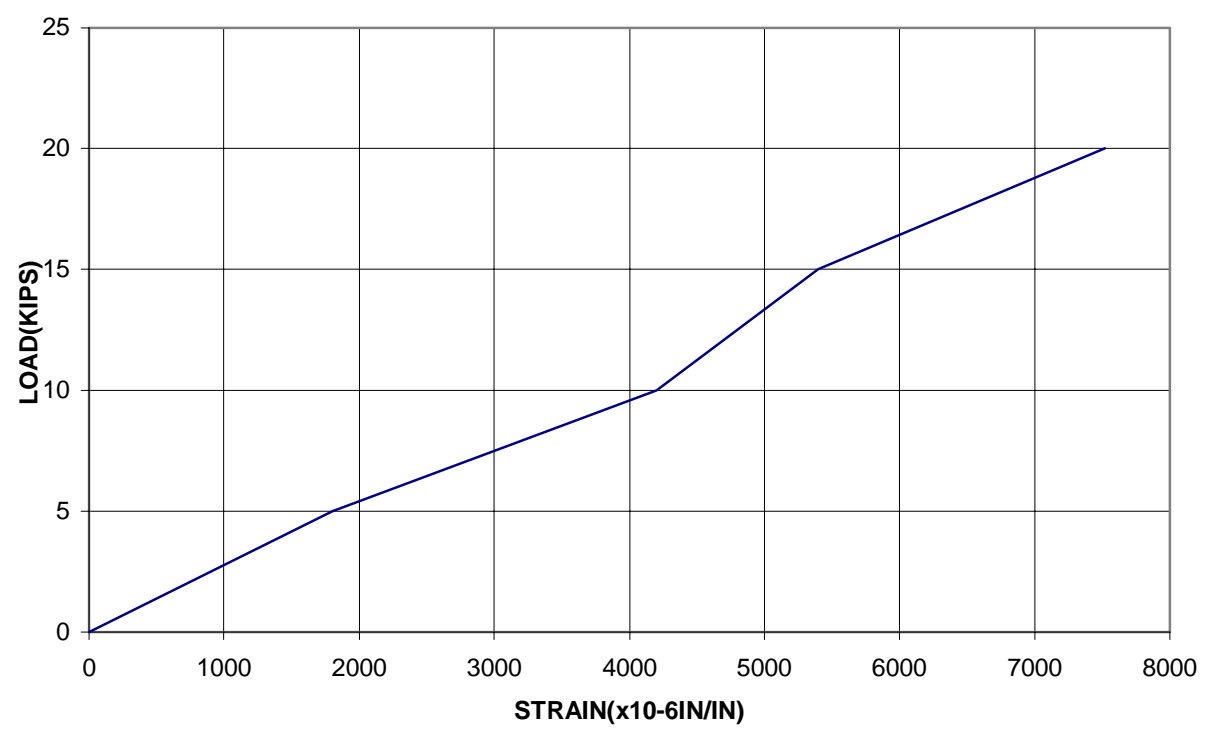

Fig 4.13 load vs. GFRP strain in beam B2C1 (cycle 2) 
Fig 4.14 shows that the load versus strain diagram of tensile GFRP bar in beam B4T1 failed in tension in the third cycle. Residual strains in the GFRP bar can also be noted in the diagram.

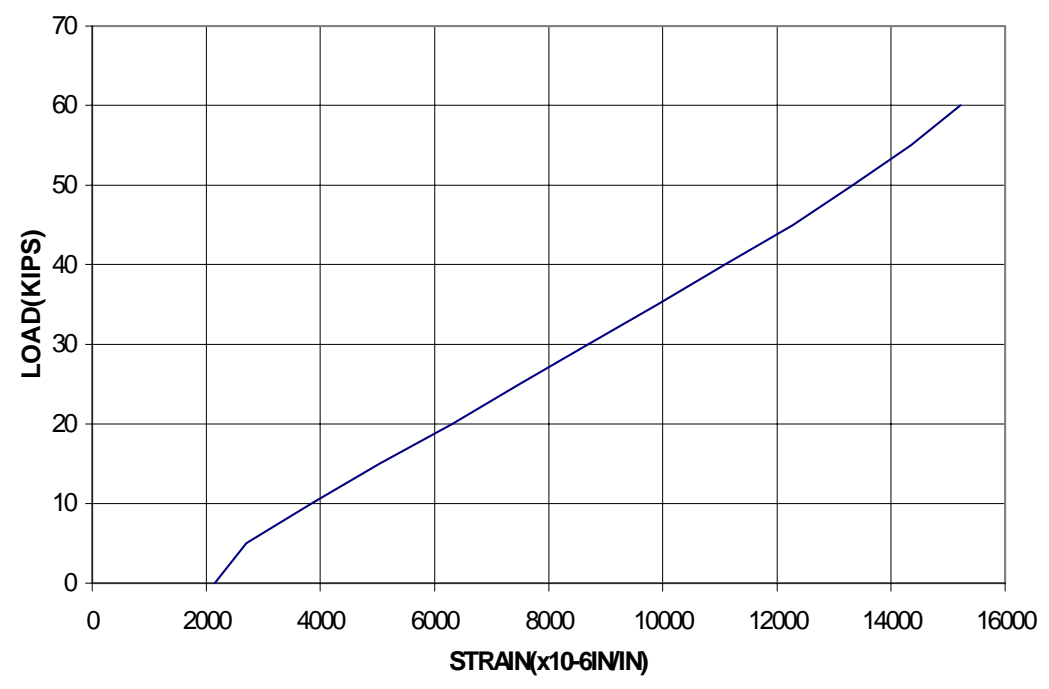

Fig 4.14 load vs. GFRP bar strain in beam B4T1 (cycle 3)

Theoretical predictions for moment capacities, crack widths, pre and post cracking deflections are compared with the experimental results in the following chapter. 


\section{CHAPTER 5}

\section{THEORETICAL CORRELATION OF EXPERIMENTAL RESULTS}

Theoretical correlation for experimental moment capacities, crack-width and deflections are provided in this chapter. Issues like classification of T-beams, balanced reinforcement ratio and effective width evaluation are discussed early in the chapter. Tbeams are commonly used in structural applications. Flanges of T-beams play an important role when they are under compression. Where flanges T-beam are subjected to tension, their contribution is nil. Therefore evaluation of effective flange width is discussed in section 5.3 before flexural behavior of T-beams is discussed in section 5.4.

\subsection{CLASSIFICATION OF T-BEAM SYSTEMS}

T-beams can be divided into two groups based on the position of their neutral axis, i.e., rectangular beam behavior if the NA were in the flange or T-beam behavior if the NA were in the web. Fig 5.1 shows the classification of T-beams based on the position of neutral-axis.

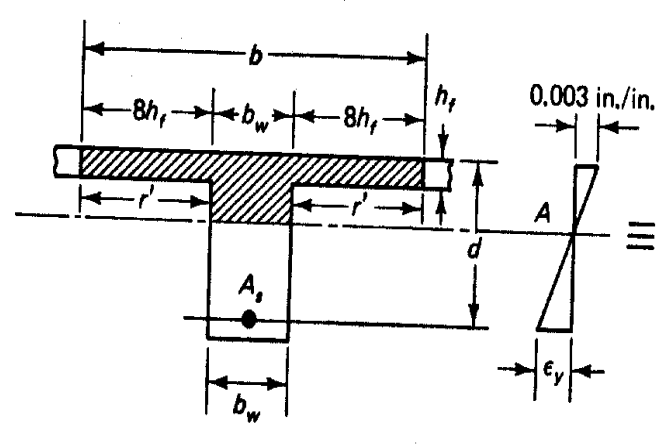

(a)

(b)

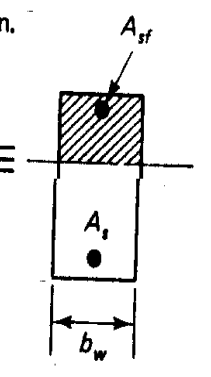

(c)

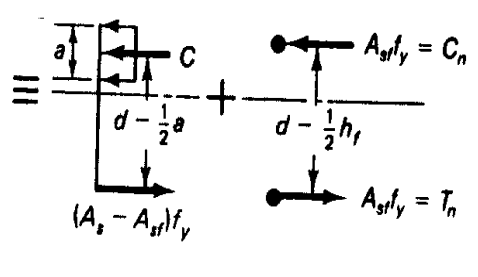

(d) (e)

Fig 5.1 a Classification of T-beam systems (Ref: Nawy, 1990)

Rectangular 


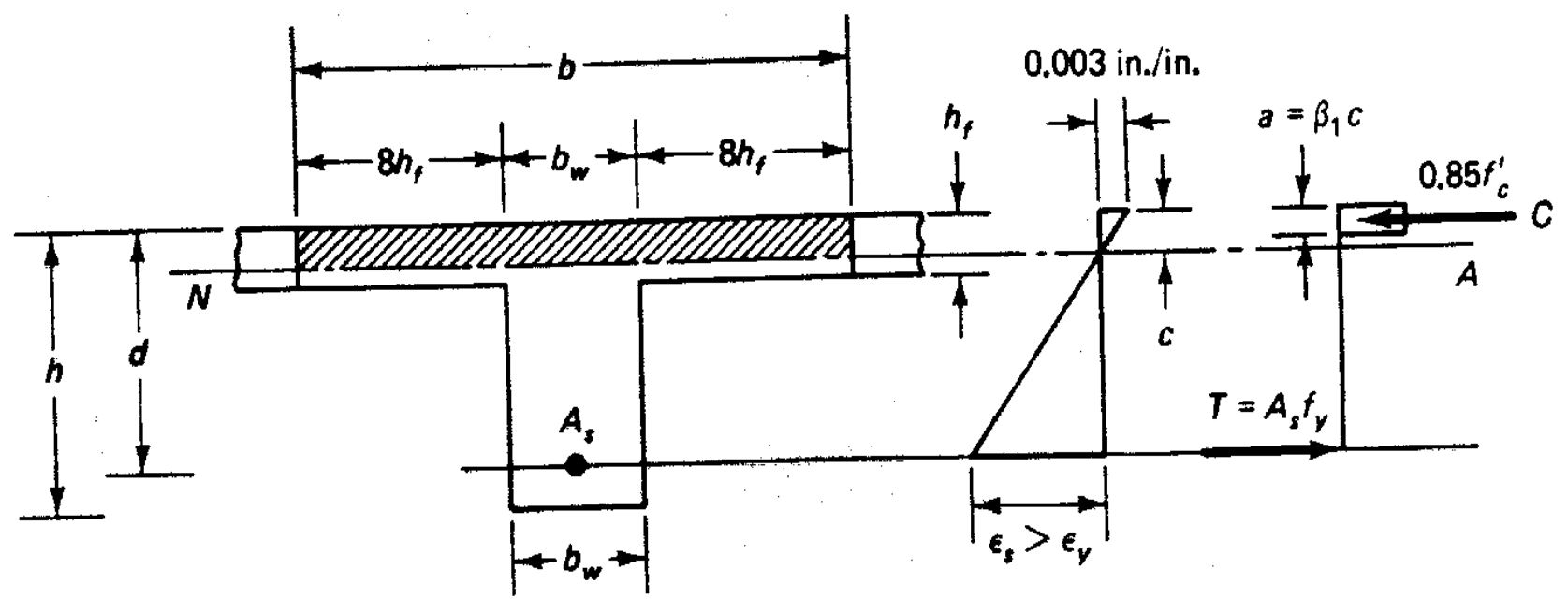

(a)

(b)

(c)

Fig 5.1 b Classification of T-beam systems (Ref: Nawy, 1990)

\section{T-beam}

\subsection{PREDICTION OF BALANCED REINFORCEMENT RATIO}

Concrete sections are said to have reached a balanced strain condition when concrete and GFRP bars in tension reach their ultimate strains simultaneously. The ratio of neutral axis depth to the effective depth (c/d) can be calculated from strain distribution diagram.

$$
\left(\frac{c}{d}\right)_{b a l}=\left(\frac{\varepsilon_{c u}}{\varepsilon_{c u}+\varepsilon_{f}}\right)
$$

Ultimate concrete strain

Ultimate strain in FRP reinforcement

$$
\varepsilon_{c u}=0.003
$$$$
\varepsilon_{f}=\frac{f_{f}}{E_{f}}
$$

$f_{f}=$ Tensile strength of GFRP rebar, Ksi

$E_{f}=$ Modulus of elasticity of FRP tensile reinforcement, Ksi

\subsubsection{T-beam with Neutral Axis in the Flange (Rectangular Behavior)}

Balanced reinforcement ratio is a condition when FRP and concrete reach their specified ultimate strain values at the same time. Reinforcement ratio of a section is 
obtained by dividing the tensile reinforcement area with flange width and effective depth of the T-beam. By equating the tensile and compressive forces.

$$
\begin{aligned}
& A_{f} f_{f}=0.85 f_{c}^{\prime} a b \\
& \rho_{b a l-r}=\frac{A_{f}}{b d} \\
& a=\beta_{1} c \\
& f_{c}^{1} \leq 4000 p s i \quad \beta_{1}=0.85 \\
& f_{c}^{1} \geq 4000 p s i \quad \beta_{1}=0.85-0.05\left(\frac{f_{c}^{1}-4000}{1000}\right)
\end{aligned}
$$

from (5.2) and (5.1), balanced reinforcement ratio of a T-beam (rectangular action) having NA in the flange can be obtained as:

$$
\rho_{b a l-r}=0.85 \beta_{1} \frac{f_{c}^{\prime}}{f_{f}}\left(\frac{\varepsilon_{c u}}{\varepsilon_{c u}+\varepsilon_{f}}\right)
$$

$\rho_{\text {bal-r }} \quad$ Balanced reinforcement ratio of a rectangular section

\subsubsection{T-beam with Neutral Axis in the Web (T-section)}

The force equilibrium equation for T-beam can obtained by considering the compressive forces of the flange and web in counteracting the tensile forces, and mathematically represented as:

$$
0.85 f_{c}^{\prime}\left(b-b_{w}\right) t+0.85 f_{c}^{\prime} b_{w} a=A_{f} f_{f}
$$

$\mathrm{A}_{\mathrm{f}} \quad$ Area of cross-section of tensile FRP reinforcement in ${ }^{2}$

a Depth of rectangular concrete stress block, in

b Flange width, in

$b_{w} \quad$ Web width, in

$f_{c}{ }^{\prime} \quad$ Compressive strength of concrete, Ksi

$f_{f} \quad$ Tensile strength of GFRP rebar, Ksi 
When the depth of neutral axis is equal to the thickness of the flange eq 5.5 again reduces to eq 5.2 , which represents a rectangular beam behavior.

Balanced reinforcement ratio for a T-section, i.e., neutral axis extending into the web is obtained by combining eqns (5.5) and (5.1).

$$
\begin{aligned}
& \rho_{b a l-t}=0.85 \frac{f_{c}^{1}}{f_{f}}\left(\beta_{1} \frac{b_{w}}{b}\left(\frac{\varepsilon_{c u}}{\varepsilon_{c u}+\varepsilon_{f}}\right)+\left(1-\frac{b_{w}}{b}\right) \frac{t}{d}\right) \\
& \rho_{b a l-t}=\frac{b_{w}}{b}\left(\rho_{b a l-r}+\rho_{f}\right) \\
& \rho_{\text {bal-t }} \quad \text { Balanced reinforcement ratio of a T-section }
\end{aligned}
$$

$\rho_{f}=$ Reinforcement ratio that contributes in counter acting the moment from the over hanging flanges of the T-beams.

Table 5.1 shows the balanced reinforcement ratio for each beam. In addition, the amount of FRP area in the beams and failure modes are given in Table 5.1. Balanced reinforcement ratios are calculated according to eqns 5.4 and 5.6 for Rectangular and Tsections, respectively. In case of beams where the reinforcement ratio is greater than 0.75 times of balanced ratio, the failure is close to balanced failure. In case of beam B4T1 where 0.85 times of balanced reinforcement is used concrete strains reached 0.0027 , indicating its proximity to balanced failure. When a reinforcement ratio above 1.25 times balanced ratio is used, compression failures are achieved. Further increase in the reinforcement ratio lead to shifting of neutral axis into the web. 
Table 5.1 Balanced Reinforcement Ratios

\begin{tabular}{|c|c|c|c|c|c|c|}
\hline \multirow[t]{2}{*}{ Beam } & \multirow{2}{*}{$\begin{array}{c}\text { Equat- } \\
\text { ion } \\
\text { no. } \\
\end{array}$} & \multicolumn{3}{|c|}{ Reinforcement ratio } & \multirow{2}{*}{$\begin{array}{c}\text { Failure } \\
\text { mode } \\
\text { As per Eq. } 5.4\end{array}$} & \multirow[t]{2}{*}{$\begin{array}{c}\text { Actual } \\
\text { Failure mode }\end{array}$} \\
\hline & & $\begin{array}{c}\text { Balanced } \\
\text { (1) }\end{array}$ & $\begin{array}{c}\text { Provided } \\
\text { (2) }\end{array}$ & $(2) /(1)$ & & \\
\hline B1T1 & 5.4 & .0057 & .0015 & .24 & $\mathrm{~T}$ & $\mathrm{~T}$ \\
\hline B2T1 & 5.4 & .0051 & .0014 & .28 & $\mathrm{~T}$ & $\mathrm{~T}$ \\
\hline $\mathrm{B} 3 \mathrm{C} 1$ & 5.6 & .0139 & 0.024 & 1.72 & C IN WEB & C IN WEB \\
\hline B4T1 & 5.4 & .0028 & .0024 & .85 & $\mathrm{~T}$ & $\mathrm{~T}^{*}$ \\
\hline B1T2 & 5.4 & .0091 & .0069 & .76 & $\mathrm{~T}$ & $\mathrm{~T}^{*}$ \\
\hline B2C1 & 5.4 & .0079 & .0128 & 1.62 & $\mathrm{C}$ & $\mathrm{C}$ \\
\hline B3C2 & 5.6 & .0195 & .0524 & 2.69 & C IN WEB & C IN WEB \\
\hline $\mathrm{B} 4 \mathrm{C} 1$ & 5.4 & .0136 & .0173 & 1.27 & $\mathrm{C}$ & $\mathrm{C}$ \\
\hline
\end{tabular}

\footnotetext{
*- CLOSE TO BALANCED FAILURE

T-TENSION FAILURE

C-COMPRESION FAILURE
} 


\subsection{EFFECTIVE FLANGE WIDTH EVALUATION}

The important parameter that governs the design of a T-beam is the flange width. The flange participates effectively in counteracting the externally applied positive moment. The design of GFRP reinforced concrete beams for compression failure requires a precise calculation of compressive force and lever arm.

When external moments are applied, the tensile reinforcement in the web is balanced by a part of the slab resisting longitudinal compression. The flange compressive stress varies from a maximum over the flange and reduces away from it. Hence, full flange width is not effective and only a partial value is effective. Effective flange width depends on span length of the beam, flange depth, thickness of the flange and spacing of the T-beams.

\subsubsection{Concrete Stress Distribution across the Flange}

In concrete T-beams, the shape of the neutral axis is a parabola due to the reduction of concrete stress over the flange. The exact shape of concrete stress block is complicated and its use by the designer for computational purposes is cumbersome and time consuming. The concept of effective width of the flange over which rectangular stress block (linear neutral axis) can be assumed is evolved to simplify design process (Brendel 1964).

\subsubsection{Existing code specifications on effective flange width}

Permissible effective width of T-beams is defined in terms of beam span ' $L$ ', flange thickness ' $t$ ' and spacing of beams. Some countries have more parameters like web dimensions governing effective width specifications. AASHTO -LRFD requirements for effective width are more stringent than the ACI requirements and are given below.

$b_{e}=\operatorname{span} / 4$

$b_{\mathrm{e}}=\mathrm{b}_{0}+12 \mathrm{t}_{\mathrm{f}}$

$b_{e}=$ Clear span between beams

The lowest of the above values should be used.

The current ACI 318 specifications on effective width are. 
$\mathrm{b}_{\mathrm{e}}=\operatorname{span} / 4$

$\mathrm{b}_{\mathrm{e}}=\mathrm{b}_{0}+16 \mathrm{t}_{\mathrm{f}}$

$b_{e}=$ Clear span between beams

The lowest of the above values should be used.

Code requirements for effective widths $b_{e}$ to be assumed in designing symmetrical $T$ beams in various countries are presented in the following table. 
Table 5.2 Code Requirements of Various Nations for Effective Flange Width (Gottfried, 1964)

\begin{tabular}{|c|c|}
\hline Country & $\mathrm{b}_{\mathrm{e}}($ efective flange width) \\
\hline Belgium & $6 \mathrm{t}$ or $\mathrm{L} / 6-\mathrm{b}_{\mathrm{o}} / 2$ \\
\hline Brazil $/ \sqrt{\mathrm{L}+100}(\mathrm{~b} / \mathrm{L})^{2}$ \\
\hline Germany & $6 \mathrm{t}$ or $\mathrm{L} / 4-\mathrm{b}_{\mathrm{o}} / 2$ \\
\hline Greece & $6 \mathrm{t}$ or $\mathrm{L} / 4-\mathrm{b}_{\mathrm{o}} / 2$ \\
\hline France & $\mathrm{L} / 6$ \\
\hline Great Britain & $6 \mathrm{t}$ or $\mathrm{L} / 6-\mathrm{b}_{\mathrm{o}} / 2$ \\
\hline Italy & $5 \mathrm{t}$ or $\mathrm{L} / 12-\mathrm{b}_{\mathrm{o}} / 2$ \\
\hline Netherlands & $8 \mathrm{t}-\mathrm{b}_{\mathrm{o}} / 2$ or $\mathrm{L} / 6-\mathrm{b}_{\mathrm{o}} / 2$ \\
\hline Austria & $\mathrm{b} / \sqrt{\mathrm{L}+100}(\mathrm{~b} / \mathrm{L})^{2}$ \\
\hline Poland & $5 \mathrm{t}$ \\
\hline Sweden & $6 \mathrm{t}$ or $\mathrm{L} / 8$ \\
\hline Russia & $\mathrm{L} / 4-\mathrm{b}_{\mathrm{o}} / 2$ \\
\hline Switzerland & \\
\hline United States $16 \mathrm{t}+\mathrm{b}_{\mathrm{o}}$ \\
\hline
\end{tabular}

$b_{e^{----e f f e c t i v e ~ f l a n g e ~ w i d t h ~}}$

$b_{0^{-----w e b ~ w i d t h ~}}$

t-----flange thickness
L-----effective span

b-----Total flange width 


\subsubsection{Effective width of orthotropic plate -beam systems}

A general design equation was developed to predict effective flange width of orthotropic plate-beam systems by Lopez and GangaRao (1996). This equation is derived to represent the behavior of stress-laminated timber T-beam bridges assuming uncracked section.

$$
\frac{b_{m}}{b}=\frac{1+v_{x y}\left(\frac{2 b}{L}\right)^{2}}{1+\frac{E_{x}}{G_{x y}}\left(\frac{2 b}{L}\right)^{2}}
$$

for uncracked concrete $v=0.2$ and $\sqrt{\mathrm{E}_{\mathrm{x}} / \mathrm{G}_{\mathrm{xy}}}=1.55$

$\mathrm{E}_{\mathrm{x}}$---longitudinal modulus of elasticity

$\mathrm{G}_{\mathrm{xy}}$--In-plane shear modulus

$v_{\mathrm{xy}}-$ Poisson's ratio

\subsubsection{Effective Width of Slabs Reinforced with GFRP Rebars}

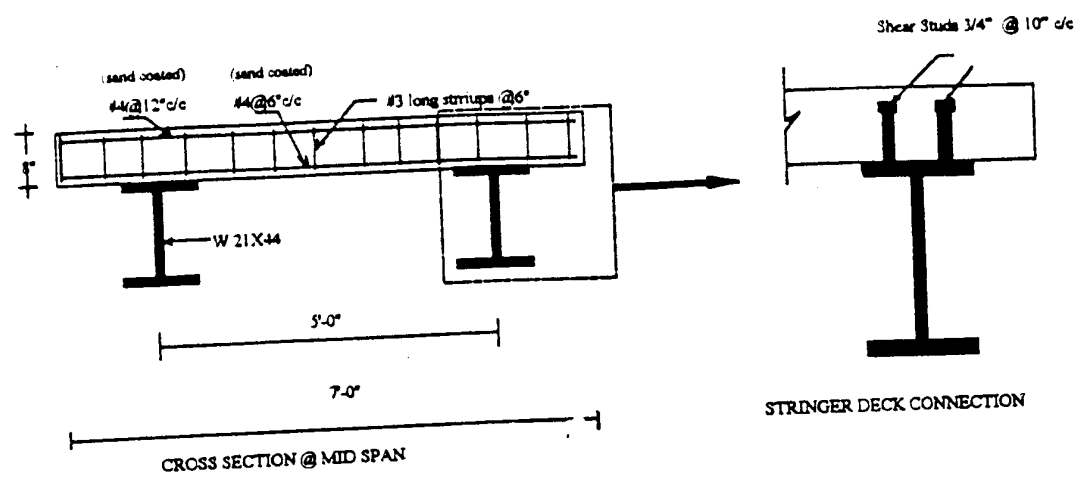

Fig 5.2 Fatigue tested concrete slabs reinforced with GFRP rebars (Sanjeev \& GangaRao, 1995)

Sanjeev \& GangaRao (1995) investigated behavior of concrete slabs reinforced with GFRP rebars. FRP rebar reinforced concrete slab on steel stringers was fatigue tested in the laboratory to evaluate parameters like compositeness of slab-stringer system, crack widths and patterns, load carrying capacity, local and global deflections. Fig 5.2 
shows the specimen details of FRP reinforced concrete slabs. Central deflections and concrete strains on top and bottom of the concrete deck were measured. The effectiveness of the deck width was evaluated by comparing theoretical and experimental deflections at the center of a deck.

Comparisons of theoretical and experimental deflections are provided in Table 5.3. The width of the slab used in computing theoretical deflections is the total width. Difference between theoretical and experimental values was within 1-2\%. Therefore it is concluded that the whole width is effective.

\section{Table 5.3 Comparison of Experimental and Theoretical Deflections (Sanjeev and GangaRao, 1995)}

\begin{tabular}{|c|c|c|c|}
\hline Deck & $\begin{array}{c}\text { Fatigue } \\
\left(\times 10^{6} \text { cycles }\right)\end{array}$ & $\begin{array}{c}\text { Experimental } \\
\text { Deflection } \\
\left(\times 10^{-3} \text { inches }\right)\end{array}$ & $\begin{array}{c}\text { Theoretical } \\
\text { Deflection } \\
\left(\times 10^{-3} \text { inches }\right)\end{array}$ \\
\hline$\# 1$ & 0.8 & 71 & 70.92 \\
\hline$\# 2$ & 1.5 & 80.5 & 80.27 \\
\hline$\# 3$ & 0.8 & 102 & 103.015 \\
\hline & 1.7 & 112 & 112.27 \\
\hline & 0.3 & 154 & 153.40 \\
\hline
\end{tabular}

\subsubsection{Evaluation of Effective flange width in McKinleyville Bridge:}

Franco et al., (1999), evaluated the performance of the first field installed GFRP reinforced concrete bridge deck on steel stringers. McKinleyville Bridge is a three span integral abutment bridge over Buffalo Creek, West Virginia. The bridge has built-in sensors to monitor strains on tension side and compression side at various critical locations. The deflection response of the bridge is examined over a period of time to study loss of compositeness between the steel stringer and bridge deck, and the effective flange width of the bridge deck. 


\section{Table 5.4 Effective Width Evaluation of McKinlyville Bridge \\ (Franco et.al. 1999)}

\begin{tabular}{|c|c|c|c|c|c|}
\hline \multirow{2}{*}{$\begin{array}{c}\text { Test Data } \\
\text { obtained from }\end{array}$} & \multicolumn{2}{|c|}{ Tocal Deflection (inch) } & \multicolumn{2}{c|}{$\begin{array}{c}\text { \% Difference } \\
\text { between theory and } \\
\text { experiment }\end{array}$} \\
\cline { 2 - 3 } & $\begin{array}{c}\text { Full } \\
\text { Effective } \\
\text { deck } \\
\text { width }\end{array}$ & $\begin{array}{c}50 \% \\
\text { Effective } \\
\text { deck } \\
\text { width }\end{array}$ & Expt. & $\begin{array}{c}\text { Fffective } \\
\text { deck } \\
\text { width }\end{array}$ & $\begin{array}{c}\text { Fflective } \\
\text { deck } \\
\text { width }\end{array}$ \\
\hline $\begin{array}{c}\text { Fall 1996 } \\
\text { load test }\end{array}$ & --- & --- & N/A & --- & -- \\
\hline $\begin{array}{c}\text { Winter 1997 } \\
\text { load test }\end{array}$ & 0.0055 & 0.0110 & 0.0098 & 78.2 & 12.2 \\
\hline $\begin{array}{c}\text { Spring 1998 } \\
\text { load test }\end{array}$ & 0.0075 & 0.0150 & 0.0118 & 51.3 & 27.11 \\
\hline $\begin{array}{c}\text { Fall 1998 } \\
\text { load test }\end{array}$ & 0.0063 & 0.0126 & 0.0114 & 80.9 & 10.5 \\
\hline
\end{tabular}

Table 5.4 provides the deflection values of McKinleyville Bridge over a period of two years. The deflections under discussion are local deck deflections; global deflection did not show much variation. Theoretical deflections are carried out by considering the entire width of the slab between stringers as effective and also by considering only $50 \%$ as effective. During the initial stages of load testing when the concrete sections were relatively uncracked and stiffness was high, deflections were calculated by using entire flange width compared well with the experimental deflections. When load tests were carried out in the fall, 1998 after the concrete slab experienced considerable amount of 
cracking, theoretical calculations using 50\% effective width are closer to the experimental deflections. 


\subsubsection{Theoretical Correlation of Effective Flange Width}

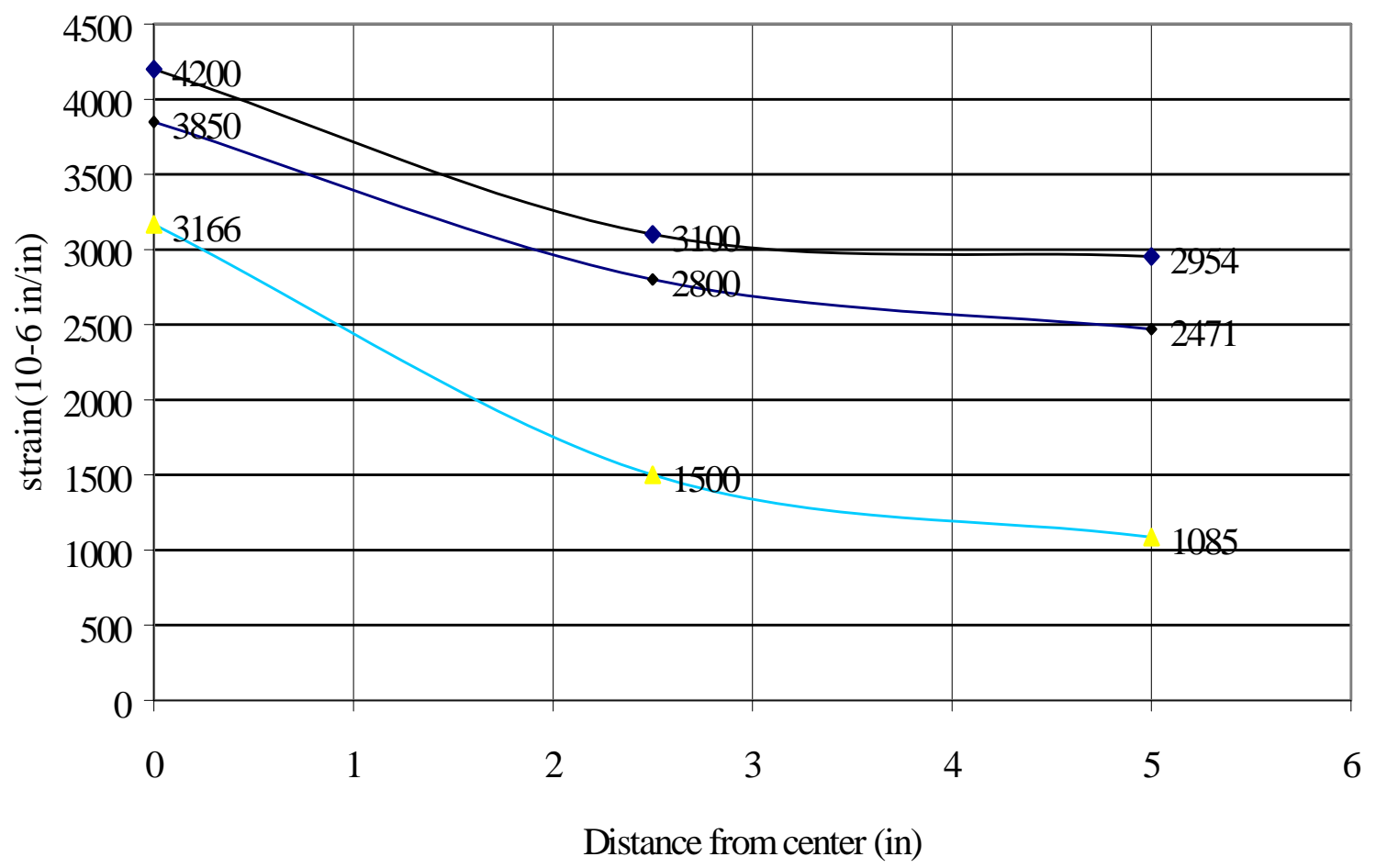

Fig 5.3 Evaluation of Effective Flange Width Based on Concrete Strains Beam B3C1

Theoretical values of effective width are calculated by using the equation proposed by Lopez and GangaRao (1993). The drawback of the equation is that it assumes uncracked sections. Therefore, the effective width values calculated by using this method are always higher than the experimental effective width values. Experiments are conducted on isolated T-beams; also there is reduction in section stiffness due to concrete cracking. Therefore, the experimental effective width was less than the calculated values from Lopez and GangaRao (1993).

Concrete strains are maximum at the center (Fig 5.3) and reduce away from the web. Strain distribution of concrete is parabolic leading to a nonlinear neutral axis as applied load increases. Thus the assumption of a linear neutral axis and the proportionality of stresses from the neutral axis is no longer valid. To simplify design procedures, the concept of effective width over which the neutral axis is straight has to be 
introduced. The area under the concrete strain diagram is obtained by numerical integration and this area is converted into an equivalent rectangular area. An effective width for a concrete beam is obtained by defining a rectangular stress block with width as effective width and height as ultimate concrete strain of 0.003 (in/in) as defined in ACI 318-95.

The area under concrete strain distribution along the width of the beam is shown in Fig 5.3. It is converted to an equivalent rectangular stress block with the width of the rectangle being the effective width of the beam. Tables 5.5 and 5.6 give a comparison of the effective widths obtained by Lopez and GangaRao with the values obtained by using the stress block conversions.

\section{Table 5.5 Evaluation of Effective Width in Beams Failing in Compression Mode}

\begin{tabular}{|c|c|c|c|c|c|}
\hline Beam & $\begin{array}{c}\text { Lopez \& } \\
\text { GangaRao } \\
\left(\mathrm{b}_{\mathrm{m}}\right)(\mathrm{in})\end{array}$ & $\begin{array}{c}\text { Expt } \\
\left(\mathrm{b}_{\mathrm{m}}\right) \\
(\mathrm{in})\end{array}$ & $\begin{array}{c}\mathrm{b}_{\mathrm{f}}=(\mathrm{b}-\mathrm{bo}) / 2 \\
\text { (in) }\end{array}$ & $\begin{array}{c}\mathrm{b}_{\mathrm{m}} / \mathrm{b}_{\mathrm{f}} \\
\text { Lopez \& } \\
\text { GangaRao }\end{array}$ & $\begin{array}{c}\mathrm{b}_{\mathrm{m}} / \mathrm{b}_{\mathrm{f}} \\
\text { Expt. }\end{array}$ \\
\hline B4C1 & 14.527 & 15.364 & 16.5 & 0.89 & 0.931 \\
\hline B2C1 & 9.948 & 8.3 & 10.5 & 0.94 & 0.790 \\
\hline B3C1 & 5.801 & 4.3 & 6 & 0.97 & 0.716 \\
\hline B3C2 & 7.293 & 6 & 7.5 & 0.97 & 0.815 \\
\hline
\end{tabular}

The ratio of effective width to total width on either side of the flange varied from 0.716-0.931 for beams designed for compression failure and it is in the range of 0.8080.915 for the beams designed for tension failure. 
Table 5.6 Evaluation of Effective Width in Beams Failing in Tension Mode

\begin{tabular}{|c|c|c|c|c|c|}
\hline Beam & $\begin{array}{c}\text { Lopez \& } \\
\text { GangaRao } \\
\left(\mathrm{b}_{\mathrm{m}}\right) \text { (in) }\end{array}$ & $\begin{array}{c}\text { Expt } \\
\left(\mathrm{b}_{\mathrm{m}}\right) \\
(\mathrm{in})\end{array}$ & $\begin{array}{c}\mathrm{b}_{\mathrm{f}}=(\mathrm{b}-\mathrm{bo}) / 2 \\
\text { (in) }\end{array}$ & $\begin{array}{c}\mathrm{b}_{\mathrm{m}} / \mathrm{b}_{\mathrm{f}} \\
\text { Lopez \& } \\
\text { GangaRao }\end{array}$ & $\begin{array}{c}\mathrm{b}_{\mathrm{m}} / \mathrm{b}_{\mathrm{f}} \\
\text { Expt. }\end{array}$ \\
\hline B1T1 & 12.389 & 12.125 & 15 & 0.826 & 0.808 \\
\hline B2T1 & 10.565 & 10.99 & 12 & 0.88 & 0.915 \\
\hline B1T2 & 12.370 & 11.17 & 13.5 & 0.916 & 0.827 \\
\hline B4T1 & 13.836 & 14.949 & 18 & 0.769 & 0.830 \\
\hline
\end{tabular}




\subsection{ANALYTICAL MODELLING OF FLEXURAL BEHAVIOR OF T-BEAMS}

\subsubsection{Stress Distribution in Compression Zone}
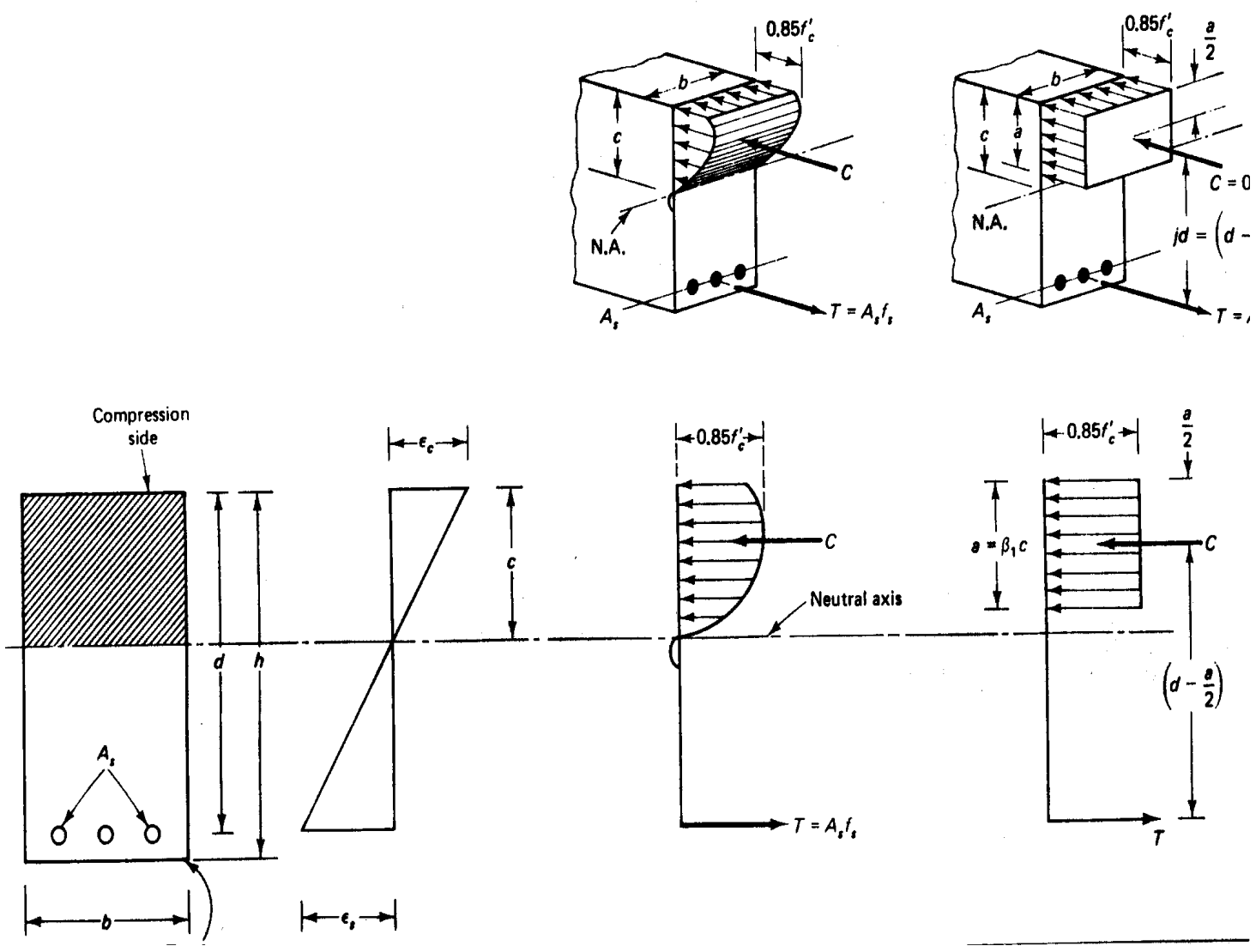

Fig 5.4 Concrete Stress distribution (parabolic shape)

(Ref : Edward G. Nawy 1990) 


\subsubsection{Force Equilibrium of T-beams}

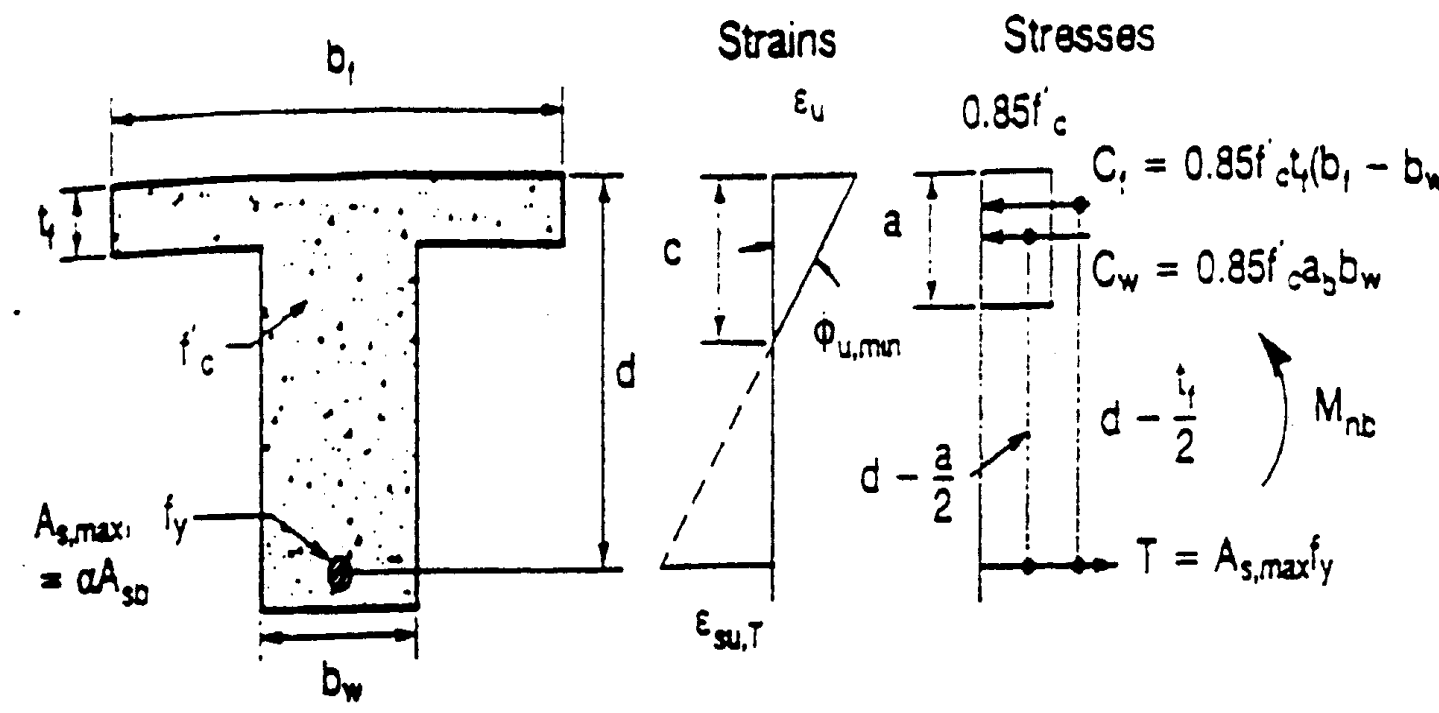

Fig 5.5 Force Equilibrium in Concrete T-beams

Equating forces for rectangular stress block for neutral axis location in the flange

$$
\mathrm{C}=\mathrm{T}
$$

$0.85 f_{c}^{1} a b=A_{f} f_{f}$

$\mathrm{C}=$ Total compressive force

$\mathrm{T}=$ Total tensile force

Equating forces for rectangular stress block for neutral axis location in the web

$\mathrm{C}_{\mathrm{f}}+\mathrm{C}_{\mathrm{w}}=\mathrm{T}$

$0.85 f_{c}^{1}\left(b-b_{w}\right) t+0.85 f_{c}^{1} b_{w} a=A_{f} f_{f}$

$\mathrm{C}_{\mathrm{f}}=$ Compressive force component due to the flange

$\mathrm{C}_{\mathrm{w}}=$ Compressive force component due to the web 


\subsubsection{Analysis of under reinforced beams}

Under-reinforced beams are designed by providing an area of reinforcement less than that required by balanced failure. Failure is characterized by rupture of rebar before concrete reaches its ultimate strain. Depending on the shape of concrete stress-strain curve and concrete strain at failure, two types of stress blocks are proposed for analysis. Type -1 Stress Block

When concrete strains are low as in the elastic range, strain distribution is linear and the shape of stress block is triangular. The force equilibrium for this case can be used to find out the depth of neutral axis 'c'.

$0.5 f_{c}^{\prime} c=A_{f} f_{f}$

The nominal moment can be calculated by

$M_{n}=T \times$ leverarm $=A_{f} f_{f}(d-c / 3)$

Type -2 Stress Block

When concrete strains exceed the linear stage, the stress distribution is no longer linear and parabolic stress distribution can be assumed. ACI 318R-95 recommends an equivalent rectangular stress block for analysis.

$0.85 f_{c}^{1} a b=A_{f} f_{f}$

The nominal moment capacity of the section is

$M_{n}=T \times$ leverarm $=A_{f} f_{f}(d-a / 2)$

\subsubsection{Analysis of over reinforced beams}

Over-reinforced beams are designed by providing an area of reinforcement higher than that required by balanced failure. Failure is initiated by crushing of concrete. Depending on the amount of reinforcement used, it may lead to a secondary tension failure. This condition must be avoided while designing over reinforced beams with GFRP rebars to avoid catastrophic tension failures.

The stress in tension reinforcement of over reinforced beams can be computed by strain compatibility condition.

$f_{f 1}=E_{f} \varepsilon_{c u} \frac{\beta_{1} d-a}{a}$ 
Depending on the position of neutral axis over reinforced beam behaves as a rectangular or a T-beam.

\subsubsection{Rectangular beam (over reinforced beam)}

Rebar stress level can be calculated from Eqn 5.13. Force equilibrium of the beam can be found from Eqn 5.14, when neutral axis depth is lower than the thickness of the flange. Quadratic equation in terms of the depth of the equivalent rectangular stress block "a" can be obtained by combining these two equations.

$f_{f 1}=E_{f} \varepsilon_{c u} \frac{\beta_{1} d-a}{a}$

$0.85 f_{c}^{1} a b=A_{f} f_{f}$

Combining (5.13) and (5.14)

$a^{2}+\kappa a d-\kappa \beta_{1} d^{2}=0$

where $\kappa=\frac{\rho E_{f} \varepsilon_{c u}}{0.85 f_{c}^{1}}$ and $\rho=\frac{A_{f}}{b d}$

The product of compressive force and its lever arm gives moment capacity.

$M_{n}=C \times$ leverarm $=0.85 f_{c}^{1} a b(d-a / 2)$

\subsubsection{T-beam (over reinforced beam)}

FRP bar stress level can be calculated from Eqn 5.17. Force equilibrium of the beams can be found from Eqn 5.18, when neutral axis depth is greater than the thickness of the flange. Quadratic equation in terms of the depth of the equivalent rectangular stress block "a" can be obtained by combining two equations 5.17 and 5.18.

$f_{f 1}=E_{f} \varepsilon_{c u} \frac{\beta_{1} d-a}{a}$

$0.85 f_{c}^{1}\left(b-b_{w}\right) t+0.85 f_{c}^{1} b_{w} a=A_{f} f_{f}$

From (5.17) and (5.18) 
$a^{2}+a \lambda d-\kappa_{t} \beta_{1} d^{2}=0$

where $\kappa_{t}=\frac{\rho_{\mathrm{w}} E_{f} \varepsilon_{c u}}{0.85 f_{c}^{1}}$ and $\rho_{w}=\frac{A_{f}}{b_{w} d}$

$\lambda=\left[\kappa_{t}+\left(\frac{b}{b_{w}}-1\right) \frac{t}{d}\right]$

The moment capacity of the beam can be computed by multiplying the compressive forces of the flange and web with their respective lever arms to the centroid of the tension reinforcement.

$$
\begin{aligned}
M_{n} & =C_{f} \times \text { leverarm }+C_{w} \times \text { leverarm } \\
& =0.85 f_{c}^{1} t\left(b-b_{w}\right)(d-t / 2)+0.85 f_{c}^{1} a b_{w}(d-a / 2)
\end{aligned}
$$

Detailed analysis of GFRP reinforced T-beams is presented in Appendix A. Design procedures are presented in Appendix B followed by a design example in Appendix C.

Table 5.7 Comparison of Experimental and Theoretical Moment Capacities (Tension Failure Mode)

\begin{tabular}{|l|l|l|l|}
\hline \multicolumn{1}{|c|}{ Beam } & \multicolumn{1}{|c|}{$\begin{array}{c}\mathrm{M}_{\text {the }} \\
\text { kip-ft }\end{array}$} & \multicolumn{1}{|c|}{$\begin{array}{c}\mathrm{M}_{\text {exp }} \\
\text { kip-ft }\end{array}$} & \multicolumn{1}{|c|}{$\mathrm{M}_{\text {the }} / \mathrm{M}_{\text {exp }}$} \\
\hline B1T1 & 73.12 & 75.00 & 0.975 \\
\hline B1T2 & 166.64 & 157.50 & 1.058 \\
\hline B2T1 & 72.97 & 79.50 & 0.918 \\
\hline B4T1 & 107.15 & 115.50 & 0.928 \\
\hline
\end{tabular}

Comparison of experimental and theoretical moment capacities of beams designed for tension failures is presented in Table 5.7. The experimental values are in reasonable comparison with the predicted values. The advantage of this analysis methodology is that it is very much similar to the existing methods except that the 
properties of GFRP material are substituted in lieu of steel rebar properties. Table 5.8 compares theoretical and experimental moment capacity of beams designed for compression failure. Theoretical and experimental correlation for moment capacity in beam $\mathrm{B} 3 \mathrm{C} 2$ varied by $13 \%$ due to the greater uncertainty in concrete strength.

Design charts for concrete T-beams reinforced with GFRP bars are provided in the Appendix D.

\section{Table 5.8 Comparison of Experimental and Theoretical Moment Capacities (Compression Failure Mode)}

\begin{tabular}{|c|c|c|c|}
\hline Beam & $\begin{array}{c}\mathrm{M}_{\text {the }} \\
\text { kip-ft }\end{array}$ & $\begin{array}{c}\mathrm{M}_{\text {exp }} \\
\text { kip-ft }\end{array}$ & $\mathrm{M}_{\text {the }} / \mathrm{M}_{\text {exp }}$ \\
\hline B2C1 & 188.24 & 180.00 & 1.05 \\
\hline B4C1 & 171.21 & 180.00 & 0.95 \\
\hline B3C1 & 153.28 & 150.00 & 1.02 \\
\hline B3C2 & 143.84 & 165.00 & 0.87 \\
\hline
\end{tabular}

\subsection{FLEXURAL CRACKING}

\subsubsection{Cracking -Overview}

- Cracking of any section reduces its stiffness and increases deflections in a structural member. Further more, cracks increase the possibility of corrosion in the case of steel reinforced beams and exposure to moisture and other chemicals in the case of GFRP reinforced beams.

The following factors play an important role in crack control of steel reinforced concrete beams as stated in ACI $318 \mathrm{M}-95$

- Geometric variables

- Thickness of concrete cover 
- Area of concrete under tension

- Depth of neutral axis

- Detailing of reinforcement

- Other variables

- Stress in the rebar at the location of crack

- Bond stress between concrete and rebar surface

- Stiffness of rebar

Prediction and control of crack widths and crack controls are necessary considering the high strength GFRP rebars and high strength concrete (> 5000 psi) available for construction.

\subsubsection{Crackwidth Modeling}

ACI recommended the existing Gergely-Lutz equation to predict the maximum crackwidth by considering the above mentioned parameters.

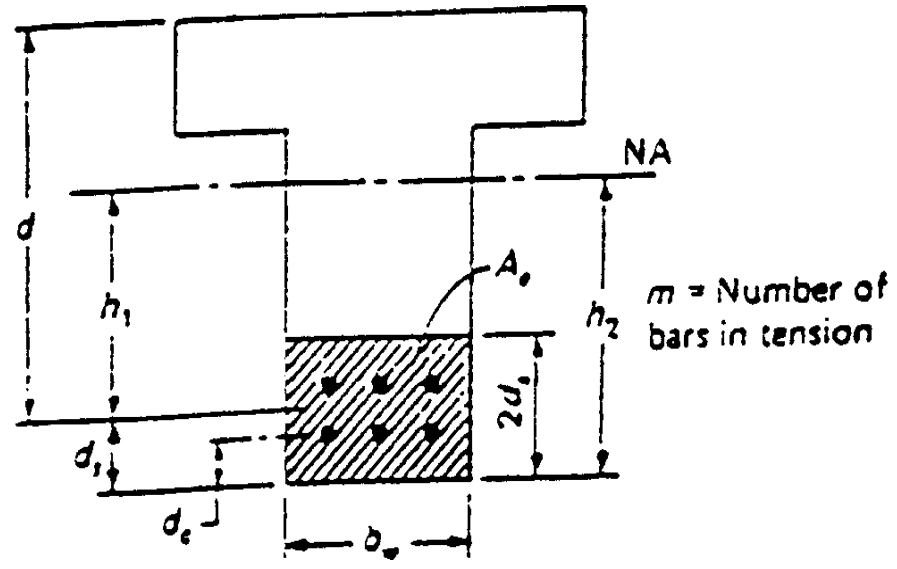

Fig 5.6 Crack-Width Evaluation

$W_{\max }=0.076 \beta f_{s} \sqrt[3]{d_{c} A} \times 10^{-3}$ 
$\beta=\frac{h_{2}}{h_{1}}, \quad f_{F R P}=$ Rebar Stress

$A=\frac{A_{E}}{m}, \quad d_{c}=$ Concrete Cover

Crack widths in case of beams reinforced with composite GFRP bars are higher due to the lower stiffness of these materials when compared to steel reinforced concrete beams. A modified Gergely-Lutz (equation 5.32) is proposed to account for lower stiffness of GFRP bars by Faza and GangaRao (1991).

$$
W_{\text {max }}=0.076 \beta \frac{E_{s}}{E_{F R P}} f_{F R P} \sqrt[3]{d_{c} A} \times 10^{-3}
$$

Crack widths proposed by the above equations are about $25 \%$ to $30 \%$ higher than the experimental crack widths. A reduction factor $\mathrm{k}(0.7)$ is being proposed to give a more realistic prediction of crack widths in beams reinforced with GFRP bars. Such discrepancy in crack width between experiment and theory is attributed to:

1. Better stiffness match between concrete and GFRP bars.

2. Better bond characteristics of these GFRP bars compared to steel rebars.

Equation 5.34 includes the proposed modification factor.

$$
W_{\text {max }}=0.076 \beta\left(k \frac{E_{s}}{E_{F R P}}\right) f_{F R P} \sqrt[3]{d_{c} A} \times 10^{-3}
$$

Table 5.9 Correlation of Crack Width Equation for Beam B1T1 (with k factor)

\begin{tabular}{|c|c|c|c|c|c|}
\hline BEAM & $\begin{array}{c}\text { Stress } \\
\text { Ksi }\end{array}$ & $\begin{array}{c}\mathrm{W}_{\text {the }} \\
\text { in }\end{array}$ & $\begin{array}{c}\mathrm{W}_{\text {expt }} \\
\text { in }\end{array}$ & $\begin{array}{c}\text { load } \\
\text { kips }\end{array}$ & $\mathrm{W}_{\text {the }} / \mathrm{W}_{\text {expt }}$ \\
\hline B1T1 & 5 & 0.0035 & 0.004 & 10 & 0.875 \\
\hline & 25 & 0.0217 & 0.021 & 20 & 1.033 \\
\hline & 35 & 0.0381 & 0.031 & 30 & 1.229 \\
\hline
\end{tabular}


Table 5.9 compares the predicted (Eqn. 5.34) and experimental values of crack widths for beam B1T1 designed for tension failure. Experimental values are lower than the predicted values by $3 \%-22 \%$. Table 5.10 compares the predicted and observed crack widths for beam B2T1 designed for tension failure. Reduction factor $(\mathrm{k}=0.7)$ mentioned in Eqn 5.34 is applied for the values in Tables 5.9 through 5.12.

Table 5.10 Correlation of Crack Width Equation for Beam B2T1 (with k factor)

\begin{tabular}{|c|c|c|c|c|c|}
\hline BEAM & $\begin{array}{c}\text { Stress } \\
\text { Ksi }\end{array}$ & $\begin{array}{c}\mathrm{W}_{\text {the }} \\
\text { in }\end{array}$ & $\begin{array}{c}\mathrm{W}_{\text {expt }} \\
\text { in }\end{array}$ & $\begin{array}{c}\text { load } \\
\text { kips }\end{array}$ & $\mathrm{W}_{\text {the }} / \mathrm{W}_{\text {expt }}$ \\
\hline B2T1 & 6 & 0.0042 & 0.004 & 10 & 1.05 \\
\hline & 30 & 0.0224 & 0.019 & 15 & 1.18 \\
\hline & 45 & 0.0329 & 0.029 & 30 & 1.13 \\
\hline
\end{tabular}

Table 5.11 Correlation of Crack Width Equation for Beam B3C1

\begin{tabular}{|c|c|c|c|c|c|}
\hline BEAM & $\begin{array}{c}\text { Stress } \\
\text { Ksi }\end{array}$ & $\begin{array}{c}\text { Wthe } \\
\text { in }\end{array}$ & $\begin{array}{c}\text { Wexp } \\
\text { in }\end{array}$ & $\begin{array}{c}\text { load } \\
\text { kips }\end{array}$ & Wthe/Wexp \\
\hline B3C1 & 8 & 0.0042 & 0.004 & 20 & 1.05 \\
\hline & 15 & 0.0077 & 0.008 & 40 & 0.96 \\
\hline & 29.5 & 0.0154 & 0.016 & 70 & 0.96 \\
\hline
\end{tabular}

Table 5.11 compares the predicted (Eqn. 5.33) and experimental values of crack widths for beam $\mathrm{B} 3 \mathrm{C} 1$ designed for compression failure. Experimental values are lower than the predicted values by $4 \%-8 \%$. Table 5.12 compares the predicted and observed crack widths for beam $\mathrm{B} 3 \mathrm{C} 2$ designed for compression failure 
Table 5.12 Correlation of Crack Width Equation B3C2

\begin{tabular}{|c|c|c|c|c|c|}
\hline BEAM & $\begin{array}{c}\text { Stress } \\
\text { Ksi }\end{array}$ & $\begin{array}{c}\text { Wthe } \\
\text { in }\end{array}$ & $\begin{array}{c}\text { Wexp } \\
\text { in }\end{array}$ & $\begin{array}{c}\text { load } \\
\text { kips }\end{array}$ & Wthe/Wexp \\
\hline B3C2 & 6 & 0.0035 & 0.004 & 10 & 0.88 \\
\hline & 22.2 & 0.0126 & 0.013 & 30 & 0.97 \\
\hline & 36 & 0.0203 & 0.025 & 60 & 0.82 \\
\hline
\end{tabular}

\subsection{DEFLECTION PREDICTIONS:}

There are two distinct regions in the load-deflection curves of the beams reinforced with GFRP rebars. The region of the graph before the concrete section is cracked is linear and the slope of the curve is higher. As soon as concrete cracks, the moment of inertia is reduced and concrete in the tensile area can be neglected for stiffness calculations. The slope in the second region of the curve is less steep and is maintained until FRP bar rupture as in the case of tensile failure or concrete crushing in case of compression failure.

For four point bending, maximum deflection at the center is given by the elastic equation:

$$
\Delta_{\max } a t(\text { center })=\frac{p a}{24 E I}\left(3 l^{2}-4 a^{2}\right)
$$

Where

$E$ - modulus of concrete

I-moment of inertia of section

$P$-applied load

The inelastic behavior of the beam is taken into account by substituting the appropriate moment of inertia (I) value into the equation 5.34

The value of elastic modulus can be calculated by using the empirical formula given by ACI 318R-95 for concrete. 


$$
E_{c}=33 w^{1.5} \sqrt{f_{c}^{1}}
$$

For normal weight concrete

$$
E_{c}=57000 \sqrt{f_{c}^{1}}
$$

\subsubsection{Deflection Prediction of uncracked concrete section:}

Deflections of the beams are calculated assuming the section is uncracked and gross moment of inertia is used. Gross moment of inertia of a T-beam can be determined from:

$$
I_{g}=\frac{b h_{f}^{3}}{12}+b h_{f}\left(\bar{y}-\frac{h_{f}}{2}\right)^{2}+\frac{b_{w}\left(h-h_{f}\right)^{3}}{12}+b_{w}\left(h-h_{f}\right)\left(y_{t}-\frac{h-h_{f}}{2}\right)^{2}
$$

Where

$$
\begin{aligned}
& \bar{y}=\frac{A_{1} y_{1}+A_{2} y_{2}}{A_{1}+A_{2}} \\
& y_{t}=h-\bar{y}
\end{aligned}
$$

Table 5.13 compares the predicted and experimental deflection values for precracking zone of deflection curve. The values predicted are on the lower than the experimental value due to internal cracking of concrete beam which is not visible to the naked eye.

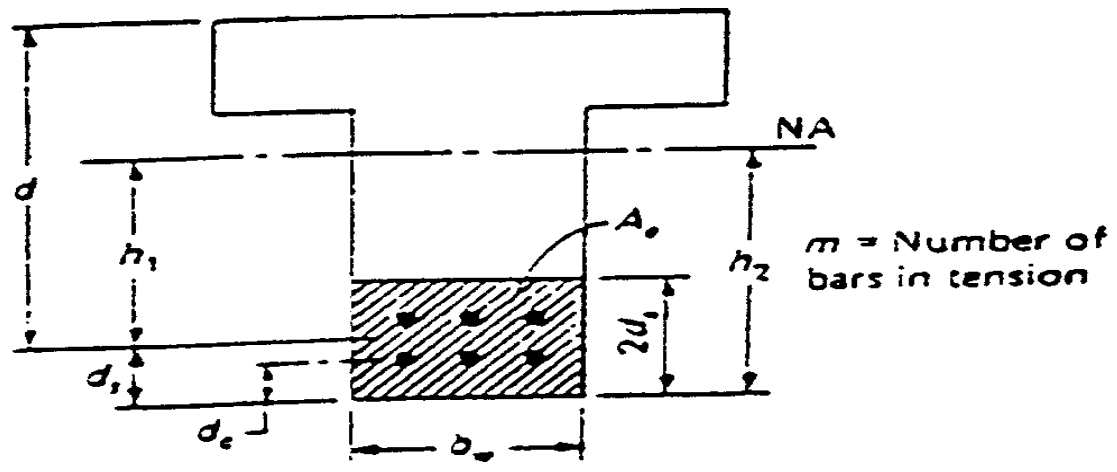

Fig 5.7 T-beam notation for calculating center of gravity 
Table 5.13 Comparison of Experimental and Theoretical Deflections during PreCracking stage

\begin{tabular}{|c|c|c|c|c|}
\hline BEAM & $\begin{array}{l}\text { Load } \\
\text { kips }\end{array}$ & $\begin{array}{c}\text { Expt Defl } \\
\text { in }\end{array}$ & $\begin{array}{c}\text { The Defl } \\
\text { in }\end{array}$ & $\begin{array}{c}\text { Expt/The } \\
\text { Defl }\end{array}$ \\
\hline B1T1 & 7 & 0.08 & $*$ & $*$ \\
\hline B1T1 & 4 & 0.041 & $*$ & $*$ \\
\hline B1T1 & 2 & 0.011 & $*$ & $*$ \\
\hline B2T1 & 7 & 0.048 & * & * \\
\hline B2T1 & 5 & 0.019 & $*$ & $*$ \\
\hline B2T1 & 2 & 0.008 & $*$ & * \\
\hline B3C1 & 8 & 0.028 & 0.02218 & 1.263 \\
\hline $\mathrm{B} 3 \mathrm{C} 1$ & 6 & 0.018 & 0.01663 & 1.082 \\
\hline B3C1 & 4 & 0.015 & 0.01109 & 1.353 \\
\hline B4T1 & 6 & 0.021 & 0.01436 & 1.462 \\
\hline B4T1 & 4 & 0.011 & 0.00958 & 1.149 \\
\hline B1T2 & 5 & 0.043 & 0.02985 & 1.441 \\
\hline
\end{tabular}




\begin{tabular}{|c|c|c|c|c|}
\hline B1T2 & 4 & 0.019 & 0.02388 & 0.796 \\
\hline B1T2 & 2 & 0.008 & 0.01194 & 0.671 \\
\hline B2C1 & 6 & 0.041 & 0.03529 & 1.162 \\
\hline B2C1 & 4 & 0.017 & 0.02352 & 0.723 \\
\hline B2C1 & 2 & 0.01 & 0.01176 & 0.851 \\
\hline B3C2 & 8 & 0.13 & 0.08378 & 1.552 \\
\hline B3C2 & 6 & 0.081 & 0.06283 & 1.289 \\
\hline B3C2 & 4 & 0.039 & 0.04189 & 0.931 \\
\hline B4C1 & 8 & 0.079 & 0.07139 & 1.107 \\
\hline B4C1 & 6 & 0.09 & 0.05354 & 1.681 \\
\hline B4C1 & 4 & 0.041 & 0.03569 & 1.149 \\
\hline
\end{tabular}

* These values are post - cracking and hence no theoretical comparison is provided 


\subsubsection{Deflection Prediction of Cracked Concrete Section.}

Theoretical deflections compared well with experiment values for beams designed for tension failure if modified moment of inertia was used. Faza and GangaRao (1992) proposed modified moment of inertia. Theoretical deflections of beams designed for compression failure can give a good comparison as well by using the effective moment of inertia concept proposed by Branson (1972).

Calculate depth of neutral axis from

$$
\begin{aligned}
& b_{w}\left(c-h_{f}\right)^{2}-2 \frac{E_{f}}{E_{c}} A_{f}(d-c)+b h_{f}\left(2 c-h_{f}\right)=0 \\
& I_{c r}=\frac{b h_{f}^{3}}{12}+b h_{f}\left(c-\frac{h_{f}}{2}\right)^{2}+b h_{f}\left(c-\frac{h_{f}}{2}\right)^{2}+\frac{E_{f}}{E_{c}} A_{f}(d-c)^{2}
\end{aligned}
$$

Branson's simplified effective stiffness calculations

$$
I_{e}=\left(\frac{M_{c r}}{M_{a}}\right)^{3} I_{g}+\left[1-\left(\frac{M_{c r}}{M_{a}}\right)^{3}\right] I_{c r} \leq I_{g}
$$

This can also be written as

$$
I_{e}=\left(\frac{M_{c r}}{M_{a}}\right)^{3}\left(I_{g}-I_{c r}\right)+I_{c r} \leq I_{g}
$$

Effective moment of inertia is modified as follows

$$
I_{m}=\frac{23 I_{c r} I_{e}}{8 I_{c r}+15 I_{e}}
$$


Table 5.14 Comparison of Experimental and Theoretical Deflections Post-Cracking Stage for Beam B3C1

\begin{tabular}{|c|c|c|c|c|}
\hline $\begin{array}{c}\text { Load } \\
\text { kips }\end{array}$ & $\begin{array}{c}\text { Expt defl } \\
\text { in }\end{array}$ & $\begin{array}{c}\text { The defl } \\
(\mathrm{Im}) \\
\text { in }\end{array}$ & $\begin{array}{c}\text { Im } \\
\operatorname{In}^{4}\end{array}$ & $\begin{array}{c}\text { Expt/The } \\
\text { Defl }\end{array}$ \\
\hline 15 & 0.374 & 0.3597 & 329.449 & 1.041 \\
\hline 20 & 0.488 & 0.4951 & 319.135 & 0.986 \\
\hline 25 & 0.654 & 0.6458 & 305.825 & 1.013 \\
\hline 30 & 0.798 & 0.8129 & 291.538 & 0.978 \\
\hline 50 & 1.123 & 1.1856 & 266.527 & 0.946 \\
\hline 50 & 1.449 & 1.5820 & 249.673 & 0.916 \\
\hline
\end{tabular}

Table 5.14 compares predicted and experimental values of deflection for beam B1T1 in the post-cracking region. It can be seen that the deflections predicted using modified moment of inertia are closer to the experimental values. 
Table 5.15 Comparison of Experimental and Theoretical Values during PostCracking Stage for Beam B1T1

\begin{tabular}{|c|c|c|c|}
\hline $\begin{array}{c}\text { Load } \\
\text { kips }\end{array}$ & $\begin{array}{c}\text { Exp defl } \\
\text { in }\end{array}$ & $\begin{array}{c}\text { The defl } \\
\text { (Im) } \\
\text { in }\end{array}$ & $\begin{array}{c}\text { Exp/The } \\
\text { Defl }\end{array}$ \\
\hline 15 & 0.102 & 0.1431 & 0.72 \\
\hline 20 & 0.126 & 0.2041 & 0.62 \\
\hline 30 & 0.221 & 0.3216 & 0.71 \\
\hline 40 & 0.322 & 0.4349 & 0.74 \\
\hline 50 & 0.431 & 0.5465 & 0.79 \\
\hline 60 & 0.531 & 0.6573 & 0.81 \\
\hline 70 & 0.621 & 0.7678 & 0.81 \\
\hline 80 & 0.737 & 0.8781 & 0.84 \\
\hline 90 & 0.851 & 0.9883 & 0.88 \\
\hline 100 & 1.009 & 1.0984 & 0.92 \\
\hline 110 & 1.2 & 1.2084 & 0.99 \\
\hline
\end{tabular}

Table 5.15 compares predicted and experimental values of deflection for beam $\mathrm{B} 3 \mathrm{C} 1$ in the post-cracking region. It can be seen that the deflections calculated using effective moment of inertia are closer to the experimental values. 


\subsection{DEFORMABILITY/DUCTILITY}

Ductility indices $(\mu)$ for steel beams are described as follows (Park and Paulay, 1975):

Deflection $(\Delta)$ Based $\quad \mu=\Delta_{u} / \Delta_{y}$

Rotation $(\theta)$ Based $\quad \mu=\theta_{u} / \theta_{y}$

Curvature $(\varphi)$ Based $\quad \mu=\varphi_{u} / \varphi_{y}$

u----Ultimate Condition

y----Yield Condition

Due to the linear stress-strain behavior of GFRP reinforcement up to failure, the energy absorbing characteristics of GFRP reinforced beams are expressed in terms of deformability factors. Deformability is defined as the ratio of energy absorption at ultimate (area under moment-curvature curve) to energy with respect to a limiting curvature $(0.005 / \mathrm{d})$ based on serviceability criteria of deflection and crack-width as defined in ACI 318/318R-96 (Vijay and GangaRao 1996).

\subsubsection{Unified Serviceability Criteria for Deformability}

Vijay and GangaRao (1996) proposed a methodology to arrive at a serviceability criterion that unifies deflection and Crackwidth limit state for beams reinforced with GFRP bars.

- Energy absorption in concrete beams can be estimated by considering the areas under load-deflection or moment-curvature diagrams. To properly account for different energy absorbing mechanisms and to satisfy both deflection and crack-width criteria, a unified serviceability-based approach can be adopted for defining Deformability.

- Consideration of total energy with respect to serviceability based energy level in a moment curvature plot provides a basis for addressing ductility and Deformability in the design of GFRP reinforced beams.

\subsubsection{Unified Curvature Limit}

The curvature at which beams designed for compression failure satisfy deflection limits of span/180 and span/300 are given in Table 5.16. Deflection limit of span/300 is 
satisfied for curvatures in the range of $0.0038 / \mathrm{d}-0.0057 / \mathrm{d}$ radians per inch. The deflection limit of span/180 can be satisfied for curvatures ranging from $0.005 / \mathrm{d}-0.0065 / \mathrm{d}$ radians per inch.

Table 5.16 Curvature Calculation at Deflection Serviceability Limit States

\begin{tabular}{|c|c|c|}
\hline BEAM & $\begin{array}{c}\text { CURVATURE } \\
\text { Radian/inch } \\
\text { Span/180 }\end{array}$ & $\begin{array}{c}\text { CURVATURE } \\
\text { Radian/inch } \\
\text { Span/300 }\end{array}$ \\
\hline B3C2 & $0.004 / \mathrm{d}$ & $0.005 / \mathrm{d}$ \\
\hline B3C1 & $0.0057 / \mathrm{d}$ & 0.00648 \\
\hline B2C1 & $0.0038 / \mathrm{d}$ & $0.0051 / \mathrm{d}$ \\
\hline B4C1 & $0.0038 / \mathrm{d}$ & $0.0046 / \mathrm{d}$ \\
\hline
\end{tabular}

Beam curvatures for satisfying crack width limit of 0.016 " is given in Table 5.17. Generally, beams designed for compression failure satisfied crack width Limit State when curvatures were below $0.0055 / \mathrm{d}$ radians per inch, where $\mathrm{d}$ is the effective depth of the beam.

Table 5.17 Curvature Calculation at Crack Width Serviceability Limit States

\begin{tabular}{|c|c|c|c|}
\hline BEAM & $\begin{array}{c}\text { Crack-width } \\
\text { inches }\end{array}$ & $\begin{array}{c}\text { Curvature } \\
\text { Radians/inch }\end{array}$ & $\begin{array}{c}\text { Load } \\
\text { kips }\end{array}$ \\
\hline B3C2 & 0.016 & $0.0055 / \mathrm{d}$ & 40 \\
\hline B3C1 & 0.016 & $0.0065 / \mathrm{d}$ & 55 \\
\hline B2C1 & 0.017 & $0.0053 / \mathrm{d}$ & 35 \\
\hline B4C1 & 0.011 & $0.0055 / \mathrm{d}$ & 30 \\
\hline
\end{tabular}


Beams designed for tension failure satisfied deflection limit of span/180, at curvature values of $0.007 / \mathrm{d}$, which were higher than curvature values for compression failure.

Table 5.18 Curvature Calculation at Deflection Serviceability Limit States

\begin{tabular}{|c|c|c|c|}
\hline BEAM & $\begin{array}{c}\text { L/180 } \\
\text { (in) }\end{array}$ & $\begin{array}{c}\text { LOAD } \\
\text { kips }\end{array}$ & $\begin{array}{c}\text { CURVATURE } \\
\text { Radian/inch }\end{array}$ \\
\hline B1T1 & 0.53 & 20.51 & $0.007 / \mathrm{d}$ \\
\hline B1T2 & 0.73 & 30.32 & $0.005 / \mathrm{d}$ \\
\hline B2T1 & 0.53 & 20.65 & $0.0071 / \mathrm{d}$ \\
\hline B4T1 & 0.53 & 27.18 & $0.007 / \mathrm{d}$ \\
\hline
\end{tabular}

Table 5.19 Curvature Calculation at Crack Width Serviceability Limit States

\begin{tabular}{|c|c|c|c|}
\hline BEAM & $\begin{array}{c}\text { Crack-width } \\
\text { inch }\end{array}$ & $\begin{array}{c}\text { Curvature } \\
\text { Per inch }\end{array}$ & $\begin{array}{c}\text { Load } \\
\text { kips }\end{array}$ \\
\hline B1T1 & 0.016 & $0.0045 / \mathrm{d}$ & 15 \\
\hline B1T2 & 0.016 & $0.0055 / \mathrm{d}$ & 30 \\
\hline B2T1 & 0.016 & $0.0057 / \mathrm{d}$ & 18 \\
\hline B4T1 & 0.016 & $0.0045 / \mathrm{d}$ & 18 \\
\hline
\end{tabular}

The curvature satisfying both deflection and crack-width criteria was found to be $(0.005 / \mathrm{d})$ to $(0.006 / \mathrm{d})$ radians/inch, by Vijay and GangaRao (1996) where ' $\mathrm{d}$ ' is depth of the beam. The results of this experimental program coincide with the results of Vijay and 
GangaRao (1996). Beams fail to satisfy crack width limits of 0.016 in and deflection limits of span/180 when curvature exceeds the range of 0.005- 0.006/d.

\subsubsection{Deformability Factors}

Deformability factors were found to be around 7 for tension failures and around 8 for beams close to balanced failure. Beams failing in compression had higher deformability factors of around 9. Deformability factors calculated at a curvature limit of 0.005/d are presented in Tables 5.20 and 5.21. Ratio of total energy at ultimate to that at curvature of $0.005 / \mathrm{d}$ is calculated in Table 5.20. If additional constraints on serviceability criteria are placed, the curvature limit will be lower than $(0.005 / \mathrm{d})$, thus increasing the cost of the structure.

Table 5.20 Deformability Factors for Beams with Varying Failure Mode (Tension)

\begin{tabular}{|l|c|c|}
\hline Beam & D.FACTOR & $\begin{array}{c}\text { FAILURE } \\
\text { Tanc }\end{array}$ \\
\hline B1T1 & 7.21 & Tension \\
\hline B2T1 & 7.02 & Tension \\
\hline B4T1 & 7.9 & Tension \\
\hline B1T2 & 8.44 & Tension \\
\hline
\end{tabular}

Table 5.21 Deformability Factors for Beams with Varying Failure Mode (Compression)

\begin{tabular}{|l|c|c|}
\hline Beam & D.FACTOR & $\begin{array}{c}\text { FAILURE } \\
\text { Compre }\end{array}$ \\
\hline B3C1 & 8.9 & Compression \\
\hline B2C1 & 8.55 & Compression \\
\hline B3C2 & 9.05 & Compression \\
\hline B4C1 & 8.1 & Compression \\
\hline
\end{tabular}


Conclusions of this experimental program are presented in the next chapter and recommendations are proposed for further development of ideas proposed in this study. 


\section{CHAPTER 6}

\section{SUMMARY, CONCLUSIONS AND RECOMMENDATIONS}

\subsection{INTRODUCTION}

Behavior of Concrete T-beams reinforced with GFRP rebars under flexure was evaluated in this research. Equations were developed for predicting moment capacities, deflection response, crack-width variation and effective flange width under varying load conditions. The advantages of compression failures over tension failures were investigated. Serviceability criterion for deflections and crack-width were evaluated. Results of this research program are summarized in the sections to follow.

\subsection{SUMMARY}

- Bending behavior of concrete T-beams reinforced with FRP rebars under flexure has been studied

- The stiffness of T-beams during pre- and post-cracking stages was evaluated, deflection response has been modeled, and equations for predicting crack-widths and ultimate moment are developed.

- Deformability factors using serviceability based curvature criteria of deflection and crack-width are evaluated.

- Shear-lag phenomenon along the flange width during pre- and post-cracking stages has been studied.

- Design equations and procedures, and design specifications for T-beams reinforced with FRP rebars have been developed. The equations are similar to the existing equations for steel reinforced T-beams. The advantages of tension failures over compression failures are verified in terms of moment capacities, deflection and crackwidth limit states and effective flange width. Based on the results of this experimental work, it is recommended to design GFRP reinforced T-beams for compression failure. 


\subsection{CONCLUSIONS}

1. All beams failed in the anticipated failure mode.

2. Tension failure in T-beams consisted of bar rupture at mid-span followed by spalling of concrete in the shape of a small vertical wedge surrounding the tension rebar at mid-span. In tension failure of T-beams, GFRP bar strain (tensile) in excess of $2 \%$ was noted.

3. Cracking along the longitudinal bar at high strains indicated possible bond failure at high GFRP strains in the flexural tension zone. Bond problems were not observed in beams designed for compression failure and tensile GFRP strains were below $1 \%$.

4. Compression failure can be classified into two types (discussed below) depending on the position of neutral axis at failure.

- Neutral axis in the flange: compression failures with neutral axis in the flange are characterized by concrete crushing at mid-span or under the load points with failure limited to middle third of the flange. Such beam behavior is similar to a rectangular beam. This type of failure can be obtained by keeping the reinforcement ratio lower than the balanced reinforcement ratio.

- Neutral axis in the web: compression failures with neutral axis in the web are characterized by concrete crushing initiation at mid-span followed by extension of crushing zone into the web. Such a beam is considered to behave as a true T-beam. This failure is achieved by using a higher tension reinforcement ratio.

5. Flexural crack propagation from web to the flange was observed in T-beams having neutral axis in the flange (all tension failures), whereas, no such crack extension was noted for beams having neutral axis in the web (all compression failures).

6. Concrete strain to failure in beams designed for compression failure was 3000-4400 micro strains.

7. In beams designed for tension failure, concrete reached strains of 1200-2500 microstrains, depending on the amount of reinforcement used and the strength of the concrete.

8. Effective widths of T-beams are around 0.8 times the total width of the beams from experimental and theoretical observations. 
9. Beams designed for tension failure reached the limiting value of crack width between 23 and $33 \%$ of their ultimate load carrying capacity, depending on the amount of reinforcement and concrete strength, while the limiting value of crack-width was 42$56 \%$ of the ultimate load beams failed under compression.

10. Theoretical and experimental capacities of beams varied by $3-9 \%$ for tension failures and $5-13 \%$ for compression failures.

11. Modified Gergely-Lutz equation predicted crack widths of beams designed for compression and tension failures within $4-8 \%$ and within 3-22 \%, respectively.

12. FRP bars in the compression flange buckled through the concrete cover near failure load during concrete crushing. Clear concrete cover of less than 1" was provided to the bars in the flange. Therefore adequate cover for FRP bars in compression flange is needed.

13. Crack spacing was observed to be approximately equal to the stirrup spacing. Crack closure effect was observed particularly in those beams that had web failure due to shifting of neutral axis into the web for beams with compression failure.

14. Distinct shear lag phenomenon was observed particularly in case of beams with 42" wide flanges. Strains at 12" and 20" away from the mid-section were $29 \%$ and 58\% less, respectively, compared to the mid-span strains in the beam B4T1 designed for tension failure. Strains at 12" and 20" away from the mid-section were identical and about $20 \%$ less compared to the mid-span strains in beam $\mathrm{B} 4 \mathrm{C} 1$ designed for compression failure. Designing beams for compression failure leads to higher effective flange width compared to tension failure and leads to improved economy and safety of the structure.

15. Deformability factors in the beams having tension and compression failures were in the range of 7-9 (compression -9 , tension -7 and balanced -8). Beams failing in compression showed higher Deformability factors as opposed to those failing in tension.

16. Compression failure is preferable over tension failure, considering the brittle rupture of GFRP bas in tension as opposed to gradual concrete crushing in compression.

17. Complying with serviceability constraints of crack width and deflection as per ACI 318-95 may be difficult in T-beams designed for tension failure because 
experimental values reached the crack width Limit State between 23-28\% of the GFRP bar stress. However, the crack width limit state in beams designed for compression failure are attained around $43 \%$ to $55 \%$ of the ultimate load capacity of an GFRP reinforced beam.

18. Based on the experimental results, pertinent articles (from Section 8 of AASHTO Standard Specifications(1992): Reinforced Concrete) are being modified in the context of GFRP reinforcing bars

\subsection{RECOMMENDATIONS}

- Various other characteristics like shear, fatigue, and aging behavior of concrete reinforced T-sections have to be studied. These characteristics have been studied for rectangular beams by various researchers (Vijay and GangaRao 1999, Benmokrane 1996 etc) and beams designed for compression failure are reported to be less vulnerable to fatigue loads and aging conditions.

- Creep behavior of GFRP reinforced concrete T-beams have to be studied.

- Minimum cover of 1 inch should be provided to avoid concrete splitting, longitudinal cracking and buckling of tension and compression GFRP bar. 


\section{APPENDIX A}

ANALYSIS OF GFRP-REINFORCED T-BEAMS

(ULTIMATE STRENGTH DESIGN APPROACH)

\section{A 1.1 Analysis of Over-Reinforced beams (Ultimate Strength Design Approach)}

\section{A 1.1.1 Rectangular beam (over - reinforced beam)}
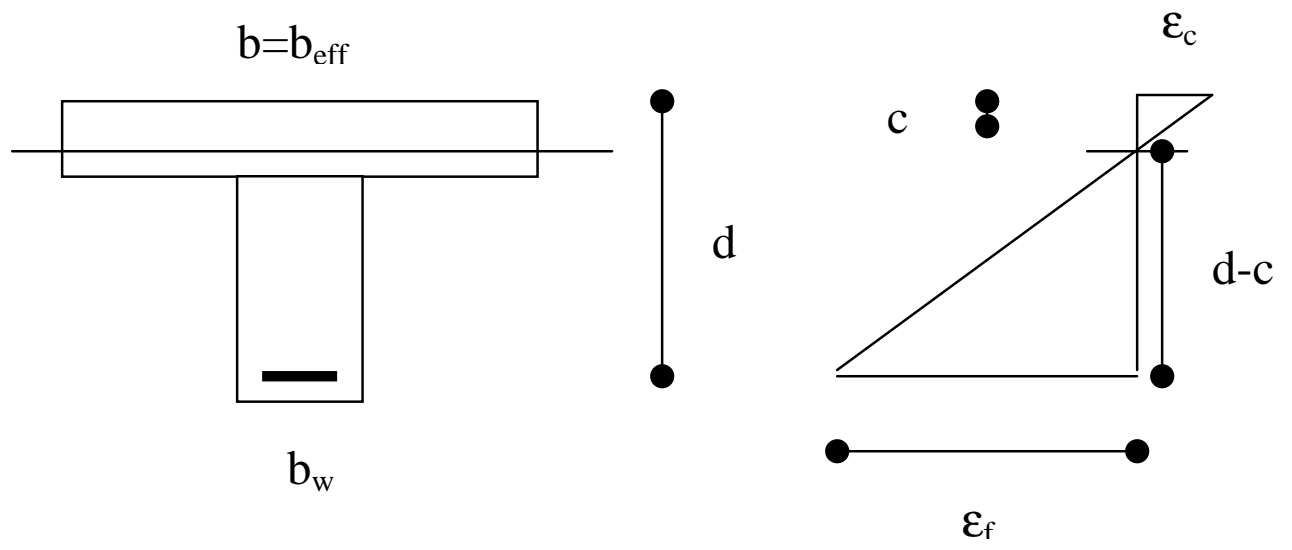

Fig A.1 Neutral axis in the flange

GFRP bar stress level can be calculated from Eqn A.1 using strain compatibility relationship (Fig A.1). Force equilibrium of the beam can be found from Eqn A.2, when neutral axis depth is lower than the thickness of the flange. Quadratic equation in terms of the depth of the equivalent rectangular stress block "a" can be obtained by combining these two equations.

$f_{f 1}=E_{f} \varepsilon_{c u} \frac{\beta_{1} d-a}{a}$

where $f_{f 1}\left(<f_{f}\right)$ is the stress level in GFRP bar at ultimate concrete strain for over reinforced beams.

$0.85 f_{c}^{1} a b=A_{f} f_{f 1}$

Combining (A.1) and (A.2)

$$
\begin{aligned}
& 0.85 f_{c}^{1} a b=A_{f}\left[E_{f} \varepsilon_{c u} \frac{\beta_{1} d-a}{a}\right] \\
& a^{2}=\frac{A_{f} E_{f} \varepsilon_{c u}}{(b d) 0.85 f_{c}^{\prime}}\left(\beta_{1} d^{2}-a d\right)
\end{aligned}
$$


$a^{2}=k\left(\beta_{1} d^{2}-a d\right)$

$a^{2}+\kappa a d-\kappa \beta_{1} d^{2}=0$

where $\kappa=\frac{\rho E_{f} \varepsilon_{c u}}{0.85 f_{c}^{1}}$ and $\rho=\frac{A_{f}}{b d}$

Depth of compressive stress block can be obtained by solving Eqn A.6

$a=\frac{d}{2}\left(\sqrt{k^{2}+4 k \beta_{1}}-k\right)$

The product of compressive force and its lever arm gives nominal moment capacity of GFRP reinforced concrete T-beam with neutral axis in the flange.

$M_{n}=C \times$ leverarm $=0.85 f_{c}^{1} a b(d-a / 2)$ 


\section{A 1.1.2 Analysis of T-beam (over - reinforced beam)}

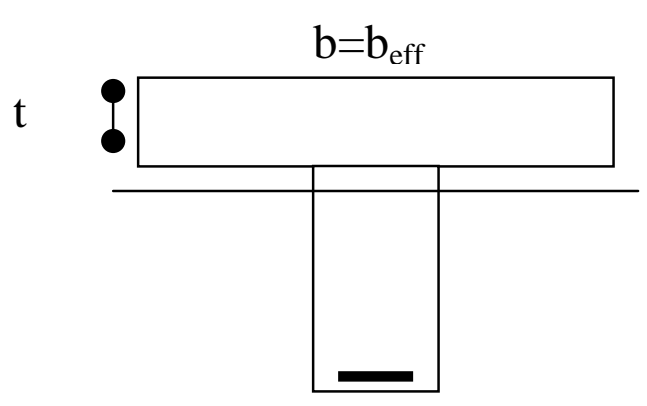

$b_{\mathrm{w}}$

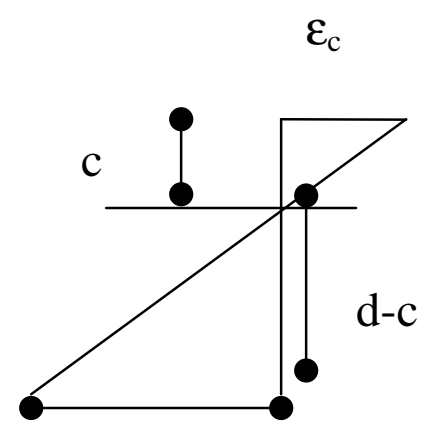

$\varepsilon_{f}$

Fig A.2 Neutral axis in the web

GFRP bar stress level can be calculated from Eqn A.1 using strain compatibility relationship (Fig A.2). Force equilibrium of the beams can be found from Eqn A.9, when neutral axis depth is greater than the thickness of the flange. Quadratic equation in terms of the depth of the equivalent rectangular stress block " $a$ " can be obtained by combining two equations A.1 and A.9.

$0.85 f_{c}^{1}\left(b-b_{w}\right) t+0.85 f_{c}^{1} b_{w} a=A_{f} f_{f 1}$

Where $f_{f 1}\left(<f_{f}\right)$ is the stress level in GFRP bar at ultimate concrete strain for over reinforced beams.

From (A.9) and (A.1)

$$
\begin{aligned}
& 0.85 f_{c}^{1}\left(b-b_{w}\right) t+0.85 f_{c}^{1} b_{w} a=A_{f}\left[E_{f} \varepsilon_{c u} \frac{\beta_{1} d-a}{a}\right] \\
& 0.85 f_{c}^{1} b_{w}\left[\left(\frac{b}{b_{w}}-1\right)+a\right]=A_{f}\left[E_{f} \varepsilon_{c u} \frac{\beta_{1} d-a}{a}\right] \\
& {\left[\left(\frac{b}{b_{w}}-1\right) \frac{t}{d}+\frac{a}{d}\right]=\frac{A_{f} E_{f} \varepsilon_{c u}}{b_{w} d 0.85 f_{c}^{1}}\left[\frac{\beta_{1} d-a}{a}\right]} \\
& {\left[\left(\frac{b}{b_{w}}-1\right) \frac{t a}{d}+\frac{a^{2}}{d}\right]=\frac{\rho_{w} E_{f} \varepsilon_{c u}}{0.85 f_{c}^{1}}\left(\beta_{1} d-a\right)}
\end{aligned}
$$




$$
\begin{aligned}
& {\left[\left(\frac{b}{b_{w}}-1\right) a t+a^{2}\right]=k_{t}\left(\beta_{1} d^{2}-a d\right)} \\
& a^{2}+a\left[\kappa_{t}+\left(\frac{b}{b_{w}}-1\right) \frac{t}{d}\right] d-\kappa_{t} \beta_{1} d^{2}=0 \\
& a^{2}+a \lambda d-\kappa_{t} \beta_{1} d^{2}=0 \\
& a=\frac{d}{2}\left(\sqrt{\lambda^{2}+4 k_{t} \beta_{1}}-\lambda\right) \\
& \text { where } \kappa_{t}=\frac{\rho{ }_{w} E_{f} \varepsilon_{c u}}{0.85 f_{c}^{1}} \text { and } \rho_{w}=\frac{A_{f}}{b_{w} d} \\
& \lambda=\left[\kappa_{t}+\left(\frac{b}{b_{w}}-1\right) \frac{t}{d}\right]
\end{aligned}
$$

Moment capacity of the beam can be computed by multiplying the compressive forces of the flange and web with their respective lever arms to the centroid of the tension reinforcement.

$$
\begin{aligned}
M_{n} & =C_{f} \times \text { leverarm }+C_{w} \times \text { leverarm } \\
& =0.85 f_{c}^{1} t\left(b-b_{w}\right)(d-t / 2)+0.85 f_{c}^{1} a b_{w}(d-a / 2)
\end{aligned}
$$




\section{APPENDIX B}

\section{DESIGN PROCEDURE}

\section{B 1 Design Procedure for Concrete T-beams reinforced with GFRP rebars}

\section{B 1.1 Design procedure for compression failure mode}

- Section dimensions are assumed according to effective width considerations and suitable span/depth ratios to counteract the external moment.

(The depths used for T-beams are less than a rectangular beam due to large compression areas available)

- Calculation of depth of equivalent rectangular stress block

\section{B 1.1.1 Rectangular beam}

Assume the depth of stress block "a" be equal to the thickness of the flange

$$
\text { If } M_{u} / \phi \leq 0.85 f_{c}^{1} t b(d-t / 2)
$$

The beam can be designed as a rectangular section

"a" can be obtained from the equation B.2.

$M_{u} / \phi=0.85 f_{c}^{1} a b(d-a / 2)$

$\frac{2 M_{u}}{0.85 f_{c}^{\prime} b \phi d^{2}} d^{2}=2 a d-a^{2}$

$k_{d 1} d^{2}=2 a d-a^{2}$

$a^{2}-2 a d+\kappa_{d 1} d^{2}=0$

where $\kappa_{d 1}=\frac{2 M_{u}}{0.85 f_{c}^{1} b \phi d^{2}}$

$a=d\left(1-\sqrt{1-k_{d 1}}\right)$ 


\section{B 1.1.1.1 Calculating the amount of GFRP reinforcement}

$f_{f 1}\left(<f_{f}\right)$ is the stress level in GFRP bar at ultimate concrete strain for over reinforced beams and can be calculated from Eqn.A.1. Depth of stress block from B.6 can be substituted in A.1 from Appendix A to obtain the stress in GFRP bar.

$f_{f 1}=E_{f} \varepsilon_{c u} \frac{\beta_{1} d-a}{a}$

The area of tensile reinforcement can be calculated from force equilibrium Eqn A.2 by substituting GFRP bar stress level from A.1.

$$
A_{f}=\frac{0.85 f_{c}^{1} a b}{f_{f 1}}
$$

\section{B 1.2.1 T section}

If $M_{u} / \phi \geq 0.85 f_{c}^{1} t b(d-t / 2)$

The beam can be designed as a T-section

"a" can be obtained from equation B.9

$M_{u} / \phi \quad=0.85 f_{c}^{1} t\left(b-b_{w}\right)(d-t / 2)+0.85 f_{c}^{1} a b_{w}(d-a / 2)$

$\frac{M_{u}}{0.85 f_{c}^{1} b_{w} \phi d^{2}} d^{2}=\frac{t}{d}\left(\frac{b}{b_{w}}-1\right)\left(1-\frac{t}{2 d}\right)+\left(1-\frac{a}{2 d}\right) \frac{a}{d}$

$2\left(\frac{M_{u}}{0.85 f_{c}^{1} b_{w} \phi d^{2}}-\frac{t}{d}\left(\frac{b}{b_{w}}-1\right)\left(1-\frac{t}{2 d}\right)=\frac{2 a d-a^{2}}{d^{2}}\right.$ 
$k_{d 1}=\frac{2 a d-a^{2}}{d^{2}}$

$a^{2}-2 a d+\kappa_{d 2} d^{2}=0$

where $\kappa_{d 2}=\frac{2 M_{u}}{0.85 f_{c}^{1} b_{w} \phi d^{2}}-2 \frac{t}{d}\left(\frac{b}{b_{w}}-1\right)\left(1-\frac{t}{2 d}\right)$

$a=d\left(1-\sqrt{1-k_{d 2}}\right)$

After calculating the depth of the stress block "a", required area of tensile reinforcement can be calculated as shown in the next section.

\section{B 1.2.1.1 Calculating the amount of GFRP reinforcement}

$f_{f 1}\left(<f_{f}\right)$ is the stress level in GFRP bar at ultimate concrete strain for over reinforced beams and can be calculated from Eqn.A.1. Depth of stress block from B.14 can be substituted in A.1 of Appendix A to obtain the stress in GFRP bar.

$f_{f 1}=E_{f} \varepsilon_{c u} \frac{\beta_{1} d-a}{a}$

The area of tensile reinforcement can be calculated from force equilibrium Eqn A.2 by substituting GFRP bar stress level from A.1.

$$
A_{f}=\frac{0.85 f_{c}^{1}\left(b-b_{w}\right) t+0.85 f_{c}^{1} b_{w} a}{f_{f 1}}
$$




\section{APPENDIX C \\ DESIGN EXAMPLE}

\section{C.1.1 Design Example}

Design a reinforced concrete T-beam bridge for a span of $40 \mathrm{ft}$ between centers of bearings for HS20-44 loading carrying two lanes of traffic 10-ft wide each and 6-ft shoulder widths on each side. Sidewalks are not required but standard parapets should be provided with railing $\left(15 \mathrm{lb} / \mathrm{ft}^{2}\right)$ on each side. A provision of $15 \mathrm{lb} / \mathrm{ft}^{2}$ of dead load should be made in the design for wearing surface. Use $f_{c}{ }^{\prime}=4000$ psi and \#8 GFRP bars $\left(E_{f}=5\right.$ million psi, $\mathrm{f}_{\mathrm{f}}-70 \mathrm{ksi}$ (Data from uniaxial tension tests at WVU)).

\section{Design of Interior girder}

Distance between the centerline of the bearing to the face of the support $=12$ in.

Span (between centers of bearings) $=40 \mathrm{ft}$.

Spacing of T-beams $=6 \mathrm{ft} 0 \mathrm{in}$.

Depth of T-beam $=0.07 \mathrm{~S}$ (AASHTO 1992 Table 8.9.2)

$=0.07 \times 40=2.8 \mathrm{ft}=33.6$ in.

Assume a total beam depth of 33 in and a stem width of 15 in.

\section{Dead Load}

$$
\begin{aligned}
& \text { Weight of slab @ } 109 \mathrm{lb} / \mathrm{ft}^{2}=0.109 \times 6.0=554 \mathrm{lb} / \mathrm{ft} \\
& \text { Weight T-beam stem }=15 \times 25.5 \times 150 / 144=481 \mathrm{lb} / \mathrm{ft} \\
& \text { Total dead load } \quad \mathrm{W}=1.052 \mathrm{k} / \mathrm{ft} \\
& \mathrm{M}_{\mathrm{D}}=1 / 8 \mathrm{w} \mathrm{L} \mathrm{L}^{2}=1 / 8 \times 1.052 \times(40)^{2}=210.4 \mathrm{k}-\mathrm{ft} \\
& \mathrm{M}_{\mathrm{L}} \text { for HS20-44 loading }=449.8 \mathrm{k}-\mathrm{ft} \\
& \text { Distribution factor, } \mathrm{DF}=\mathrm{S} / 6=6.0 / 6=1.0 \\
& \text { Impact factor, } \mathrm{I}=50 /(40+125)=0.3 \\
& \mathrm{M}_{\mathrm{L}+\mathrm{I}}=(\mathrm{LLM} \text { due to one truck) } 0.5 \text { (Dist.Factor) }(1+\mathrm{I}) \\
& =449.8 \times 0.5 \times 1.0 \times(1+0.3) \\
& =292.5 \mathrm{k}-\mathrm{ft} \\
& \mathrm{M}_{\text {total }}=\mathrm{M}_{\mathrm{D}}+\mathrm{M}_{\mathrm{L}+\mathrm{l}}=502.9 \mathrm{k}-\mathrm{ft}
\end{aligned}
$$




\section{Working Stress Design (AASHTO 1992 section 8.9.2)}

This section deals with working stress design of concrete T-beams where strain in concrete is limited to the linear zone of stress-strain diagram. This design was further refined and steps for load factor design are given in the section t follow.
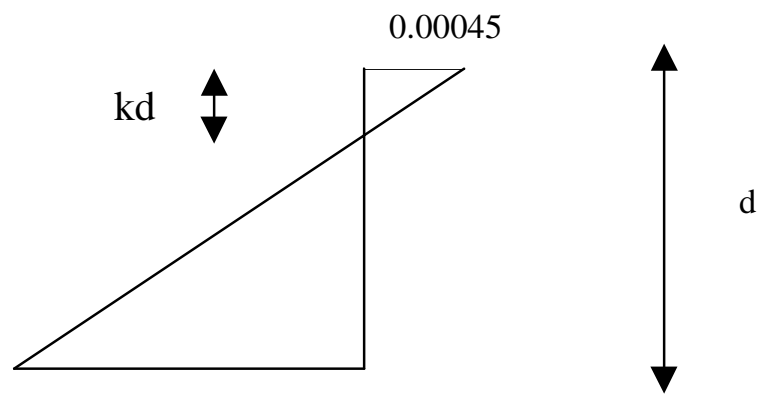

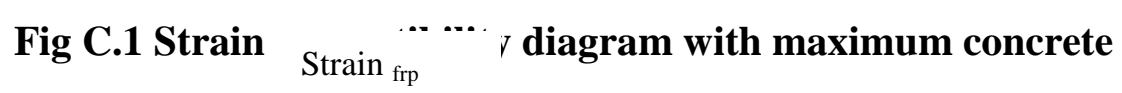 Strain of 0.00045 in/in.(corresponding to $0.40 f_{c}^{\prime}$ )}

By equating moment of the compressive force to the design moment

$$
\begin{aligned}
& M=\frac{1}{2}\left(\varepsilon_{\text {conc }}\right) E_{c} b(k d)\left(d-\frac{k d}{3}\right) \\
& 500 \times 12 \times 1000=\frac{1}{2}(0.00045) 3.6 \times 10^{6} \times 60(k d)\left(d-\frac{k d}{3}\right)
\end{aligned}
$$

Solving equation A. $2, \mathrm{k}=0.2$

By equating tensile and compressive forces

$$
\begin{aligned}
& \frac{1}{2}\left(\varepsilon_{\text {conc }} \times E_{c}\right) b(k d)=E_{f} \times A_{f} \times \varepsilon_{f} \\
& \varepsilon_{f}=0.00045\left(\frac{1-k}{k}\right)
\end{aligned}
$$

Equation C. 4 can be obtained from fig C. 1 (strain compatibility) and substituting $\mathrm{k}=0.2$ in C. $3, \mathrm{~A}_{\mathrm{f}}$ is found as $29 \mathrm{in}^{2}$. 


\section{Load Factor Design (AASHTO 1992 section 8.16)}

All loads (moments) were calculated earlier. These values will be used for calculating the factored loads. From calculations for working stress method, $M_{D}=207.5 \mathrm{k}-\mathrm{ft}$ and $\mathrm{M}_{\mathrm{L}+\mathrm{I}}$ $=292.5 \mathrm{k}$-ft. Therefore,

$$
\begin{aligned}
M_{u} & =1.3\left[\beta_{D} D+\beta_{L}\left(M_{L+1}\right)\right] \\
& =1.3[1 \times 207.5+1.67(292.5)]=904.8 \mathrm{k}-f t \\
M_{n} & =\frac{M_{u}}{\phi}=\frac{904.8}{0.9}=1005.33 \mathrm{k}-f t
\end{aligned}
$$

Assume the depth of stress block "a" be equal to the thickness of the flange

$$
M_{u} / \phi \leq 0.85 f_{c}^{1} t b(d-t / 2)
$$

$1005.33 \mathrm{k}-\mathrm{ft}<2964.35 \mathrm{k}-\mathrm{ft}$

The beam can be designed as a rectangular section

"a" can be obtained from the equation C.6

$M_{u} / \phi=0.85 f_{c}^{1} a b(d-a / 2)$

Expressing eqn A.6 as a quadratic in terms of a,

$a^{2}-2 a d+\kappa_{d 1} d^{2}=0$

$$
a^{2}-54 a+145.8=0
$$

where $\kappa_{d 1}=\frac{\frac{2 M_{u}}{\phi}}{0.85 f_{c}^{1} b d^{2}}=0.2$

$$
a=d\left(1-\sqrt{\left(1-k_{d 1}\right)}\right.
$$

Depth of stress block computed from above equations is a $=2.98$ "

\section{- Calculating the amount of GFRP reinforcement}

Area of tensile reinforcement can be calculated from the force equilibrium equation C.9

$$
A_{f}=\frac{0.85 f_{c}^{1} a b}{f_{f 1}}
$$

stress in the GFRP bar can be calculated by using strain compatibility equation. 
$f_{f 1}=E_{f} \varepsilon_{c u} \frac{\beta_{1} d-a}{a}$

Solving C. 9 and C. 10 for area of tensile reinforcement $A_{f}=8$ in $^{2}$

Calculating balanced reinforcement ratio

$$
\begin{aligned}
& \rho_{\text {bal }-r}=0.85 \beta_{1} \frac{f_{c}^{\prime}}{f_{f}}\left(\frac{\varepsilon_{c u}}{\varepsilon_{c u}+\varepsilon_{f}}\right) \\
& \rho_{b a l-r}=0.85 \times 0.85 \frac{4}{70}\left(\frac{0.003}{0.003+0.014}\right)=0.856 \% \\
& A_{b a l-r}=\rho_{b a l-r} \times b d=13.88 \mathrm{in}^{2}>8 \mathrm{in}^{2}
\end{aligned}
$$

Therefore provide 1.33 times balanced reinforcement ratio to achieve compression failure. GFRP reinforced concrete T-beams are designed for compression failure to satisfy serviceability criterion for deflection and crack width.

$$
A_{f}=1.33 \times 13.88=18.46 \mathrm{in}^{2}
$$

Therefore provide eight \#8 GFRP bars as flexural reinforcement for the T-beam.

Depth of concrete stress block "a" can be obtained by substituting area of reinforcement in A.9 and A.10.

$\mathrm{a}=4.93$ "

Check for nominal moment capacity of the section

$M_{n}=0.85 f_{c}^{\prime} a b(d-a / 2)=0.85 \times 4 \times 4.93 \times 60 \times(27-4.93 / 2) \times 1 / 12=2056 k-f t$

$>$ Re quired $M_{n}(1005.33 k-f t)$

Therefore acceptable 


\section{APPENDIX D}

\section{DESIGN CHARTS}

\section{Design Chart \#1}

$$
\left(h_{f} / d=0.25, b_{w} / b=0.21\right)
$$

1-Balanced Reinforcement ration for \#4 bars and $4 \mathrm{ksi}$ concrete

2-Balanced Reinforcement ration for \#4 bars and $5 \mathrm{ksi}$ concrete

3-Balanced Reinforcement ration for \#4 bars and 6 ksi concrete

4-Balanced Reinforcement ration for \#8 bars and 4 ksi concrete

5-Balanced Reinforcement ration for \#8 bars and 5 ksi concrete

6-Balanced Reinforcement ration for \#8 bars and 6 ksi concrete

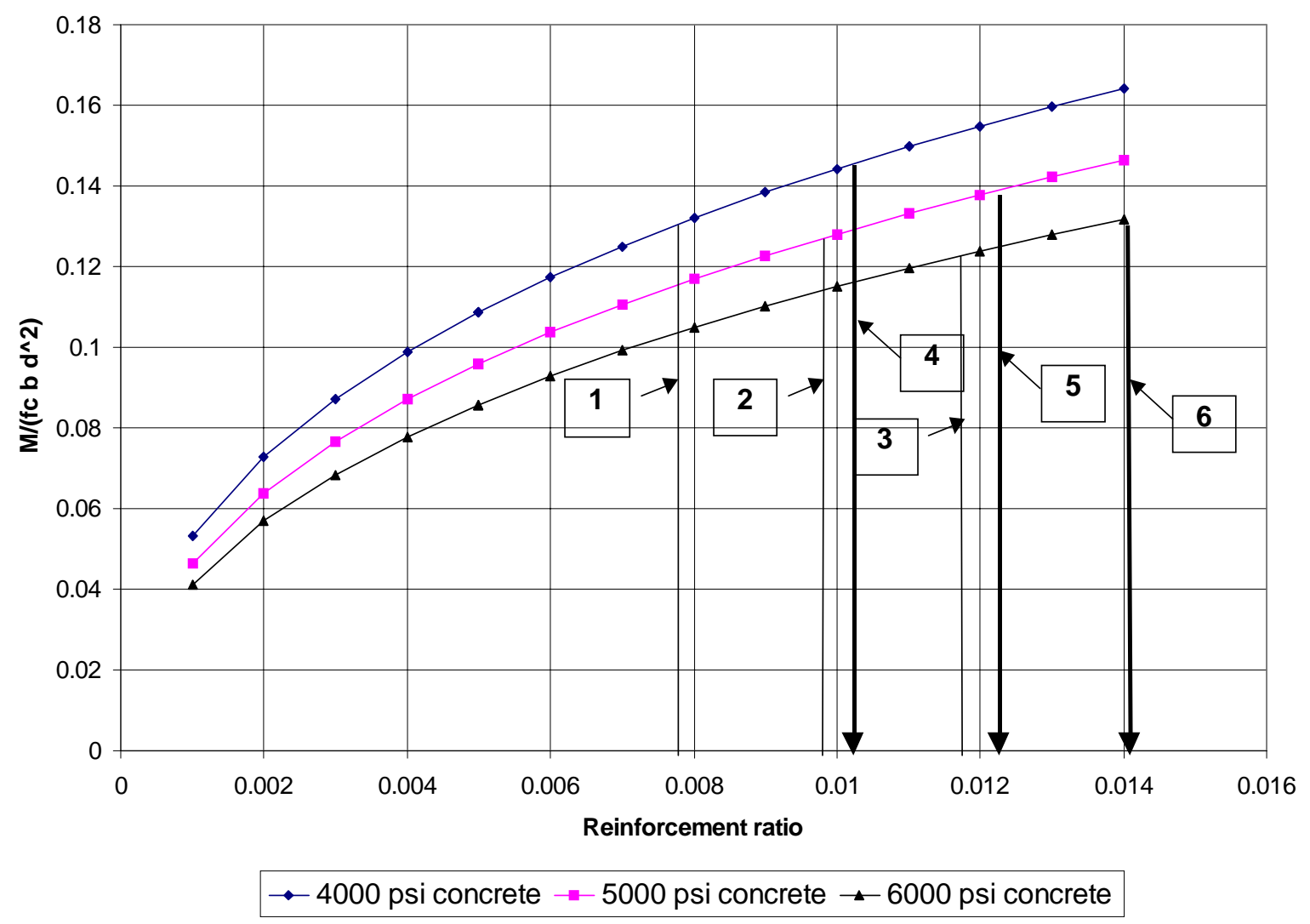




\section{Design Chart \#2}

$\left(h_{f} / d=0.167, b_{w} / b=0.167\right)$

1-Balanced Reinforcement ration for \#4 bars and 4 ksi concrete

2-Balanced Reinforcement ration for \#4 bars and 5 ksi concrete

3-Balanced Reinforcement ration for \#4 bars and 6 ksi concrete

4-Balanced Reinforcement ration for \#8 bars and 4 ksi concrete

5-Balanced Reinforcement ration for \#8 bars and 5 ksi concrete

6-Balanced Reinforcement ration for \#8 bars and 6 ksi concrete

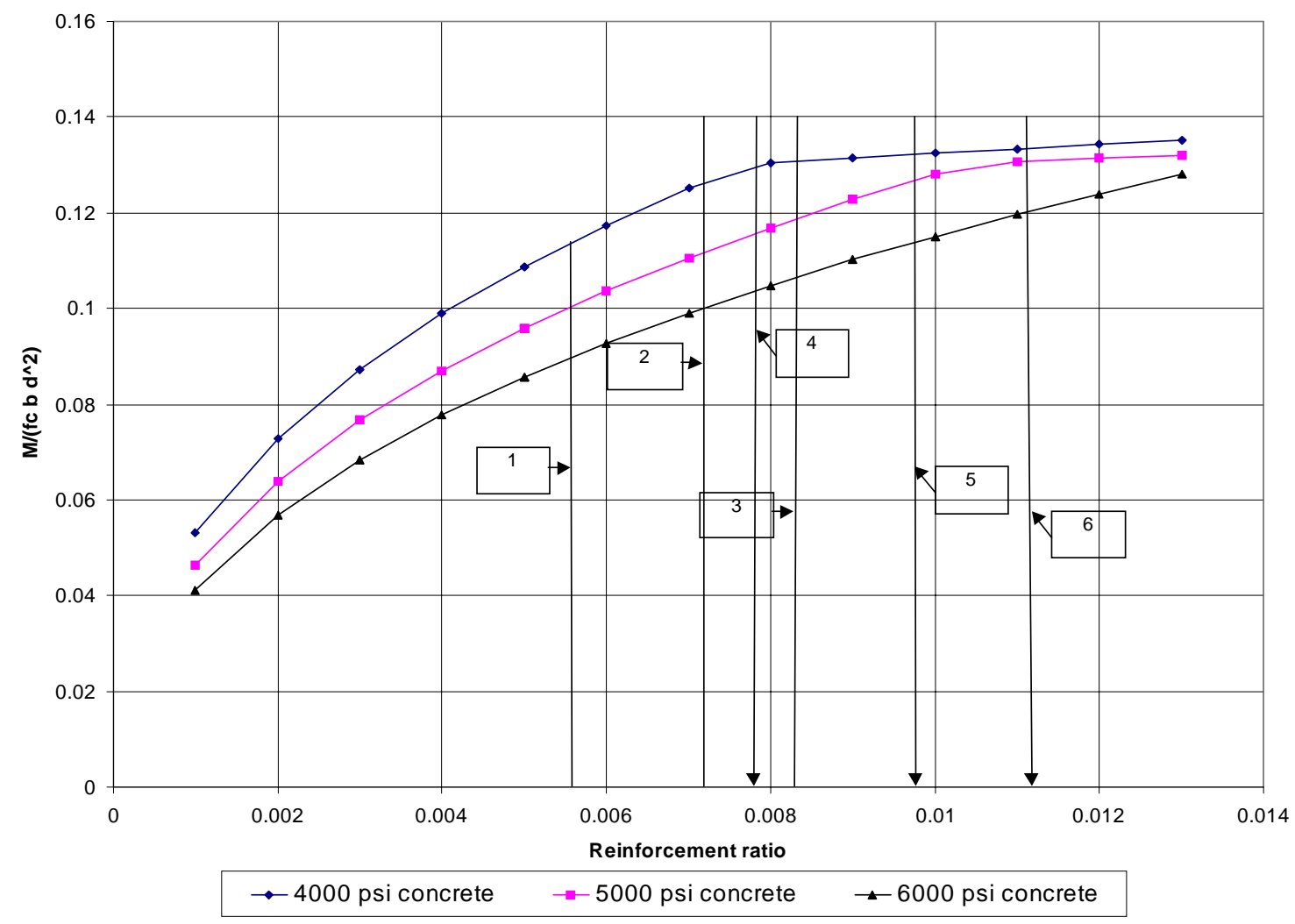




\section{Design Chart \#3}

\section{$\left(h_{f} / d=0.125, b_{w} / b=0.1\right)$}

1-Balanced Reinforcement ration for \#4 bars and 4 ksi concrete

2-Balanced Reinforcement ration for \#4 bars and 5 ksi concrete

3-Balanced Reinforcement ration for \#4 bars and 6 ksi concrete

4-Balanced Reinforcement ration for \#8 bars and 4 ksi concrete

5-Balanced Reinforcement ration for \#8 bars and 5 ksi concrete

6-Balanced Reinforcement ration for \#8 bars and 6 ksi concrete

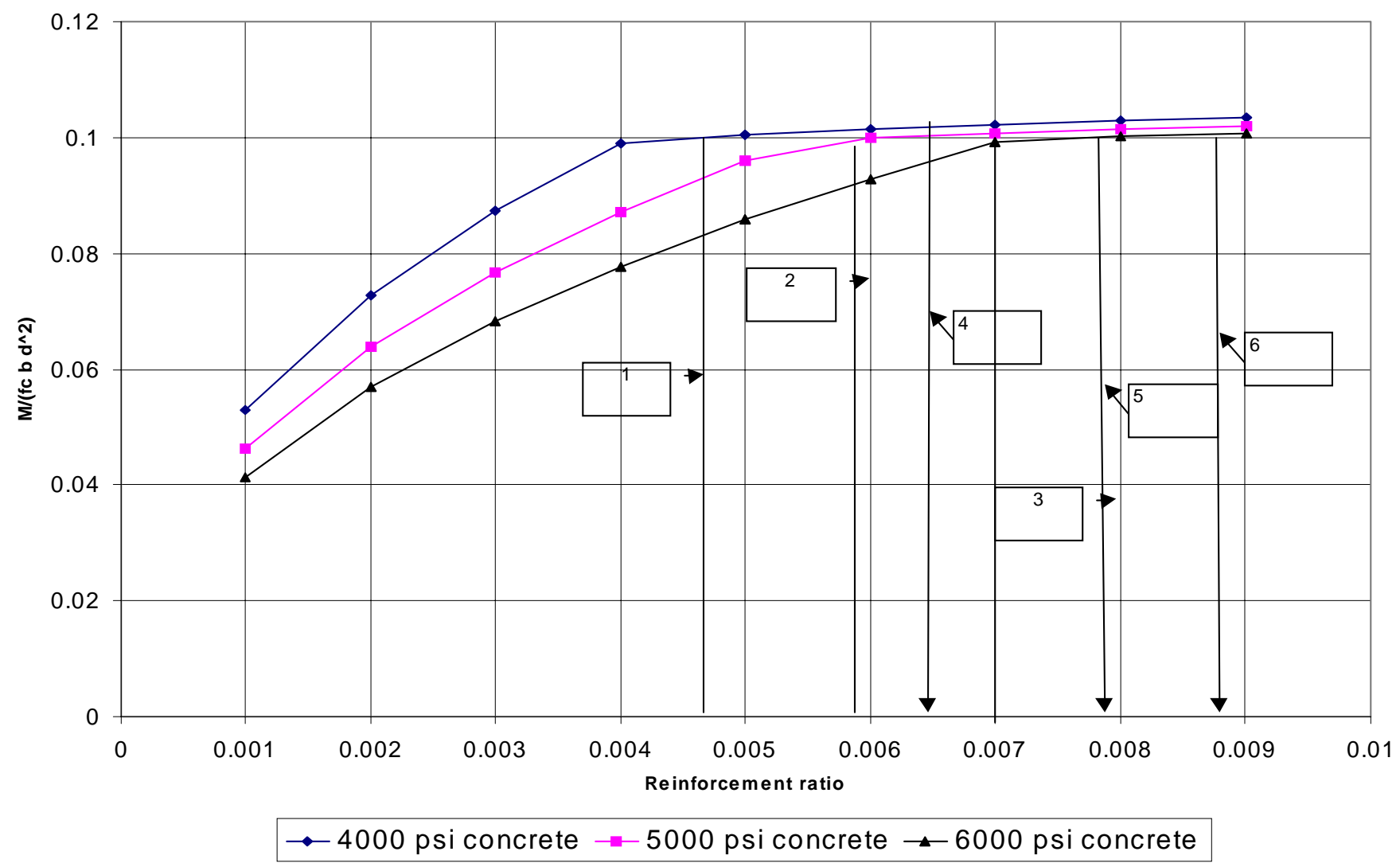




\section{REFERENCES}

1. AASHTO Standard Specifications for Highway Bridges, $15^{\text {th }}$ ed., AASHTO, Washington, DC, 1992.

2. Abdalla, H., El-badry, M.M., and Rizkalla, S., "Deflection of Concrete Slabs Reinforced with Advanced Composite Materials," Edited by Mamdouh El-Badry, ACMBS-II, Montreal, Canada pp-201-208, August1996.

3. ACI Building Code Requirements for Reinforced Concrete (ACI 318-95), American Concrete Institute, Detroit, MI, 1995.

4. Afshari A.A., Frazer D.G., and Creese R.C., "Ultrasonic Techniques for the Bonding of Bar in Concrete Structures," Structural Materials Technology, NDT Conference, San Diego, California, Feb 20-23, 1996.

5. Almusallam, T.H., Alsayed, S.H., and Amjad, M.A., "Evaluation Of Service Load Deflection for Beams Reinforced by GFRP Bars," Edited by Mamdouh El-Badry, ACMBS-II, Montreal, Canada pp173-179, August, 1996.

6. Altizer S.D., Vijay P.V., and GangaRao H.V.S., "Performance Evaluation of Conditioned GFRP Bars with Different Resin Systems," Report Submitted to Reichhold Chemical, Inc 1997.

7. “America's Highways”, Transportation Research Board, National Research Council, Washington, D.C., 1984.

8. Arockiasamy, M., Amer, A., Shahawy, M., and Chidambaram, S., " Long-Term Behavior of Concrete Beams Reinforced With CFRP Bars Under Sustained Loads," Edited by Mamdouh El-Badry, ACMBS-II, Montreal, pp. 673-680, August,1996.

9. Bedard, C., Composite Reinforcing Bars: Assessing Their use in Construction, Concrete International, 14(1): 55-59 1992.

10. Benmokrane, B., Masmoudi, R., "FRP C-Bar as Reinforcing Rod for Concrete Structures," Edited by Mamdouh El-Badry, ACMBS-II, Montreal, Canada pp181188, August, 1996.

11. Benmokrane, B., Masmoudi, R., Challal, O. (1996). Flexural Response of Concrete Beams Reinforced with FRP rebars. ACI Structural journal, 93(1): 46-55. 
12. Brown and Bartholomew, C.V., "Long-Term Deflections of GFRP-Reinforced Concrete Beams," ICCI'96, Proc. of First International Conference on Composites in Infrastructure, Tuscon, AZ, pp.389-400, January, 1996.

13. Canadian Standards Association, Draft Chapter 16: "Fiber Reinforced Structures" and Commentary, Canadian Highway Bridge Design, February and October 1995.

14. Composites for Infrastructure, "A Guide for Civil Engineers"- Ray Publishing publication, 1998.

15. Ehsani, Saadatmeanesh, H., and Tao, S., "Bond Behavior and Design Recommendations for Fiberglass Reinforcing Bars, ICCI'96, Proc. of First International Conference on Composites in Infrastructure, Tucson, AZ, pp.466-480, January, 1996.

16. Faza S.S. and GangaRao H.V.S., "Pre and Post cracking Deflection Behavior of Concrete Beams Reinforced with Fiber-reinforced Plastic Rebars," ACMBS-I Conference, pp.151-160, 1992.

17. Faza S.S., and GangaRao H.V.S., "Bending and Bond Behavior and Design of Concrete Beams Reinforced with Fiber Reinforced Plastic Rebars," Fiber Reinforced Plastics for Bridge Decks, WVDOH RP 83, 1992.

18. Faza S.S., GangaRao H.V.S., and Dalal Nar., "Behavior of Bridge Decks Reinforced with FRP Rebars and NMR Characterization," Fiber Reinforced Plastics for Bridge Decks, WVDOH RP 83, Phase II, 1993.

19. Franco et. al., "Design and Field Testing of Jointless Bridges," Masters Thesis, WVU, 1999.

20. GangaRao H.V.S., "Concrete Beams Reinforced with FRP Rebars Under Static and Fatigue Loads," Constructed Facilities Center Report, CFC RP \# 230-96, 1998.

21. Gottfried B., "Strength of the Compression Slab of T-beams Subject to Simple Bending," Journal of the American Concrete Institute, proceedings v. 61 no1., January 1964.

22. Hosny, O. El-Nawawy, E. I. Mostafa, Khalil, V., "Behaviour of Concrete Slabs Reinforced with Fiber-Glass Bars," The First Middle East Workshop on Structural Composites, Egypt, pp.267-280, June, 1996. 
23. Jaeger L.G., Tadros G., and Mufti A.A., "Balanced section, ductility and deformability in concrete with FRP reinforcement," Research Report submitted in Joint US - Canadian Meeting at West Virginia University, June 121995.

24. Jaeger, L.G., Tadros, G., and Mufti, A.A., "Balanced section, ductility and deformability in concrete with FRP reinforcement," Research Report submitted in Joint US - Canadian Meeting at West Virginia University, June 121995.

25. Kumar S.V., GangaRao H.V.S., and Faza S.S., "Fatigue Response and Design of Concrete Decks Reinforced with Fiber Reinforced Plastic (FRP) Rebars," WVDOH RP 92, 1997.

26. Kumar S.V., "Fatigue Response and Design of Concrete Decks Reinforced with Fiber Reinforced Plastic (FRP) Rebars," Masters Thesis, WVU 1995.

27. Maruyama, K., Zhao, W., "Size Effect in Shear Behavior of FRP Reinforced Concrete Beams," Edited by Mamdouh El-Badry, ACMBS-II, Montreal, Canada pp227-236, August, 1996.

28. Matthys and Taerwe, L., "Behavior of Concrete Slabs Reinforced with FRP Grids Under Service and Ultimate Loading," ICCI'96, Proc. of First International Conference on Composites in Infrastructure, Tucson, AZ, pp.359-373, January 1996.

29. Nanni, A., "Flexural Behavior and Design of Reinforced Concrete Using FRP Rods," J. of Structural Engg., ASCE, Vol. 119, No. 11, Nov. 1993, pp 3344-3359.

30. Nawy, E.G., "Reinforced Concrete: Fundamental Approach," Prentice Hall Publications.99 70-300 1990.

31. Park and Paulay, "Reinforced Concrete Structures," John Wiley and Sons 1975.

32. Razaqpur and Ali, A.M., "A New Concept for Achieving Ductility in FRPReinforced Concrete," ICCI'96, Proc. of First International Conference on Composites in Infrastructure, Tuscon, AZ, pp.401-413, January, 1996.

33. Schutter, G.De., Taerwe, L., and Matthys, S., "Influence of Transverse Thermal Expansion of FRP Reinforcement on the critical Concrete Cover," Edited by Mamdouh El-Badry, ACMBS-II, Montreal, Canada pp. 665-672, August, 1996. 
34. Sonobe, Y., Fukuyama, H. Okamoto, T,, Kani, N., Kimura, K., Kobayashi, K,. Masuda, Y., Matsuzaki, Y., Nochizuki, S., Nagasaka, T,. Shimizu, A. , Tanano, H., Tanigaki, M, Teshigawara, M., Design Guidelines of FRP Reinforced Concrete Building Structures, Journal of Composites for Construction, pp.90-115, Aug. 1997

35. State-of-Art Report on FRP for Concrete Structures, ACI Committee 440R-96, Manual of Concrete Practice, ACI Farmington Hills, Michigan, 1996

36. Tighiouart, B., Benmokrane, B., and Gao, D., "Investigation on the Bond of Fiber Reinforced polymer (FRP) Rebars in Concrete," ICCI 98, Edited by- Eshani, M.R., Saadatmanesh, pp-102-111, January, 1998.

37. USDOT-FHWA, “The Status of the Nation's Highway Bridges: Highway Bridge Replacement and Rehabilitation Program”. FHWA, 1997

38. Umoto, T., and Ohga, H., "Performance of Fiber Reinforced Plastics for Concrete Reinforcement," pp-125-132, Edited by Mamdouh El-Badry, ACMBS-II, Montreal, Canada, August,1996.

39. Vijay P.V., Kumar S.V., and GangaRao H.V.S., " Shear, Ductility and Creep Response of Concrete Beams Reinforced with FRP Rebars," WVDOH RP112.

40. Vijay P.V., Kumar S.V., and GangaRao H.V.S., "Shear and Ductility Behavior of Concrete Beams Reinforced with GFRP Bars," Proceedings of ACMBS-II Conference, Montreal, Canada, Aug. 1996.

41. Vijay, P.V. and GangaRao, H.V.S, "Development of Fiber Reinforced Plastics for Highway Application: Aging Behavior of Concrete Beams Reinforced with GFRP bars," CFC-WVU Report No. 99-265 (WVDOH RP \#T-699-FRP1), 1999.

42. Vijay, P.V. and GangaRao, H.V.S., "A Unified Limit State Approach Using Deformability Factors in Concrete Beams Reinforced with GFRP Bars," Materials for the New Millennium, 4th Material Conference, ASCE, Vol.1, Washington D.C., 657$665,1996$.

43. Wu Wei-Pin, "Thermomechanical Properties of Fiber Reinforced Plastic (FRP) Bars,” Ph.D Dissertation, WVU, 1990. 


\section{VITA}

Rajesh Kumar Kalluri was born in Vizag, India on January 31, 1976. He received his primary education in V.T.College and pre-university education in Dr.L.B.College, Vizag. He received a Bachelors degree in civil engineering in August 1997.

Mr.Kalluri enrolled for a Masters program in civil engineering at WVU during fall 97. During the course of his study he worked as a graduate research assistant in the area of evaluation of Glass Reinforced Composites at the Constructed Facilities Center. Presently, he is a candidate for the degree of Masters of Science in Civil Engineering in December 1999. 